\title{
Monitoring and Assessment of the BS - ERA.Net Pilot Joint Call (PJC)
}

Final Version

Nikos Sidiropoulos

September 2012 


\section{Summary}

\section{Introduction}

The BS-ERA.NET is an ERA.NET project funded by the European Commission within the 7th Framework Program for Research and Technology Development (FP7). The BS-ERA.NET consortium decided to set up and run a Pilot Joint Call (PJC) to explore the potential of collaboration between R\&D funding programmes and agencies for transnational coordinated funding of research and development in the extended Black Sea region. In this framework, 11 out of the 13 Countries of the BS-ERA.NET's consortium participated in the BS-ERA.NET Pilot Joint Call.

\section{Conclusions regarding the preparation phase}

It is a great achievement that eleven (11) funding parties from eleven (11) countries with different RTDI systems have decided to cooperate in allocating national funds to a joint call and to overcome bureaucratic barriers originating from their different administration and legislation structures. It should be mentioned that for many partners, beyond the scientific merit, there was strong political interest to support and participate in a regional structure such as a joint call.

The terms of references of the Pilot Joint Call are standing clear and informative. The thematic focus of the joint call was selected based on the existing evidence-based identification of the research priorities in the Black Sea region. The research priorities have been identified through detailed analytical work, in which the relevant adequate methodologies were used. Moreover, it was a very good approach not to expand the thematic areas of the call in more scientific disciplines due to the limited budget of this call and its pilot character where the first priority was to test and improve the call's procedures.

The launching of the call was adequate using all the dissemination means that could be used (BS-ERA-net website, leaflets etc.). The documents of the Pilot Joint Call (terms of reference, guidelines for applicants) were detailed, sufficiently clear and concise and provided sufficient support to potential applicants. There is room for improvement such as including in the terms of reference the ways that the applicants could be informed on the results and especially the reviewers' comments of their proposals.

The National Contact Points showed significant efficiency during the preparation phase of the Pilot Joint Call. However, their performance during the preparation phase was not appreciated by a significant percentage of unsuccessful applicants. It is possible that better guidance and support during the preparation phase was expected and this is something that should be considered. The Joint Call Secretariat's performance in the preparation phase was appreciated by the majority of the applicants and the funding parties. 


\section{Conclusions regarding the submission phase}

A notable number of applicants noted that they needed more time to set up their consortium and submit their proposal. This is a suggestion that should be taken into account. The proposal form was simple, clear and easy in handling. Without doubt the use of the PT-Outline system was a great advantage for the Pilot Joint Call. During the submission of their proposal, most applicants found the web based tool efficient and functional.

Almost all successful as well as unsuccessful applicants reported positive experiences during the application procedure, finding it clear and transparent. The Joint Call Secretariat's performance in the submission phase was appreciated by the majority of the applicants and the funding parties. The number of submitted for funding projects proves that there was a mobilization of the research communities in the region but not equally so in all of the participating countries.

\section{Conclusions regarding the evaluation phase}

Of the 66 proposals submitted, 11 were approved for funding. So they were submitted 6 times more proposals that the ones that could be funded. This is a common ratio in similar calls and the oversubscription rate is deemed normal. On the other hand, the large number of submitted for funding projects indicates that there was a mobilization of the research communities in the region although not equally in all the participating countries. The majority of the group of funding parties is rather satisfied with the number of proposals that have been submitted.

The water pollution topic dominates in the submitted projects. This gives a strong indication of the scientific and environmental importance of this discipline in the Black Sea region.

The followed steps in the evaluation of the projects are in line with the international practice and have also been applied in other joint calls of ERA-NETs. Still there is room for a number of improvements in the eligibility check, the database of evaluators, and the aim of the scientific council. The time duration of the evaluation of the proposals (time from the submission to the announcement of the results) could be reduced basically in the stage of the preliminary check of the national eligibility criteria.

It was reported by unsuccessful applicants and the Joint Call Secretariat that there was no feedback to the unsuccessful applicants regarding the reasons of their failure. The usual practice is to be sent an explanatory letter with an attachment of the relevant marks by criterion and an adapted summary of the comments of the reviewers. This is a principal that assures the transparency of the evaluation procedure and more importantly helps the applicant improve in the future submissions of project proposals. Some of the National Contact Points have been contacted by the applicants during the evaluation phase in order to complain about the prolonged duration of the evaluation of their proposals. 
Skipping highly ranked projects because of lack of available funds by the funding parties is most usual in all the virtual common pot schemes. Of course this is unfair for the scientists that had been evaluated successfully, as they are above the threshold but cannot be funded. Two solutions have been suggested in this report, in order to overcome the specific issue.

Analyzing the number of successful applicants per country, Romania is leading with 11 partners, followed by Germany and Bulgaria with 7 partners. Calculating the success rate as the number of successful applicants over the number of total applicants, Armenia is leading (25\%) followed by Germany, Greece and Turkey (19\%). The distribution per topic of the approved proposals is dominated by the water pollution prevention for coastal zones and tourist areas.

The Scientific Council has concluded that the scientific merit and the expected impact of the projects recommended for funding was high. Moreover, all the responded members of the Scientific Council declared that the quality of the consortium of the projects, the quality of the management of the projects, the quality of the presentation of the project proposals recommended for funding was high.

\section{Conclusions regarding the contracting phase}

The double contracting procedure is requested due to the virtual common pot scheme and the national funding of the approved projects, which is based on national rules and regulations. It is easily understood that this double contracting process causes serious delays in the contracting of the projects. A significant number of successful applicants pointed out that the administrative procedures of the Joint Call Secretariat concerning the Umbrella Project Contract as well as their Funding Party concerning the National Project Contract were not efficient and adequate in time and effort. All the National Contact Points have been contacted by the partners of the approved projects in order to provide support in the contracting phase and more specifically regarding the completion of the contracts.

\section{Conclusions regarding the monitoring phase}

For the projects that it was reported that the first funding rate to the project partners was not synchronized, was not efficient and not adequate in time, could be affected the scientific quality of their implementation. The partners of the approved projects are rather satisfied with the effective monitoring of their projects by the Joint Call Secretariat, while the majority of the group of funding parties presents a neutral approach regarding the effective monitoring of the approved projects by the Joint Call Secretariat.

For the majority of the project partners the funding from the Pilot Joint Call was crucial for carrying out their project and that without this funding, the specific project could never have been implemented. On the other hand the members of the 
funding parties consider that beyond the Pilot Joint Call, the partners could have been found another funding instrument from their organization. Many of the project partners consider they needed additional funding for their project which they have found from other sources. In most of the cases project implementation run smoothly. On the contrary, all funding parties considered the approved budget of the projects exactly right for what was needed.

It is of great importance what is clearly stated by the majority of the members of the Scientific Council, that the original objective of the Pilot Joint Call to promote collaborative research on Climate \& Environment and Energy taking a proactive and innovative approach to developing solutions for a sustainable development was fulfilled.

\section{Conclusions regarding the future perspectives}

A future call of the Black Sea Research Programme is rather popular and desirable:

The large majority of the scientists irrelevant if they were successful or unsuccessful clearly declare that after taking into account the experience from the Pilot Joint Call, they would participate through a collaborative transnational project application in a future call of the Black Sea Research Programme. The funding parties, having had the experience from the Pilot Joint Call are positively oriented towards participating in a future Joint Call of the Black Sea Research Programme with some reservations expressed by Italy. As it was stated by the Italian partner ENEA, the interest of Italy depends on the possibility of finding external to the consortium of BS.ERA-NET funding parties, which is also in line with the wish to attract to a future call additional funders. Moreover, many NCPs had been contacted by potential applicants who were interested in participating in a future Black Sea Research Programme.

\section{Recommendations}

Proposals for improvement were made for almost all the phases of the Pilot Joint Call. Among others, the successful applicants propose more thematic topics and more participating countries. The unsuccessful applicants focus their interest on more thematic topics and improvement of the evaluation phase as well as in the rules of participation and funding. It is extremely interesting that the funding parties and the Scientific Council both have exactly the same approach as the applicants of the Pilot Joint Call.

This evaluation and assessment report provides eighteen (18) concrete recommendations on possible modifications and improvements of the call procedures, in order to enhance the performance of future trans-national calls, as well as to increase the impact of the projects to be funded. This provides input for a possible follow-up funding programme between the EU MS/AC and the Black Sea Region. 


\section{General Conclusion}

The Pilot Joint Call has proven to be a successful exercise for the funding parties of the BS-ERA.NET and the Joint Technical Secretariat. A set of provided recommendations on possible modifications and improvements of the call procedures is expected to improve the performance of future trans-national calls, as well as to increase the impact of the projects to be funded. Moreover, the funding parties have expressed their intention to participate in future Joint Calls of the Black Sea Research Programme by allocating national funds and the Joint Technical Secretariat has proven its capacity to successfully administrate future calls. The road for the development of a Black Sea Research Programme (BSRP) is more than open. 


\section{Table of Contents}

Summary

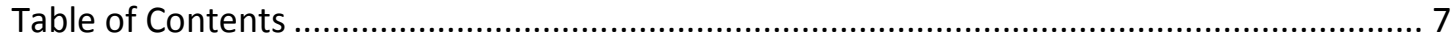

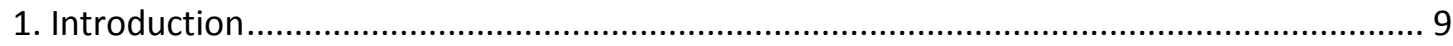

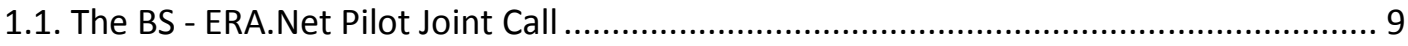

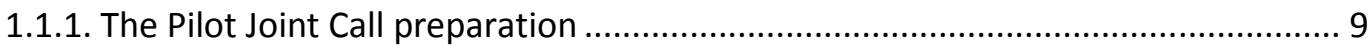

1.1.2. The launch of the Pilot Joint Call. The objective, the thematic areas and the basic

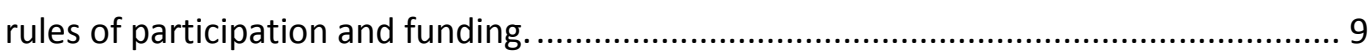

1.1.3. The projects' proposals submission, evaluation, selection, contracting and

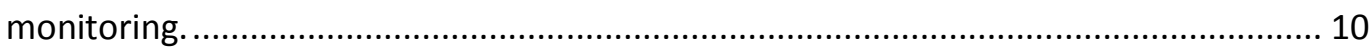

1.2. The Concept of the Monitoring and Assessment of the Pilot Joint Call ....................... 11

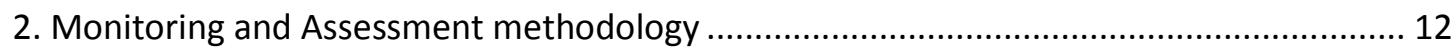

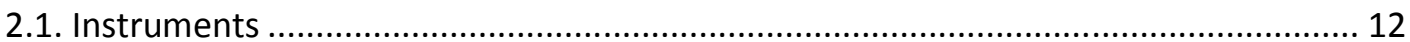

2.2. Call preparation, stimulation and dissemination activities ...................................... 15

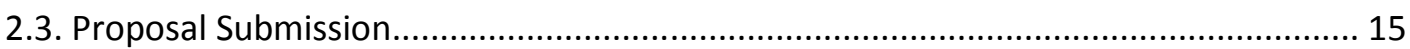

2.4. Evaluation and Selection Procedure........................................................................ 16

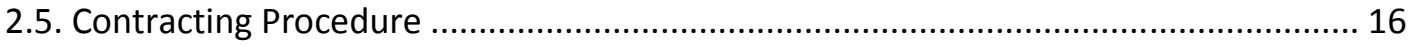

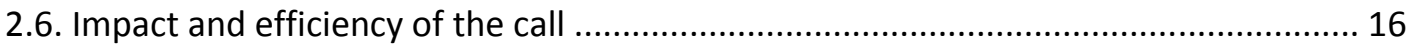

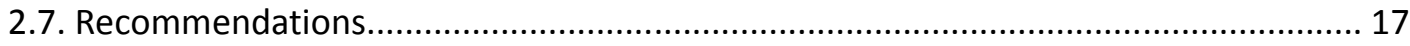

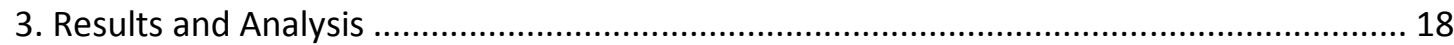

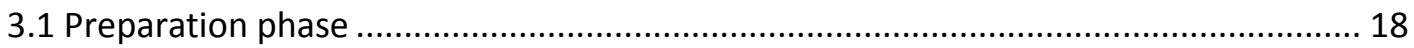

3.1.1. Setting up the Group of Funding Parties for the Pilot Joint Call. ......................... 18

3.1.2. Setting up the terms of references of the Pilot Joint Call. ................................... 19

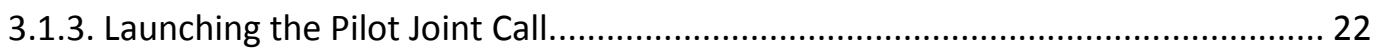

3.1.4. The documents of the Pilot Joint Call................................................................ 26

3.1.5. The NCPs performance in the preparation phase............................................. 29

3.1.6. The Joint Call Secretariat's performance in the preparation phase...................... 33

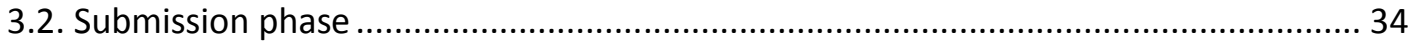

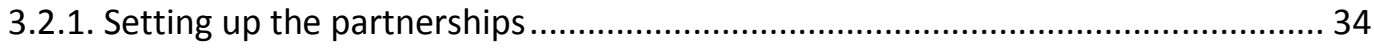

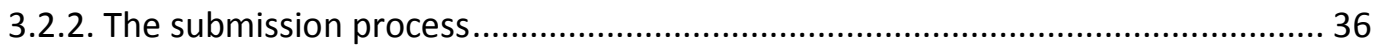

3.2.3. The NCPs performance in the submission phase.............................................. 42 
3.2.4. The Joint Call Secretariat's performance in the submission phase. 45

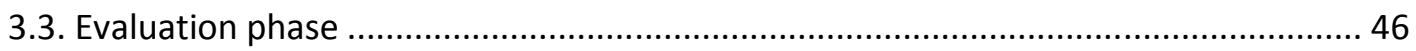

3.3.1. The proposals that have been submitted in the frame of the Pilot Joint Call....... 46

3.3.2. The way that the evaluation of proposals had been organized ............................. 48

3.3.3. The view of the applicants, the funding parties and the Scientific Council

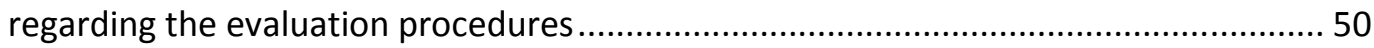

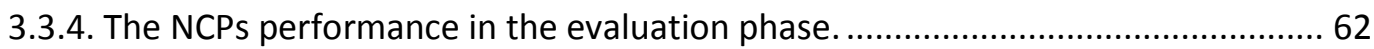

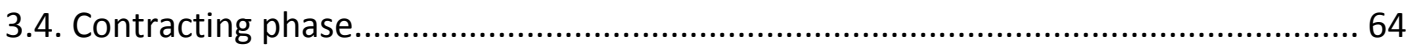

3.4.1. The virtual common pot and the availability of national funds........................... 64

3.4.2. The successful proposals of the Pilot Joint Call..................................................... 65

3.4.3. The quality of the approved for funding projects of the Pilot Joint Call............... 68

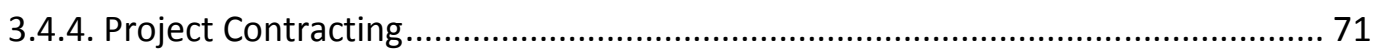

3.4.5. The NCPs performance in the contracting phase............................................. 76

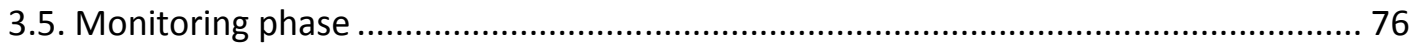

3.5.1. The funding of the approved projects ................................................................. 76

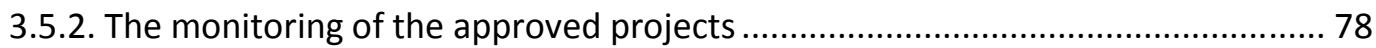

3.5.3. The NCPs performance in the monitoring phase................................................. 79

3.6 Impact of efficiency of the Pilot Joint Call ................................................................... 80

3.7. The future Call(s) of the Black Sea Research Programme ............................................. 83

3.7.1. The demand for a future Black Sea Research Programme................................... 83

3.7.2. Improvements in the future call(s) of the Black Sea Research Programme.......... 85

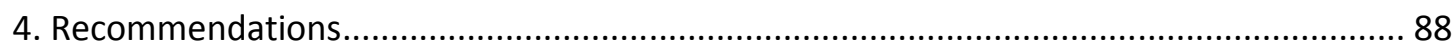

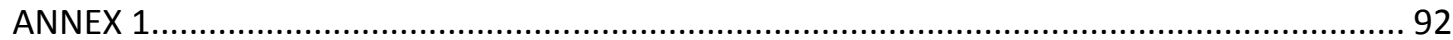




\section{Introduction}

\subsection{The BS - ERA.Net Pilot Joint Call}

\subsubsection{The Pilot Joint Call preparation}

The BS-ERA.NET is an ERA.NET project funded by the European Commission within the 7th Framework Programme for Research and Technology Development (FP7). The consortium of the BS ERA.NET project consists of 17 partners coming from 13 countries. The BS-ERA.NET consortium decided to set up and run a structure to sustain and strengthen the collaboration between R\&D funding programmes and agencies for transnational coordinated funding of research and development in the extended Black Sea region. In this framework, a Pilot Joint Call (PJC) of interested programme owners/programme managers in the Member States of the European Union (MS), the Associated Countries to the 7th Framework Programme (AC) and the extended Black Sea region has been launched on 27th September 2010 and has closed on 14th January 2011 at 18:00 Brussels time.

Eleven (11) out of the thirteen (13) Countries of the BS-ERA.NET's consortium have participated in the BS-ERA.NET Pilot Joint Call. The Programme owners/Programme managers of these 11 countries that have signed an Implementation Agreement and confirmed their participation in the Group of Funding Parties of the Call, are: SCS-RA (Armenia), SDF(Azerbaijan), MEYSB (Bulgaria), SNRSF(Georgia), BMBF (Germany), GSRT (Greece), ENEA (Italy), ASM (Moldova), CNMP(Romania), TÜBITAK (Turkey), SCSII (Ukraine).

\subsubsection{The launch of the Pilot Joint Call. The objective, the thematic areas and the basic rules of participation and funding.}

The objective of the Pilot Joint Call is to promote collaborative research on Climate \& Environment and Energy by taking a proactive and innovative approach to developing solutions for a sustainable development. The implementation of this Pilot Joint Call is an early step towards meeting the overall aim of the BS-ERA.NET project, namely the development of a Black Sea Research Programme (BSRP).

The Group of Funding Parties agreed to support joint research projects. The joint research projects addressed mostly applied research. However, basic research of direct relevance to the thematic focus of the call has too been addressed. The institutions that applied for funding were required to be eligible for funding by their respective national Funding Party. They could be higher education and research institutes, R\&D companies and SMEs. Each project consortium was required to comprise of at least 3 eligible institutions from 3 different participating countries to 
the BS-ERA.NET Joint Call, of which at least one from an EU country and one from a non-EU country from the extended Black Sea region. One of the participating institutions would be designated as Coordinating Institution. The duration of a project would be between 18 and 36 months and the maximum funding allocated per project is $€ 300,000$.

The Pilot Joint Call was implemented through a coordinated funding scheme whereby each Funding Party has funded its own teams within each multilateral research project, with a view to harmonize the funding contributions in order to guarantee the funding of as many as possible of the projects selected through a peer review process.

The financial contributions of each Funding Party have been topped-up by a contribution based on a transfer of INTAS financial assets to the funding parties from the Joint Call Secretariat. The principle was on a pro-rata basis depending on the total actual contribution of each Funding Party in relation to the total financial contribution of the Group of Funding Parties.

\subsubsection{The projects' proposals submission, evaluation, selection, contracting and monitoring.}

A Joint Call Secretariat (JCS) has been entrusted with the operational management of the Pilot Joint Call by the Group of Funding Parties. The submission of the project proposals was through an on-line submission system, the "PT-Outline". A total number of $\mathbf{6 6}$ project proposals have been submitted. The Joint Call Secretariat verified that $\mathbf{5 6}$ project proposals met the eligibility criteria, whereas 10 non-eligible project proposals were rejected.

The final $\mathbf{1 1}$ excellent projects that were selected out of the $\mathbf{5 6}$ project proposals were recommended for funding. The selection was based on an international, independent peer-review procedure. More specifically, firstly, a dedicated pool of evaluators, consisting of external independent experts, anonymously assessed the merits of the submitted proposals. Afterwards, a Scientific Council, which has been appointed by the Joint Call Secretariat based on the nominations of the Group of Funding Parties, consisting of high level scientific experts, consolidated the results of the evaluation and made recommendations to the Group of Funding Parties. The final funding decision rested with the Group of Funding Parties.

For each approved project the Joint Call Secretariat executed an Umbrella Project Contract, which had been signed both by the Joint Call Secretariat on behalf of the Group of Funding Parties and by each Coordinating institution of a consortium. Umbrella Project Contracts were complemented by National Project Contracts between each participating institution in a consortium and its corresponding Funding Party in case these organisations were two separate legal entities.

The Joint Call Secretariat was responsible for the overall monitoring of the project. 


\subsection{The Concept of the Monitoring and Assessment of the Pilot Joint}

\section{Call}

The concept of the Monitoring and Assessment of the Pilot Joint Call is the evaluation of the implementation of the PJC, particularly the call preparation and dissemination, as well as the proposal submission, evaluation, selection and contracting procedures. The monitoring expert also assesses and discusses the efficiency of the coordination of national funding instruments in this ERA.Net call and provides recommendations for possible follow-up funding activities. 


\section{Monitoring and Assessment methodology}

\subsection{Instruments}

2.1.1. A questionnaire addressed to successful and unsuccessful scientists involved in submitting project proposals had been sent to probe their satisfaction with call implementation and selection procedures, as well as the overall effort of the submitting project consortium for preparing a proposal. Moreover, the questionnaire that was addressed to the partners of the 11 selected for funding projects, had additional questions regarding their experience and assessment on the contracting and monitoring procedures.

The response rate of the successful partners is rather high and reaches the $59 \%$. In contrast, the response rate of the unsuccessful applicants lies rather low, at $10 \%$ and was achieved after sending multiple e-mails ( 3 reminders) to this specific target group. This figure is quite common in such surveys through questionnaires, due to the fact that the disappointed applicants are not motivated easily to participate in follow up surveys.

\begin{tabular}{|c|c|c|c|}
\hline & Total Number & Responders & Response Rate \\
\hline succesful applicants & 44 & 26 & $59 \%$ \\
\hline unsuccesful applicants & 203 & 20 & $10 \%$ \\
\hline
\end{tabular}

The distribution of responders per country is shown below:

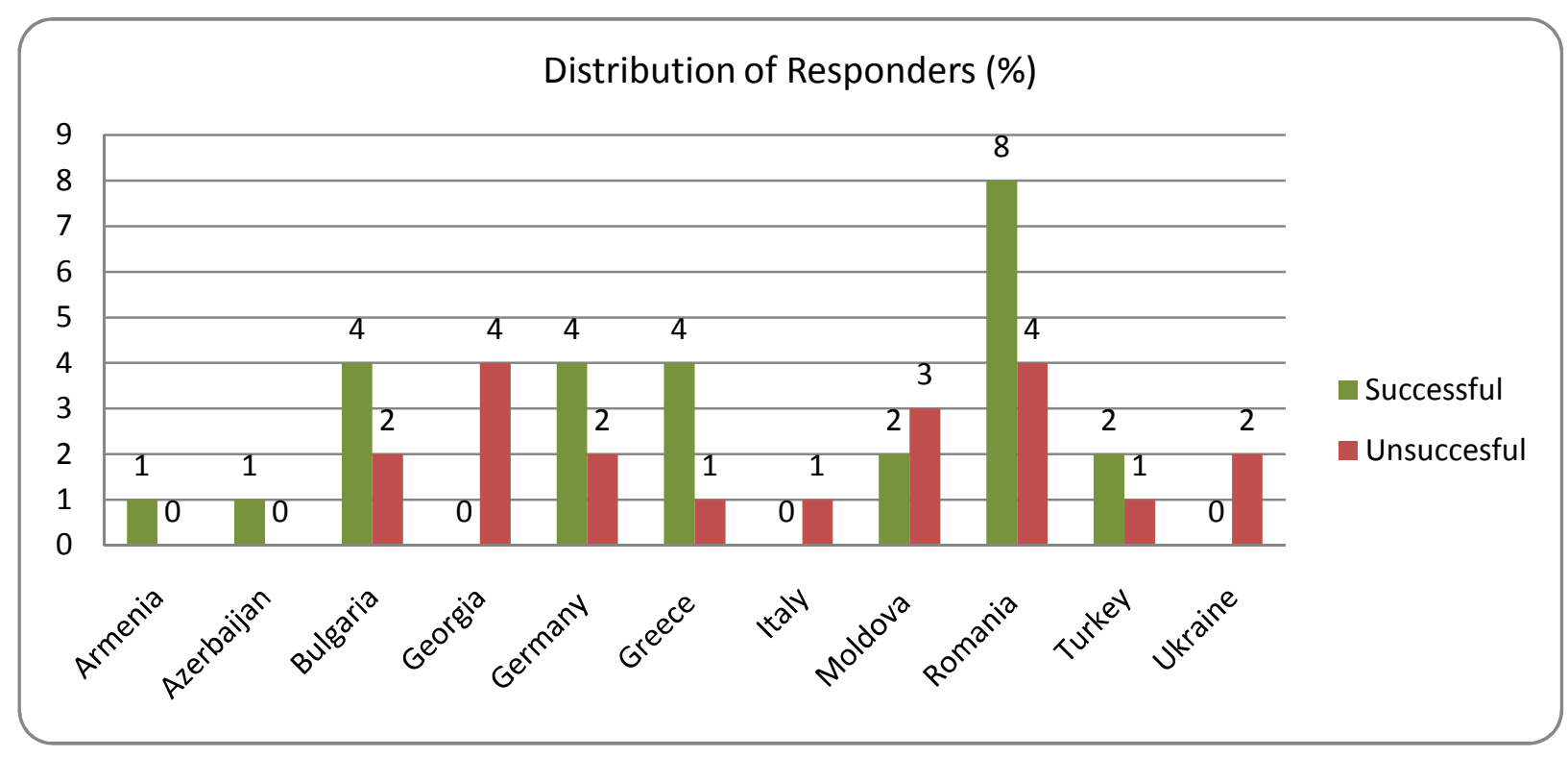


Most of the responders come from Universities and Research institutes.

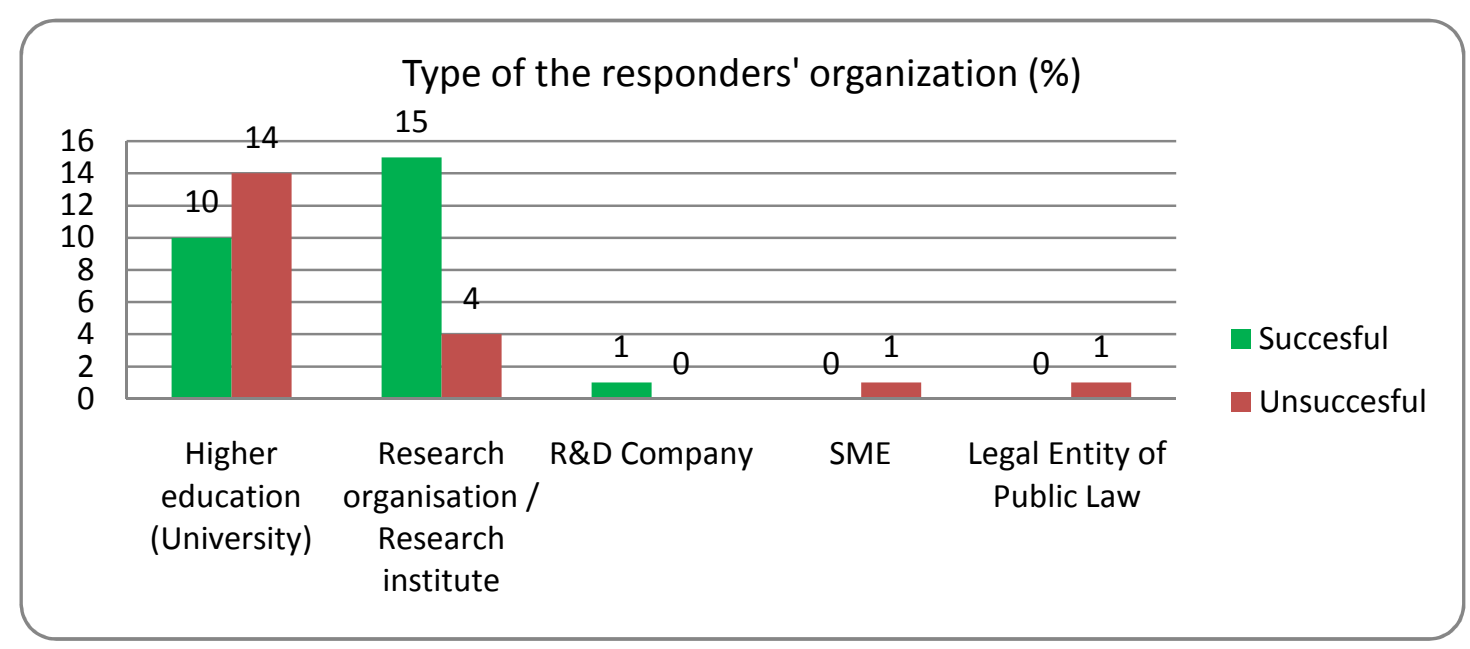

They usually prefer to submit proposals in national / regional calls for proposals but they are active in transnational cooperation calls and EU FPs calls as well.

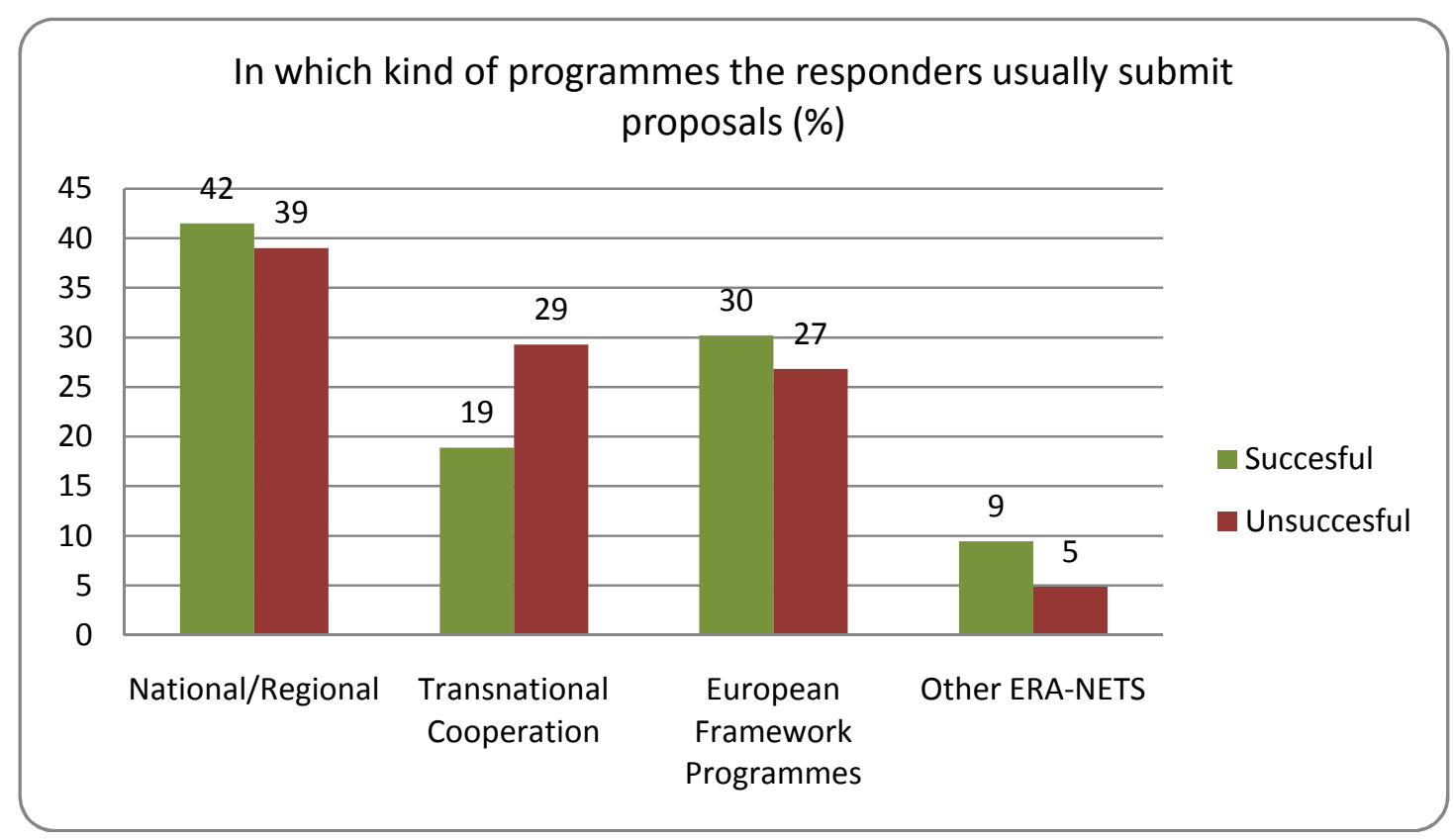

Most of the responders submit 1 to 3 proposals per year towards launched calls 


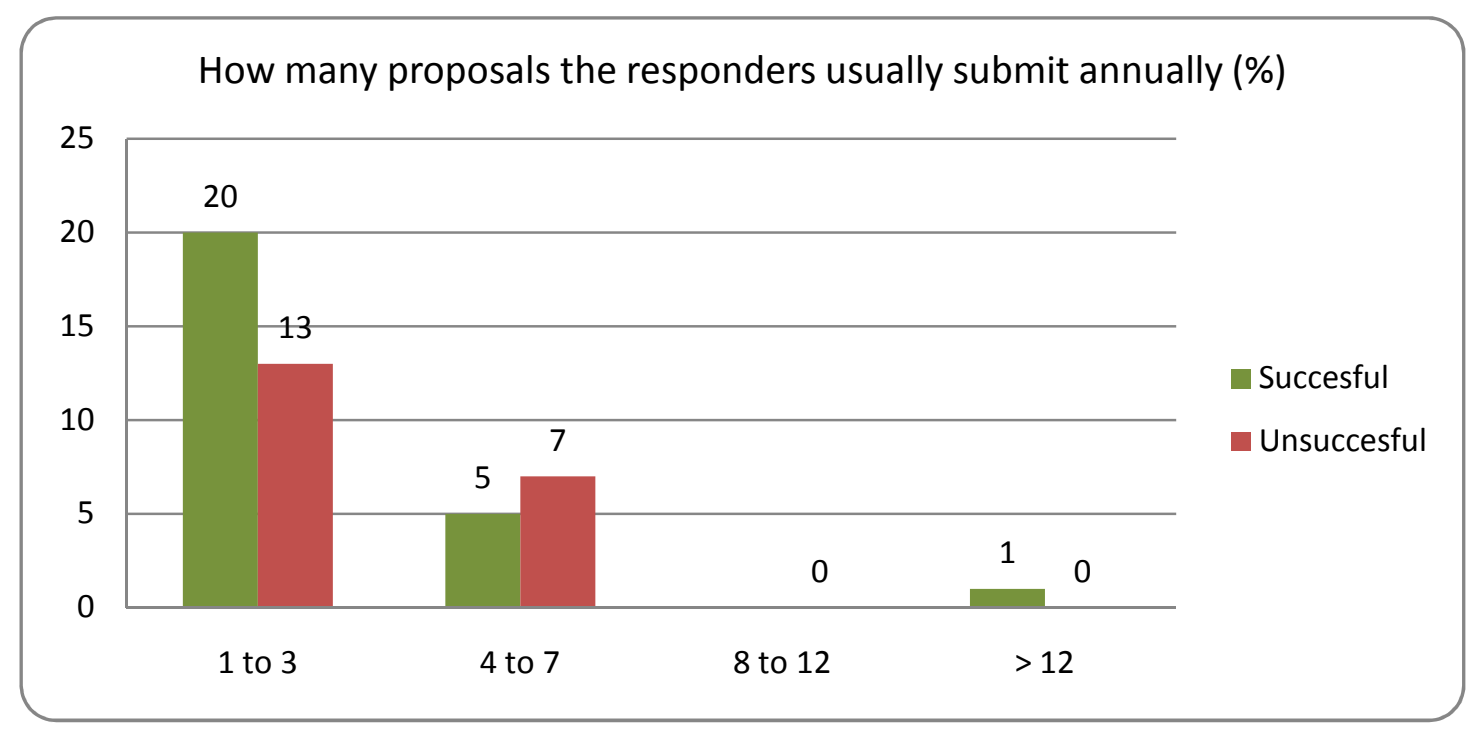

2.1.2. A questionnaire addressed to the members of the Scientific Council (Evaluation and Selection Procedure).

\begin{tabular}{|c|c|c|c|}
\hline & Total Number & Responders & Response Rate \\
\hline $\begin{array}{c}\text { Scientific Council } \\
\text { Members }\end{array}$ & 12 & 5 & $42 \%$ \\
\hline
\end{tabular}

The response rate in the case of the Scientific Council Members is remarkably low, although it took a great effort through multiple e-mails ( 3 times) to motivate them to answer the questionnaire.

2.1.3. A questionnaire addressed to the Group of Funding Parties (Call Preparation, Stimulation and Dissemination Activities, Proposal Submission, Evaluation and Selection Procedure, Contracting Procedure, Monitoring Procedure).

\begin{tabular}{|c|c|c|c|}
\hline & Total Number & Responders & ResponseRrate \\
\hline $\begin{array}{c}\text { Group of Funding } \\
\text { Parties }\end{array}$ & 11 & 8 & $73 \%$ \\
\hline
\end{tabular}

2.1.4. A questionnaire addressed to National Contact Points for the call (Stimulation and Dissemination Activities, Proposal Submission).

\begin{tabular}{|c|c|c|c|}
\hline & Total Number & Responders & Response Rate \\
\hline National Contact Points & 11 & 10 & $91 \%$ \\
\hline
\end{tabular}

2.1.5. Interviews ${ }^{1}$ with 2 (two) officers of the Pilot Joint Call Secretariat (Call Preparation, Stimulation and Dissemination Activities, Proposal Submission,

${ }^{1}$ All the interviewees are enlisted at the Annex 1 
Evaluation and Selection Procedure, Contracting Procedure, Monitoring Procedure). The interviews were conducted during the visit to the Pilot Joint Call Secretariat at Bonn.

2.1.5. Interviews with 6 (six) officers nominated as National Contact Points for the call (Stimulation and Dissemination Activities, Proposal Submission). The interviews were implemented in the framework of the Steering Board meeting at Bucharest.

2.1.6. Interviews with 9 (nine) representatives of the Group of Funding Parties (Call Preparation, Stimulation and Dissemination Activities, Proposal Submission, Evaluation and Selection Procedure, Contracting Procedure, Monitoring Procedure). The interviews were conducted in the framework of the Steering Board meeting at Bucharest

2.1.7. Interviews with the Project Coordinator and other key persons of the BSERA.NET project.

\subsection{Call preparation, stimulation and dissemination activities}

The procedures of the call preparation and dissemination have been analysed. For this purpose, the following have been studied:

- BS - ERA.Net internal processes that led to the setting up of the Pilot Joint Call (Project's description of work, Steering Board meetings minutes) as well as any relevant regional or national studies and reports.

- Call documents that had been launched.

- Interviews with representatives of the non participating countries to the Pilot Joint Call have been conducted in order to explore the cause of their absence.

- Stimulation and dissemination activities of the call on national and international level, collecting data through a structured questionnaire and interviews with the relevant stakeholders (e.g. officers of the Pilot Joint Call Secretariat, National Contact Points for the call). Emphasis has been given beyond the qualitative to the quantitative analysis of the dissemination activities (quantitative data have been kindly provided mainly by the national contact points)

An analysis of the Call preparation, stimulation and dissemination activities has been produced

\subsection{Proposal Submission}

The PJC Proposal Submission Process has been evaluated. For this purpose, the external expert:

- Visited the Pilot Joint Call Secretariat in order to evaluate the operation of the Proposal Submission System. 
- Interviewed the officers of the Pilot Joint Call Secretariat.

- Collected data regarding the performance of the National Contact Points for the call through a structured questionnaire.

- Collected the opinion of the users of the Proposal Submission System which were the applicants through a structured questionnaire.

An analysis of the Proposal Submission has been produced

\subsection{Evaluation and Selection Procedure}

The Evaluation and Selection Procedure has been analysed. Under this task:

- All the available documents of the Pilot Joint Call Secretariat concerning the methodology of the evaluation processes and the analysis of the call results have been examined.

- The officers of the Pilot Joint Call Secretariat have been interviewed.

- Members of the Scientific Council and representatives of the Group of Funding Parties have provided feedback through a structured questionnaire. Additional interviews with members of the Scientific Council and representatives of the group of funding parties complete the overall picture of the evaluation and selection procedure.

- The experiences of the successful and unsuccessful applicants were collected through structured questionnaires

An analysis of the Evaluation and Selection Procedure has been produced.

\subsection{Contracting Procedure}

The competence of the Pilot Joint Call Secretariat and the National Funding Bodies regarding the Contracting Procedures has been examined through:

- Interviews with officers of the Pilot Joint Call Secretariat

- Interviews with representatives of the Group of Funding Parties

- Questionnaires addressed to the partners of the approved projects.

An analysis of the Contracting Procedure has been produced.

\subsection{Impact and efficiency of the call}

The impact and the efficiency of the call have been measured and analysed. Indicators such as success rate of the call, regional distribution of proposers, proposed topics, etc have been assembled. Quantitative data is presented in suitable graphical form.

All the needed data have been provided by the Pilot Joint Call Secretariat. 
An analysis of the impact and efficiency of the call has been produced.

\subsection{Recommendations}

The monitoring report includes recommendations on possible modifications and improvements of the call procedures, in order to enhance the performance of future trans-national calls, as well as to increase the impact of the projects to be funded. This provides input for a possible follow-up funding programme between the EU MS/AC and the Black Sea Region. 


\section{Results and Analysis}

\subsection{Preparation phase}

\subsubsection{Setting up the Group of Funding Parties for the Pilot Joint Call.}

As it was mentioned earlier, 11 out of the 13 Countries of the BS-ERA.NET's consortium decided to participate in the BS-ERA.NET Pilot Joint Call by allocating national funding. The funding parties of France and Malta opted not to participate in the call, due to their limited available funds at the particular period of the call in combination with other higher priorities in their funding agenda.

The incentives for the group of funding parties to provide funding and participate in the Pilot Joint Call are almost equally spread between 3 considerations, with slightly more weight being attributed to the fact that the PJC was a funding instrument which was complementary to other existing funding instruments.

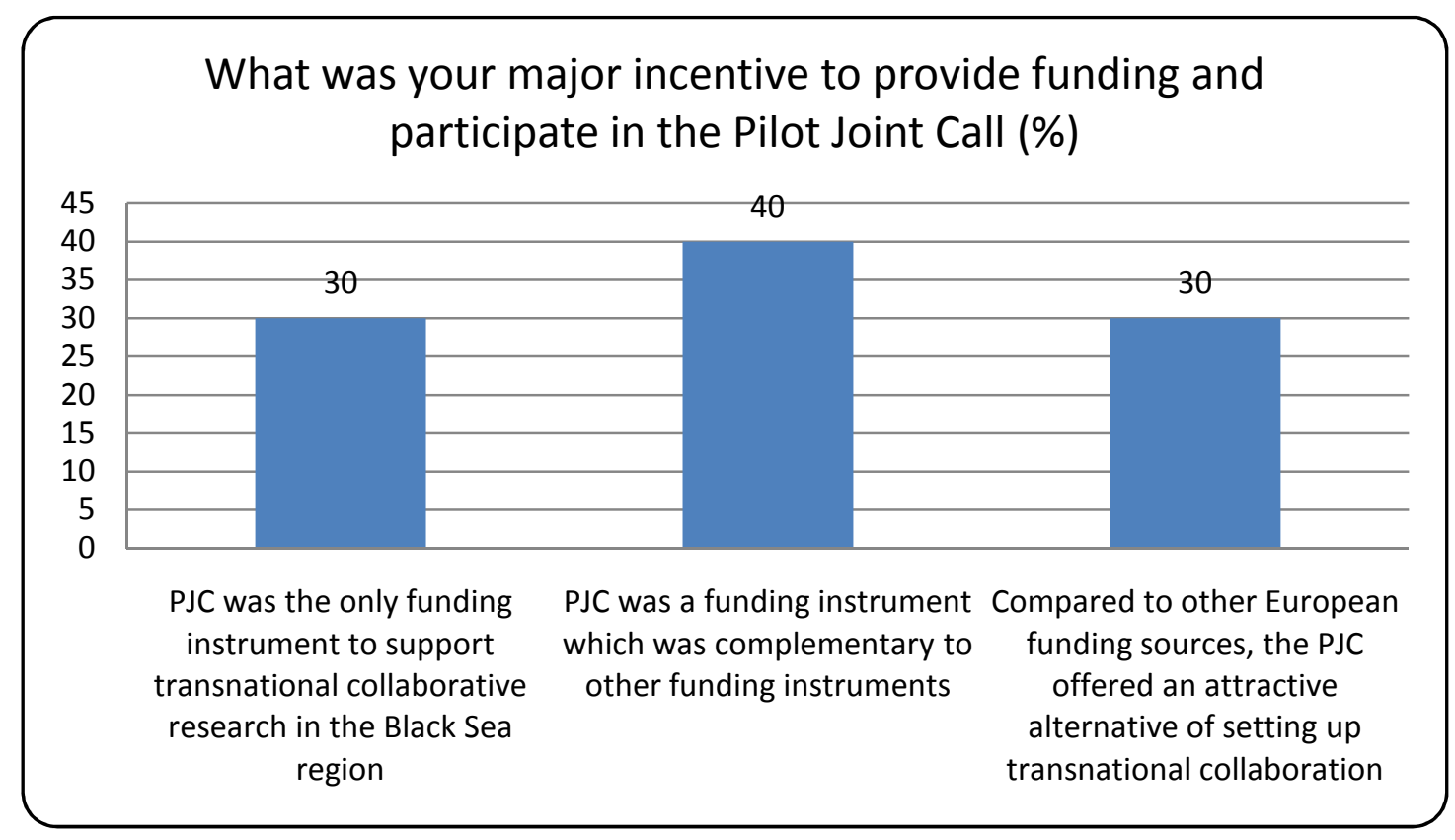

Conclusion 1: It is a great achievement that 11 funding parties coming from 11 countries with different RTDI systems, decided to cooperate allocating national funds to a joint call and overcoming all the bureaucratic barriers that originated from their different administration and legislation structures.

The incentives for the group of funding parties to provide funding and participate in the Pilot Joint Call are almost equally spread between 3 considerations, , with slightly more weight being attributed to the fact that the PJC was a funding instrument which was complementary to other existing funding instruments. 
It should be mentioned that for many partners, beyond the scientific merit, there was a strong political interest to support and participate in a regional structure such as a joint call.

\subsubsection{Setting up the terms of references of the Pilot Joint Call.}

All the partners have been actively involved in the preparation of the Pilot Joint Call and its scope was reflected in their expectations.

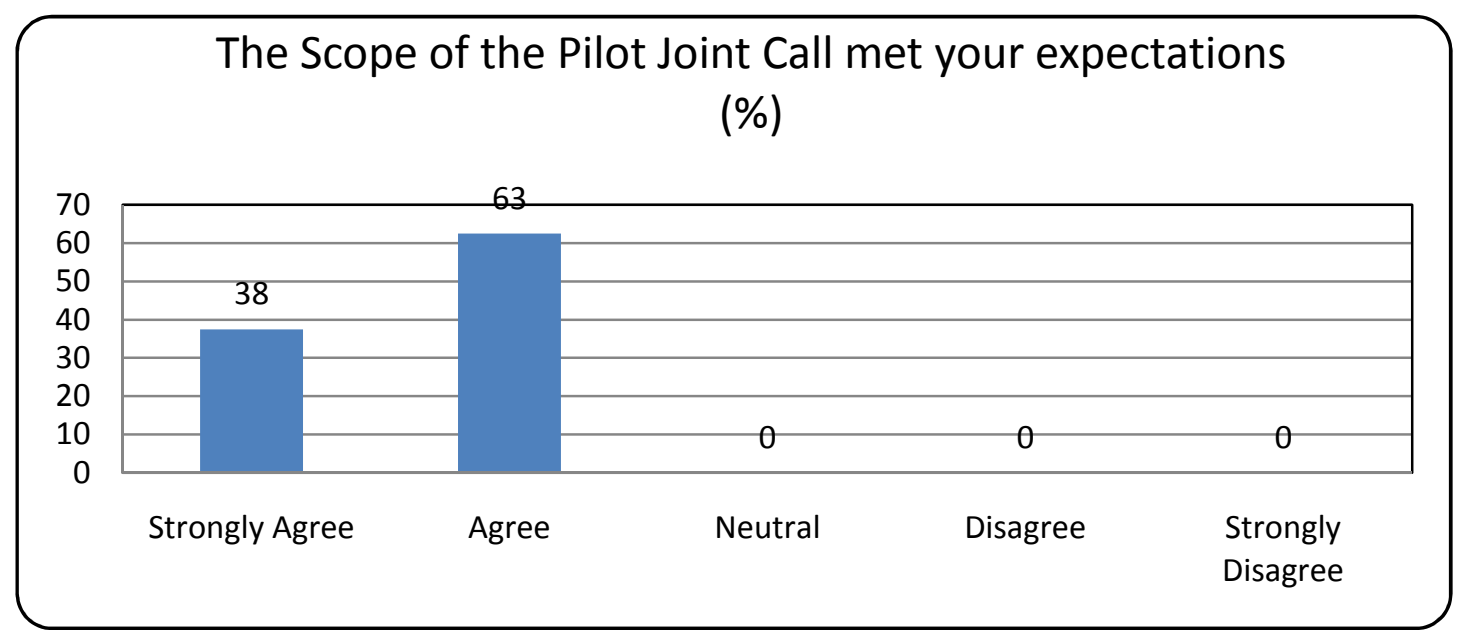

The identification of the thematic focus of the Pilot Joint Call was initiated having had as starting points:

- The research priorities of the BSEC economic agenda and the Black Sea action plan

- The thematic priorities that had been identified in the framework of the BS-ResPot project ${ }^{2}$. More specifically, it had been defined the most promising fields of collaboration in research and innovation among the countries of the region and with the EU.

- The outcome of 3 thematic workshops in the priorities "Environment", "Food, Agriculture, and Biotechnology" and "Energy" that were organized as part of the BS-ResPot follow-up activities by the International Centre

\footnotetext{
${ }^{2}$ The Research Potential of the BSEC countries (BS-ResPot) was a project coordinated by the ICBSS and funded by the Sixth Framework Programme of the European Commission. The aim of BS-ResPot was to transform the political will for cooperation into concrete actions. To achieve this goal, BSResPot, evaluated the strengths of the research potential in every country; Investigated the legal and regulatory framework in each country with a view to promote the coordination of national policies at a regional level and with the EU; Assessed the current state of affairs in the field of innovation and explored more effective ways for the exploitation of research results; Defined the most promising fields of collaboration in research and innovation among the countries of the region and with the EU.
} 
for Black Sea Studies (ICBSS) in cooperation with the Turkish Academy of Sciences (TUBA)

Furthermore, after a relevant consultation and voting among the funding parties, it was decided to launch the Pilot Joint Call on the following topics:

1. Climate and Environment

1.1 Exploitation and transport of mineral resources: impact on environment

1.2 Water pollution prevention options for coastal zones and tourist areas

2. Energy

2.1 Hydrogen production from $\mathrm{H} 2 \mathrm{~S}$ rich Black Sea Water

$2.2 \mathrm{CO} 2$ capture and storage technologies for zero emission power generation in the Black Sea region.

The approach to focus in only 2 thematic topics and 4 subtopics is a common practice in these cases since this was a pilot call with limited budget and there was no need to cover more scientific disciplines.

The thematic focus of the Pilot Joint Call met the expectations of the group of funding parties

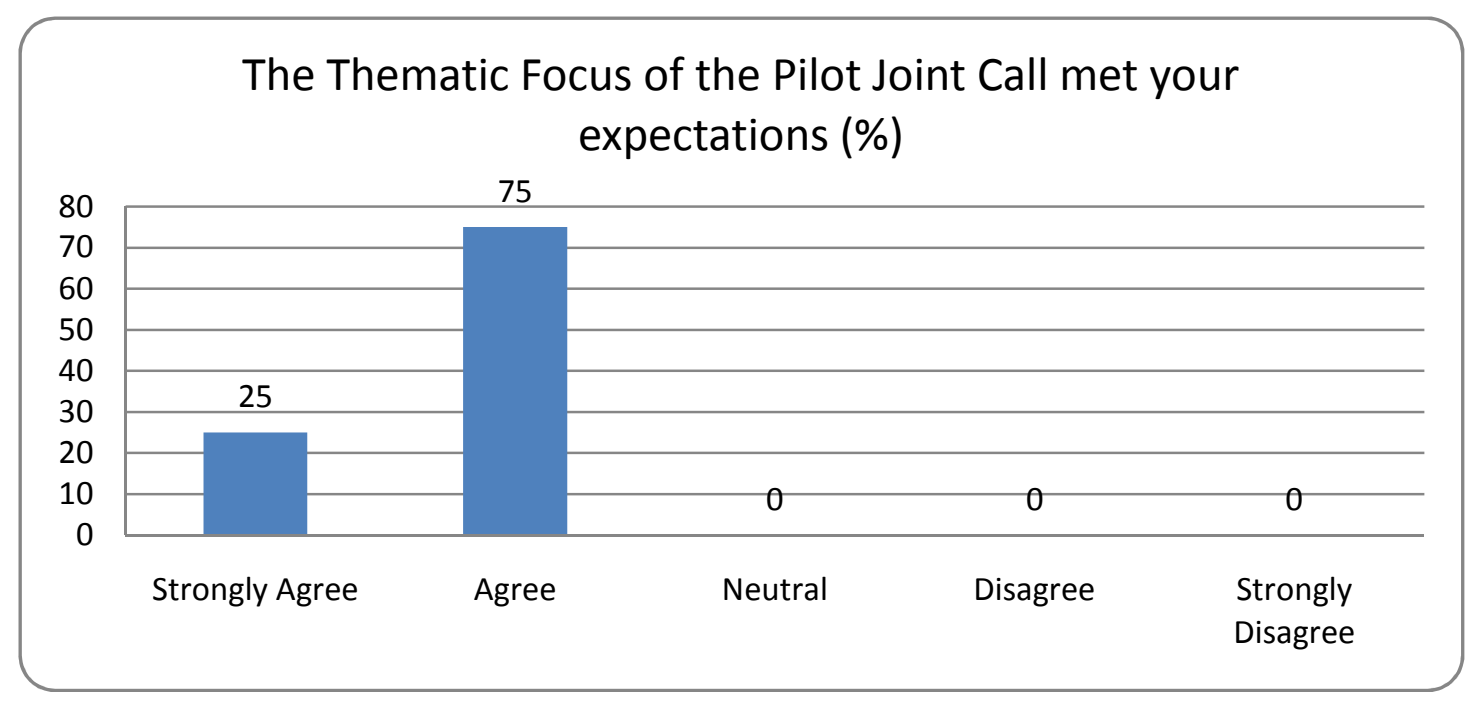

Conclusion 2: The selection of the thematic focus of the joint call was relied on the existing evidence based identification of the research priorities of the Black Sea region. The research priorities have been identified through a detailed analytical work in which the relevant adequate methodologies were used.

Moreover, it is a very good approach not to expand the thematic areas of the call in more scientific disciplines due to the limited budget of the call and its pilot character where the first priority is to test and improve the call's procedures. 
Concerning other key issues of the call such as the duration, the maximum funding allocated per project and the eligibility criteria, the perspective of the group of funding bodies is less adequate.
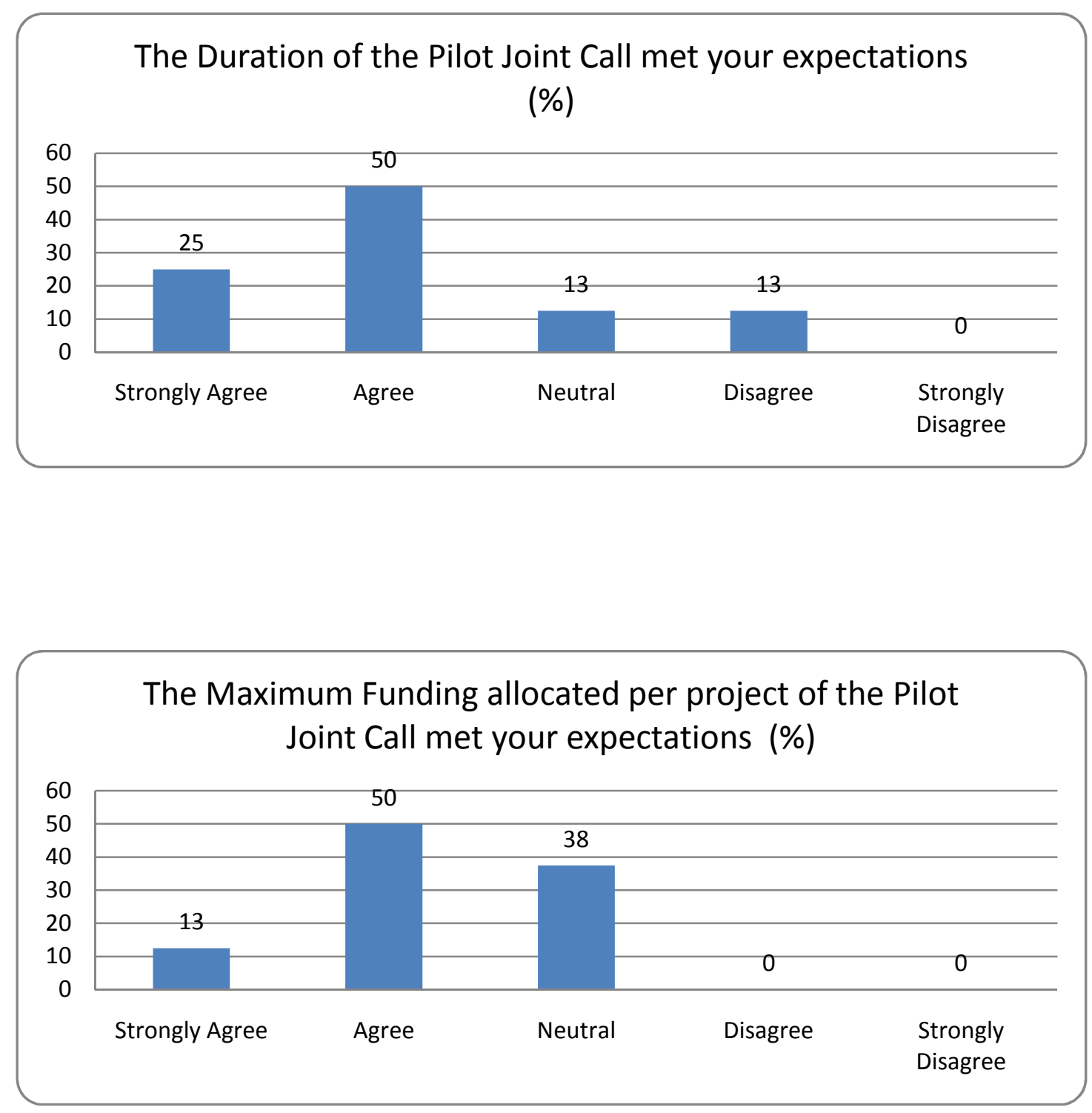


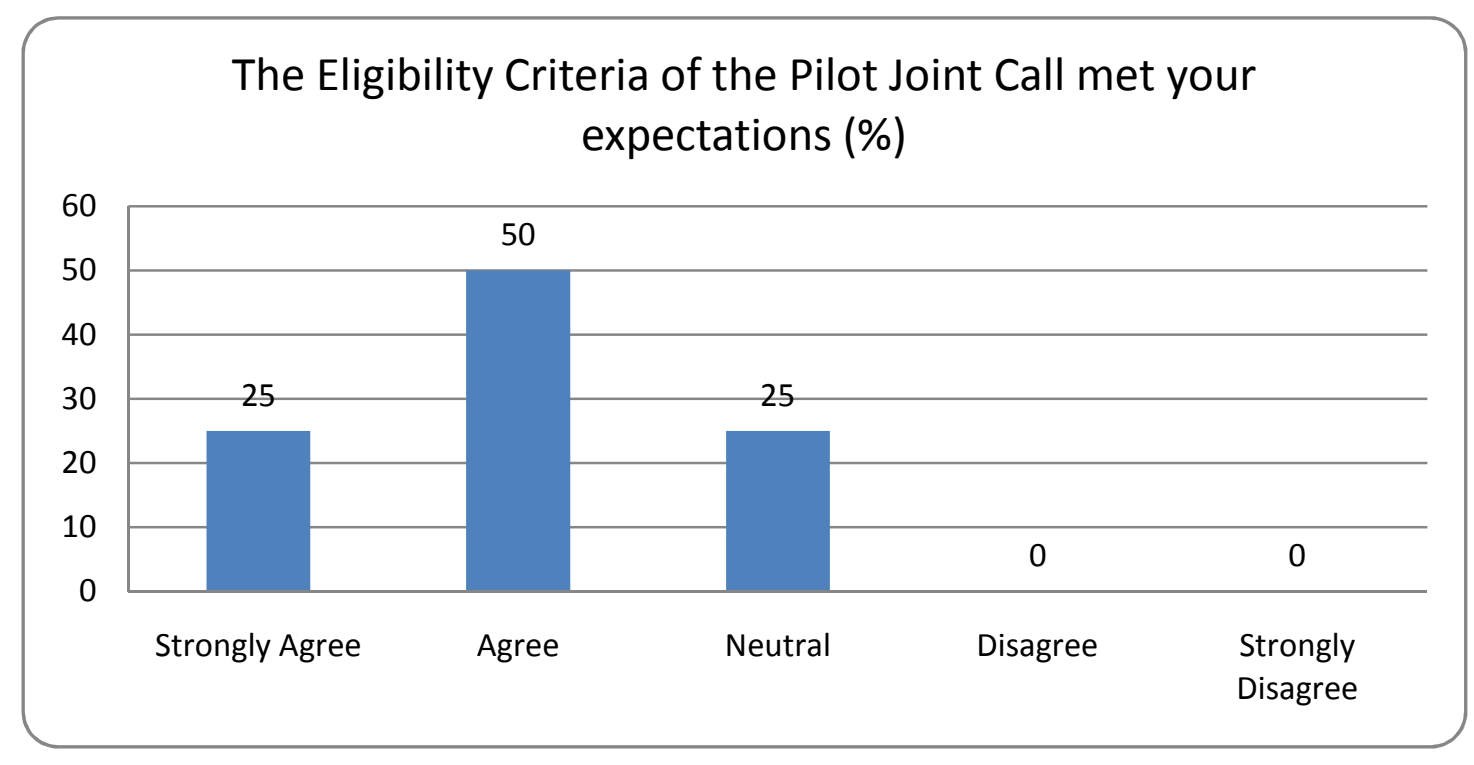

Conclusion 3: The terms of references of the Pilot Joint Call are standing clear and informative.

Analysing the feedback of the group of funding parties regarding the terms of references, it seems that apart from the scope and the thematic focus, a consensus has not been reached on key issues such as the duration, the maximum funding allocated per project and the eligibility criteria.

Perhaps, more elaboration was required on the abovementioned issues, in order to meet the full appreciation of all funding parties.

\subsubsection{Launching the Pilot Joint Call.}

The scientific communities have declared several sources of information regarding the launch of the Pilot Joint Call. It is interesting that the greater part of the successful applicants found the needed information through the BS - ERA.Net webpage, while the majority of the unsuccessful applicants received the needed information via their project partners or their project coordinator. 


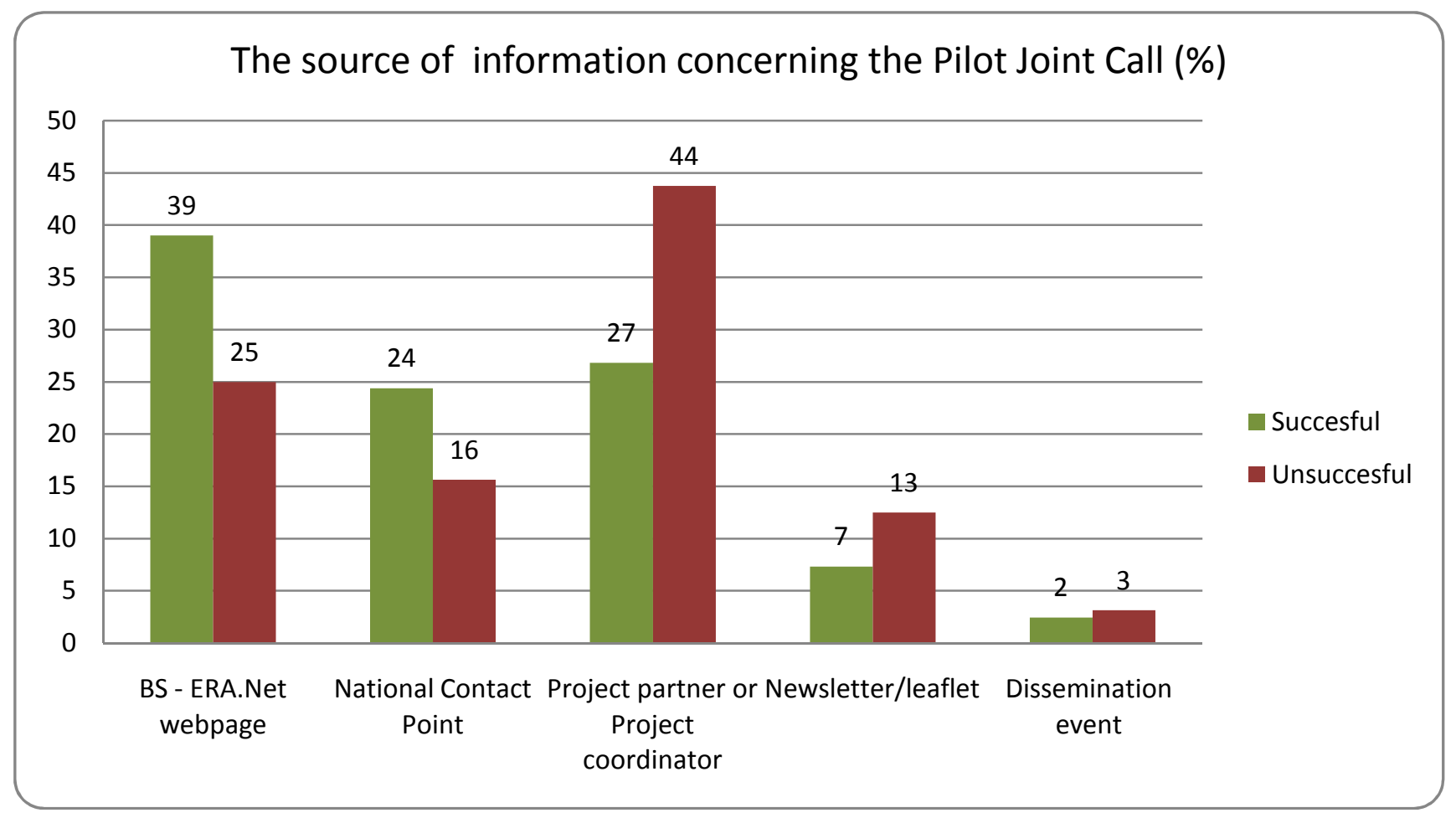

Moreover, the majority of the successful applicants consider that the publication of the call was adequately announced. On the other hand, less satisfied on this issue are the unsuccessful applicants.

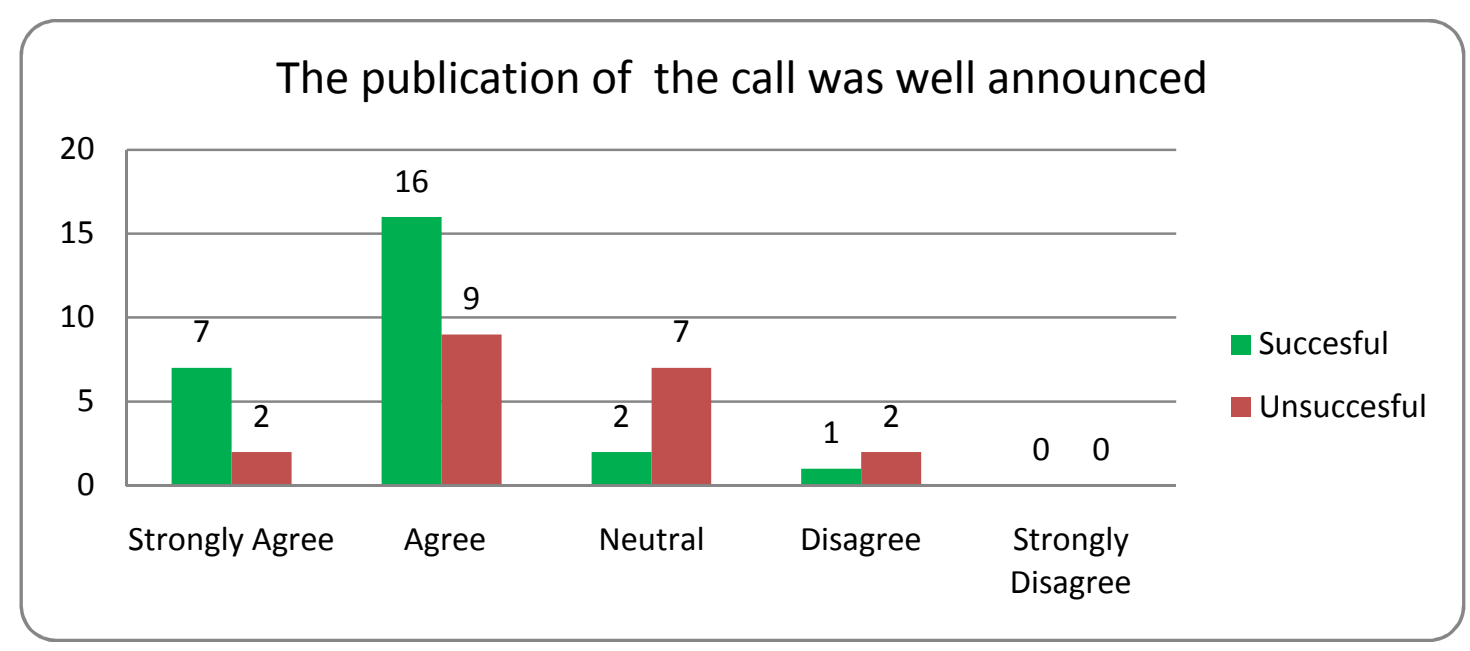

For the same subject, the opinion of the group of funding bodies is positive. 


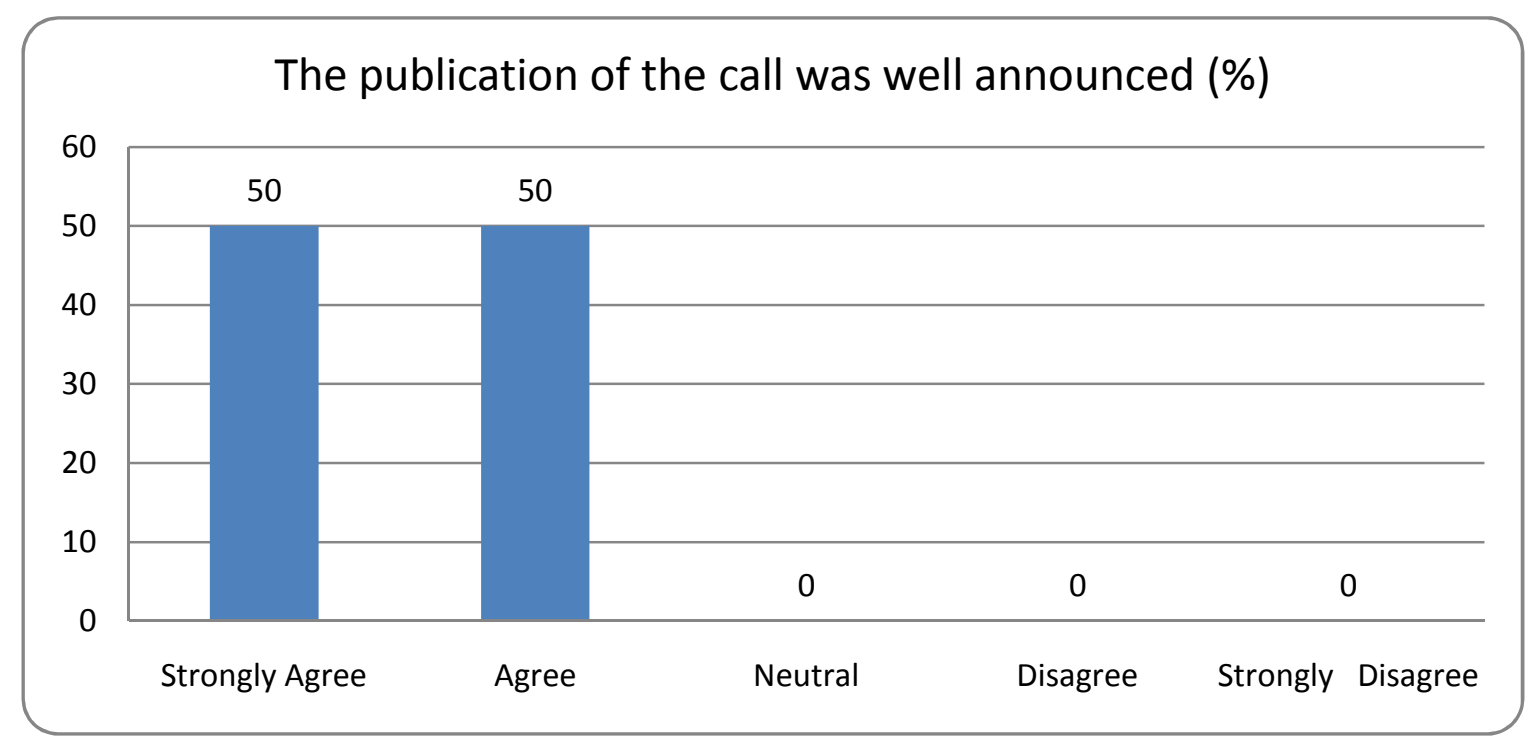

Most of the applicants found the PJC website clear and transparent.

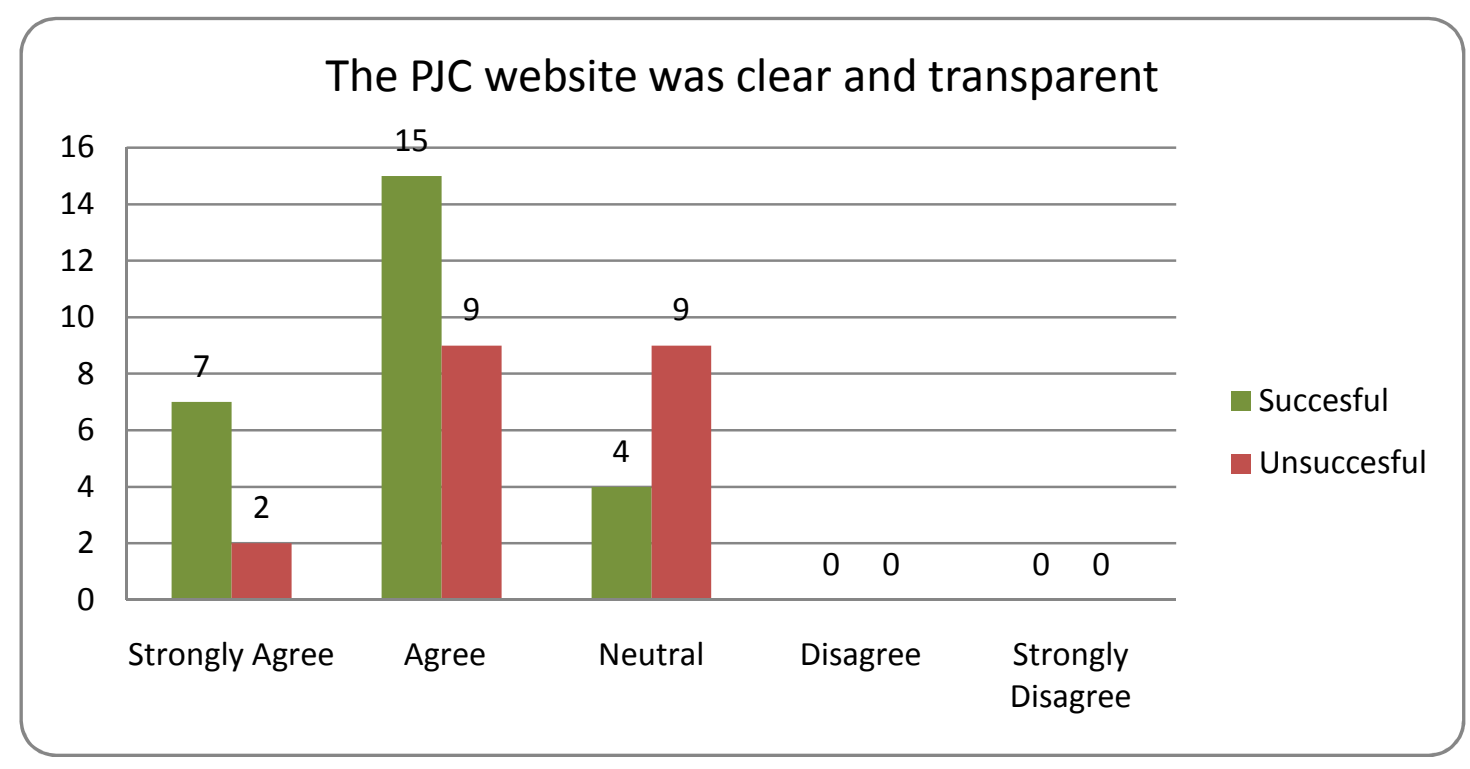

Completely satisfied from the PJC website are the members of the group of funding parties. 


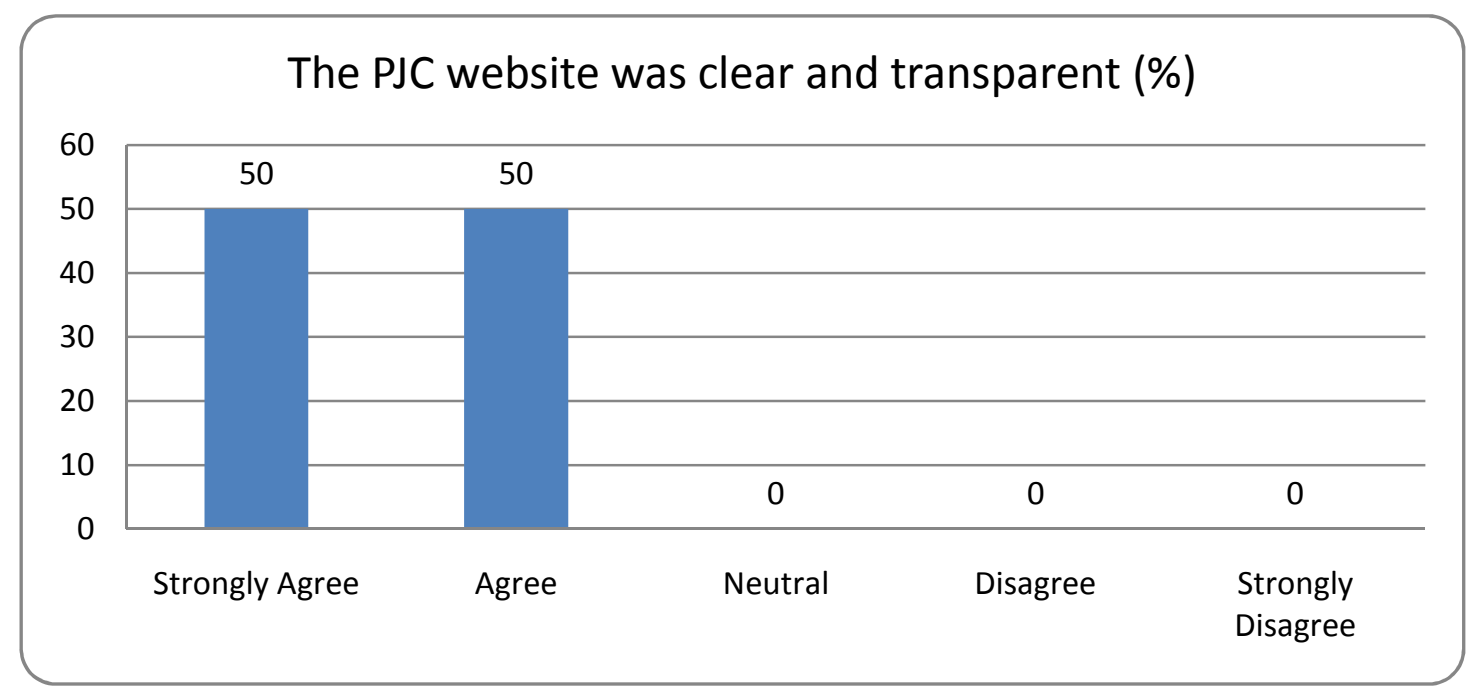

The greater part of the responded applicants agree that the flyer/leaflet of the PJC was welldesigned (general layout, content information,...)

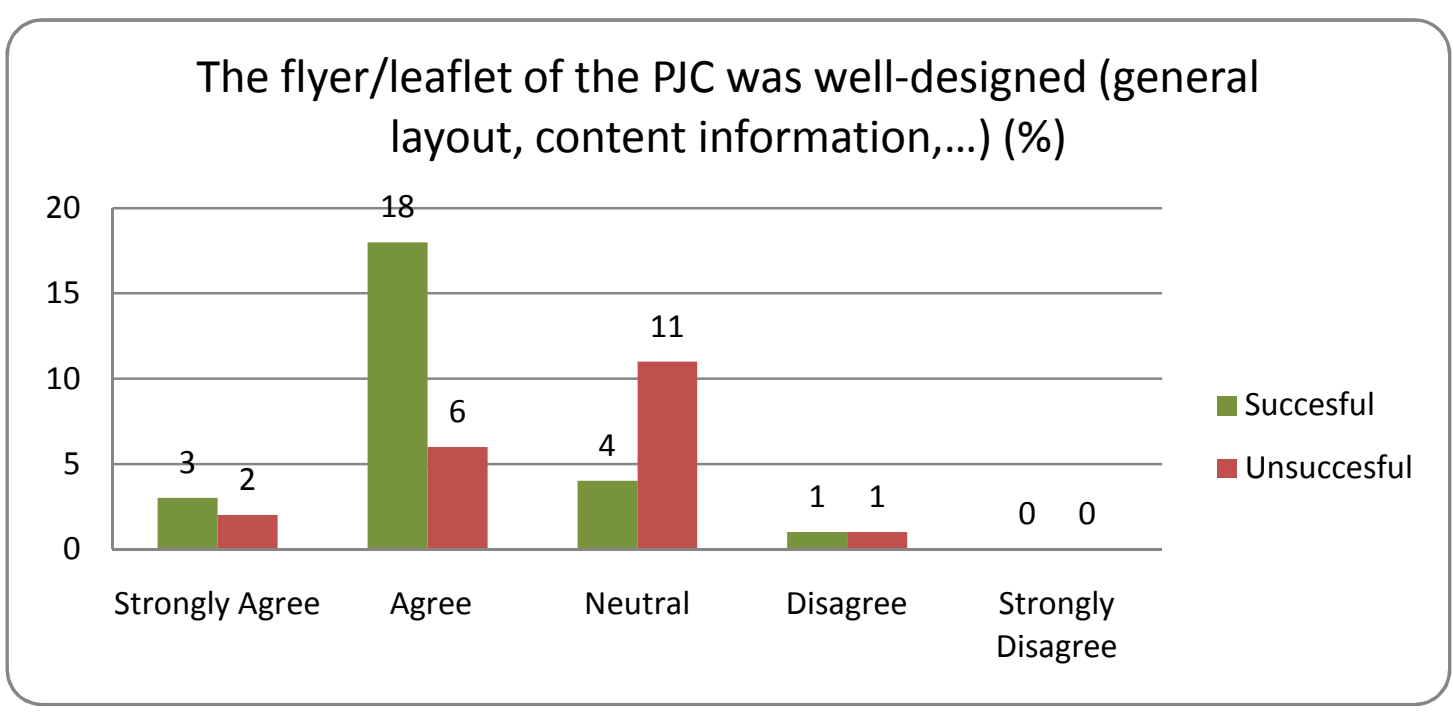

A positive view on the PJC flyer/leaflet was declared by the group of funding parties

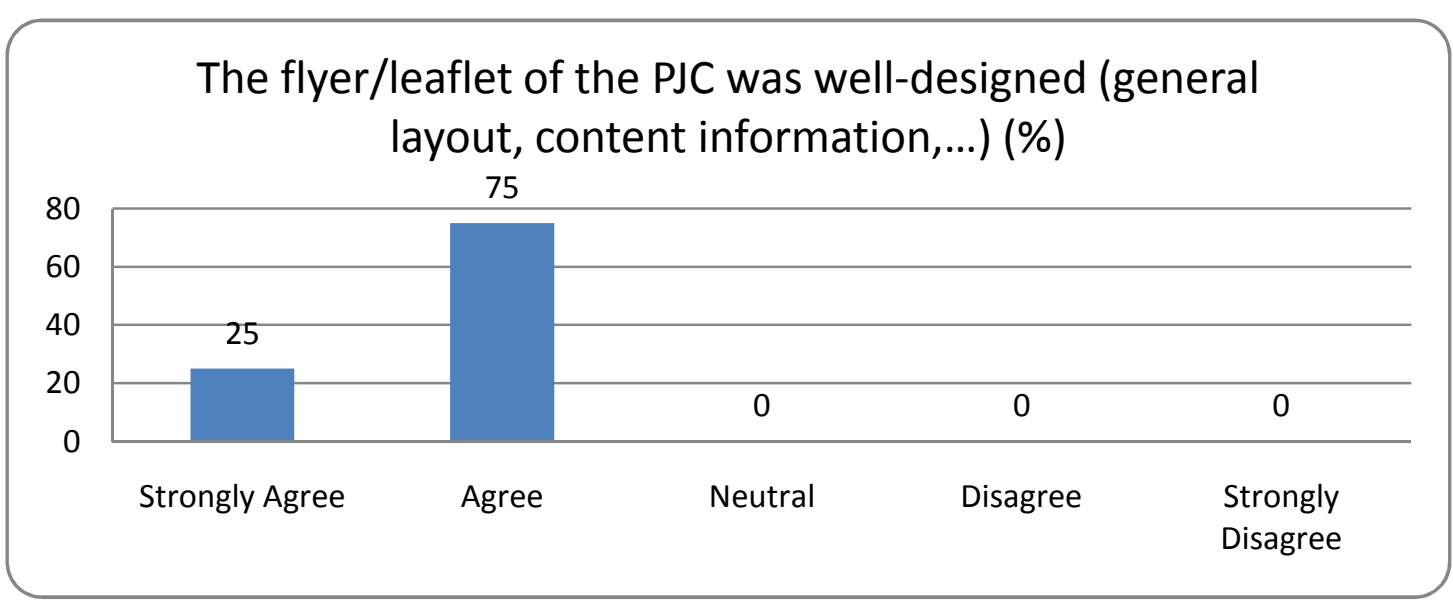


Conclusion 4: The launching of the call was adequate using all the disseminations means that could be used (BS-ERA-net website, leaflets etc). Moreover, most of the applicants as well as the members of the funding parties have a positive view concerning the BS-ERA-net website and the flyer/leaflet.

Analysing the feedback from the applicants produces the interesting conclusion that the majority of successful applicants found the needed information through the BSERA.Net webpage, while the majority of unsuccessful applicants received the needed information via the project partners or the project coordinator. This could highlight the usefulness of the information that was posted at the web-site.

\subsubsection{The documents of the Pilot Joint Call.}

The PJC Terms of Reference were found sufficiently clear and concise by the majority of applicants and provided sufficient support to them.

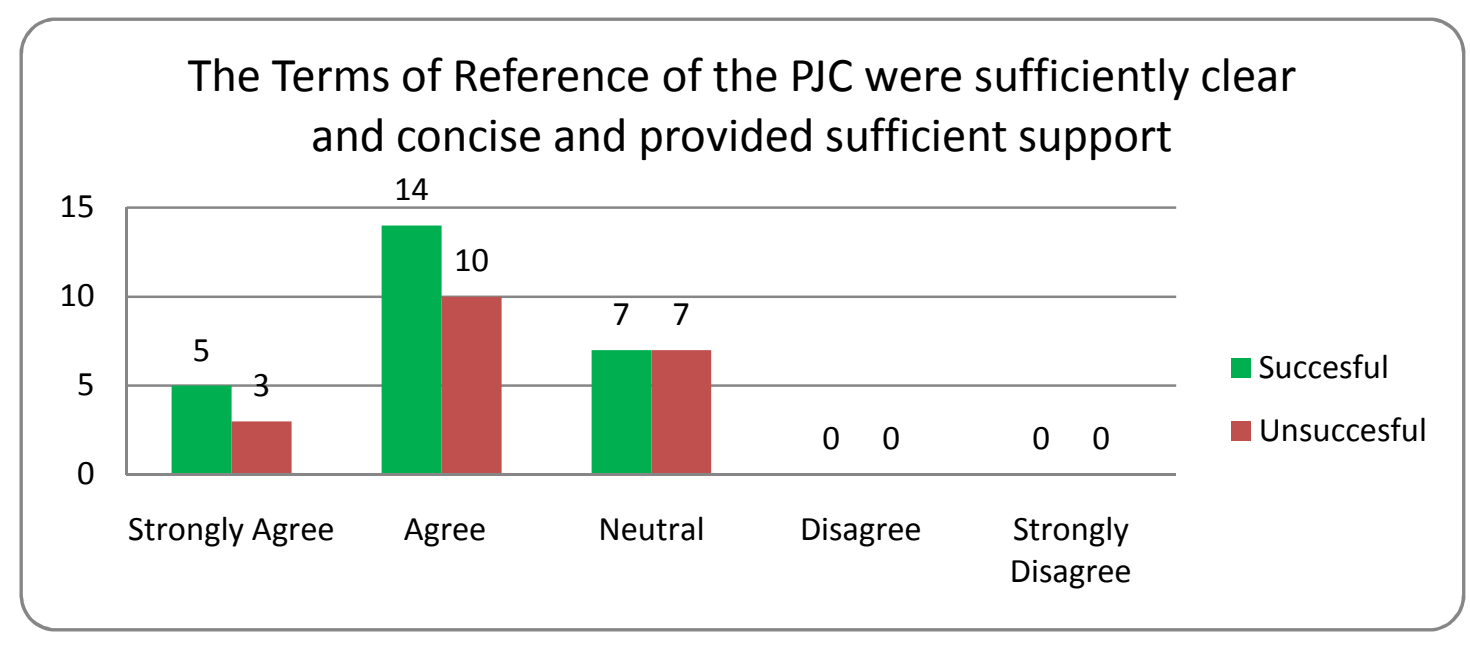

Most of the funding parties consider that the PJC Terms of Reference were sufficiently clear and concise and provided sufficient support to the applicants. 


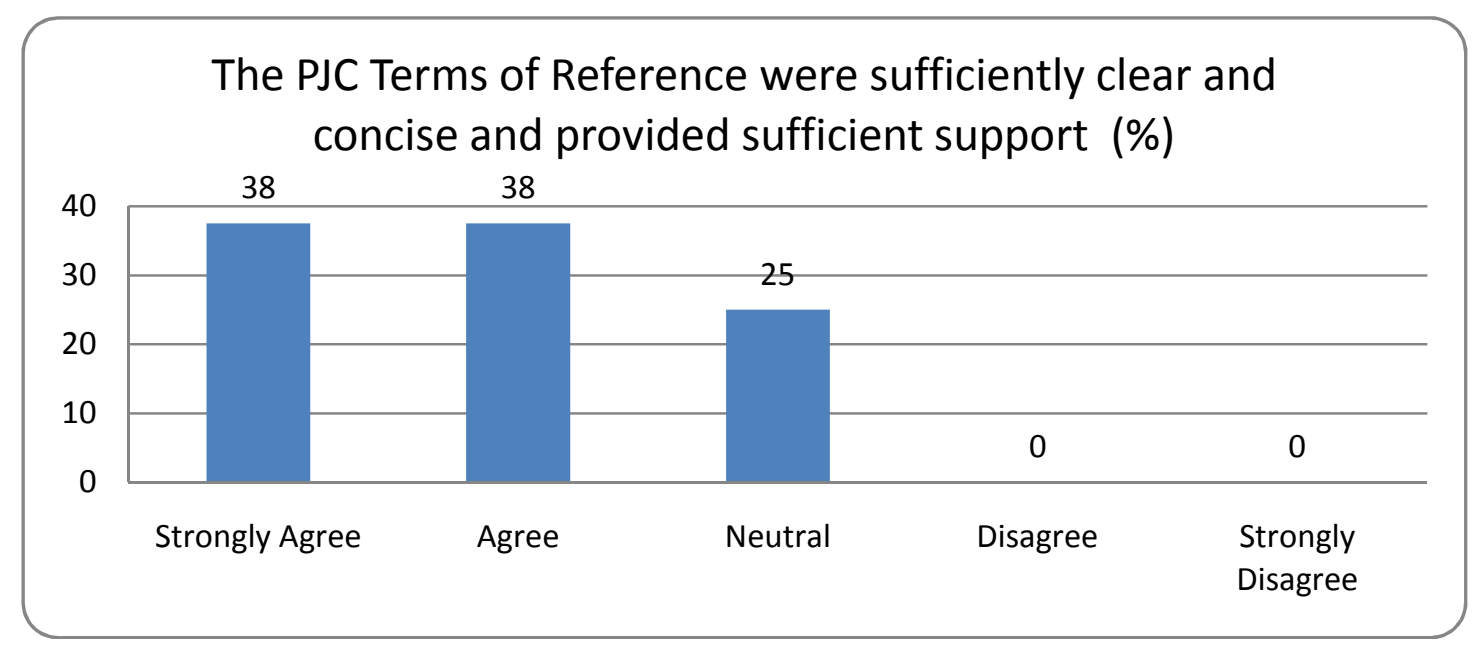

The Scientific Committee highly approves the quality of the PJC Terms of Reference

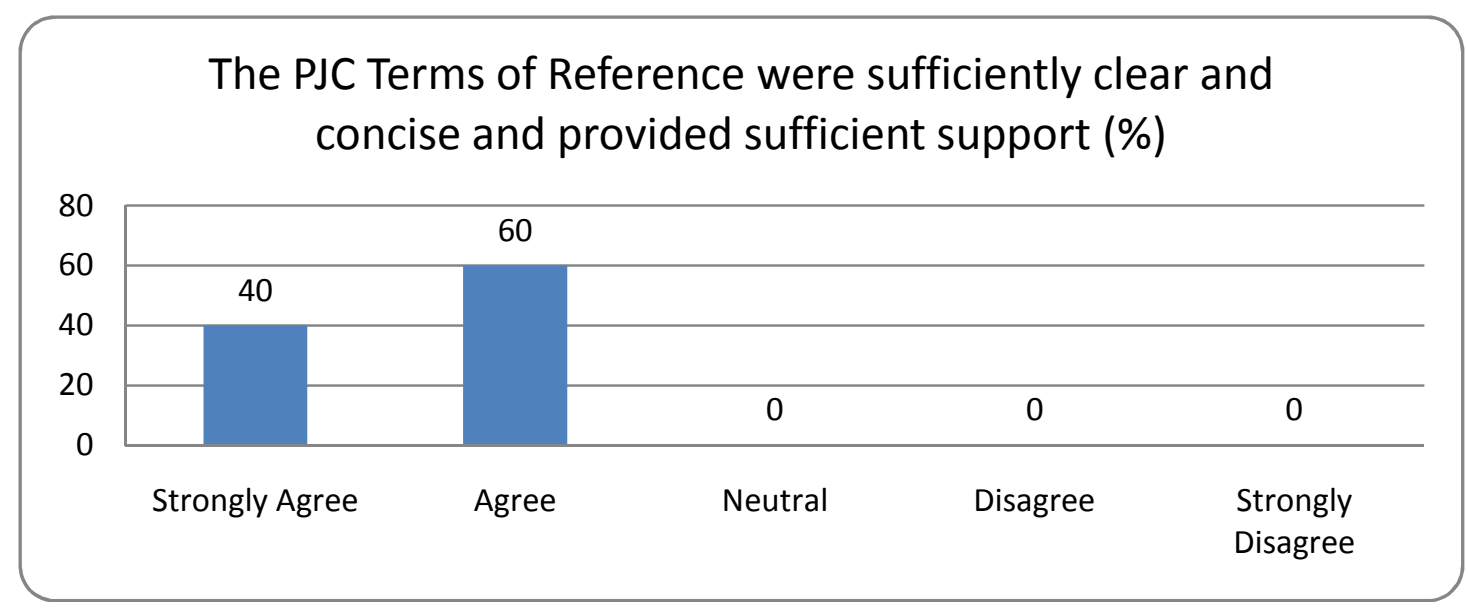

Concerning the PJC guidelines for applicants, some of the responding scientists declared that they were not sufficiently clear and concise and provided insufficient support. 


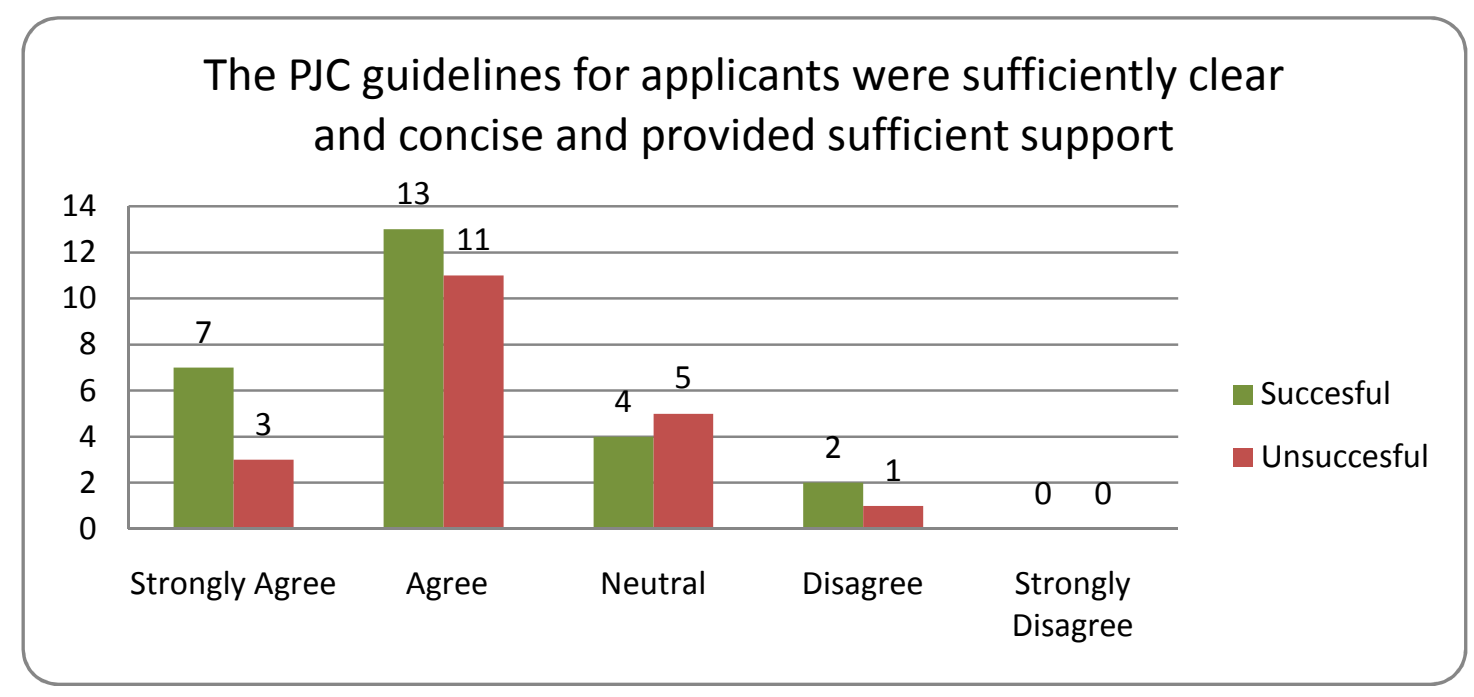

The majority of the group of funding parties is satisfied with the content and the functionality of the guidelines.

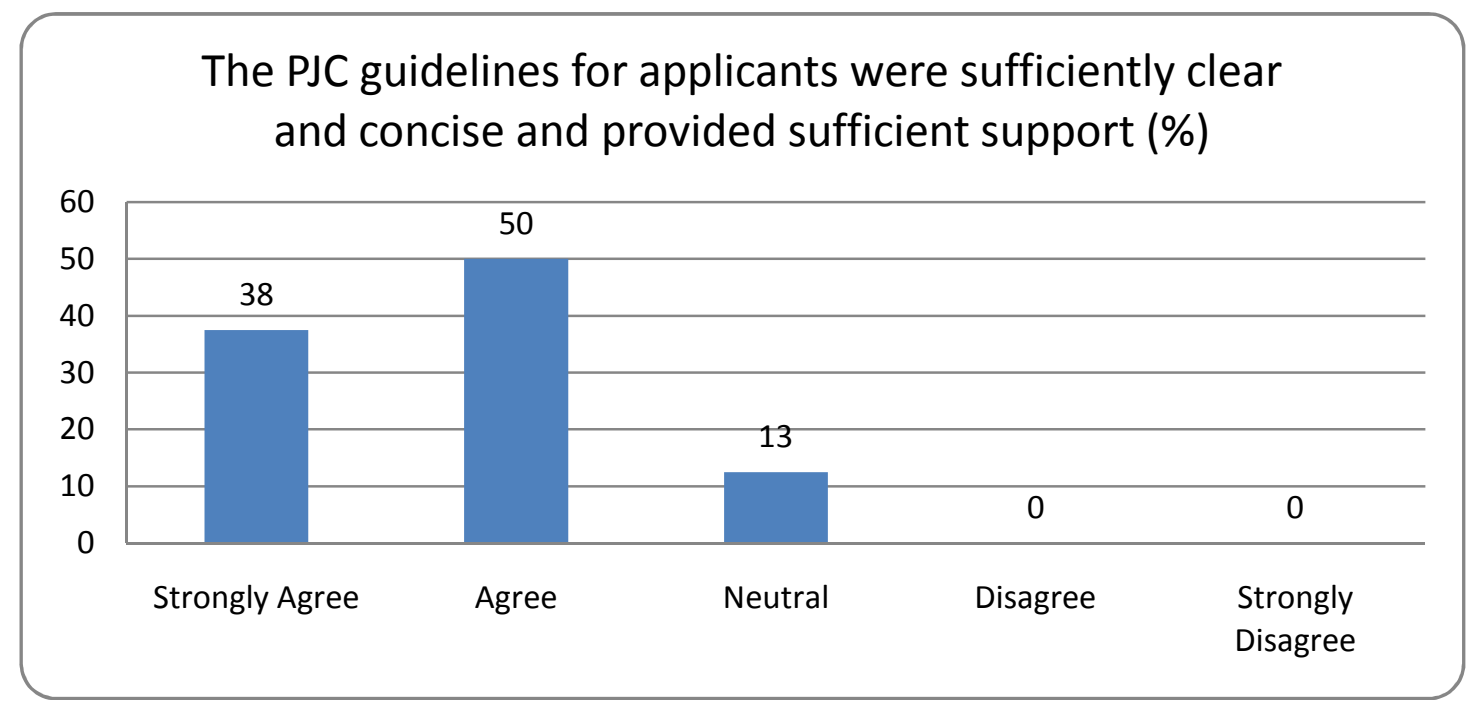

The view of the Scientific Council is almost identical. 


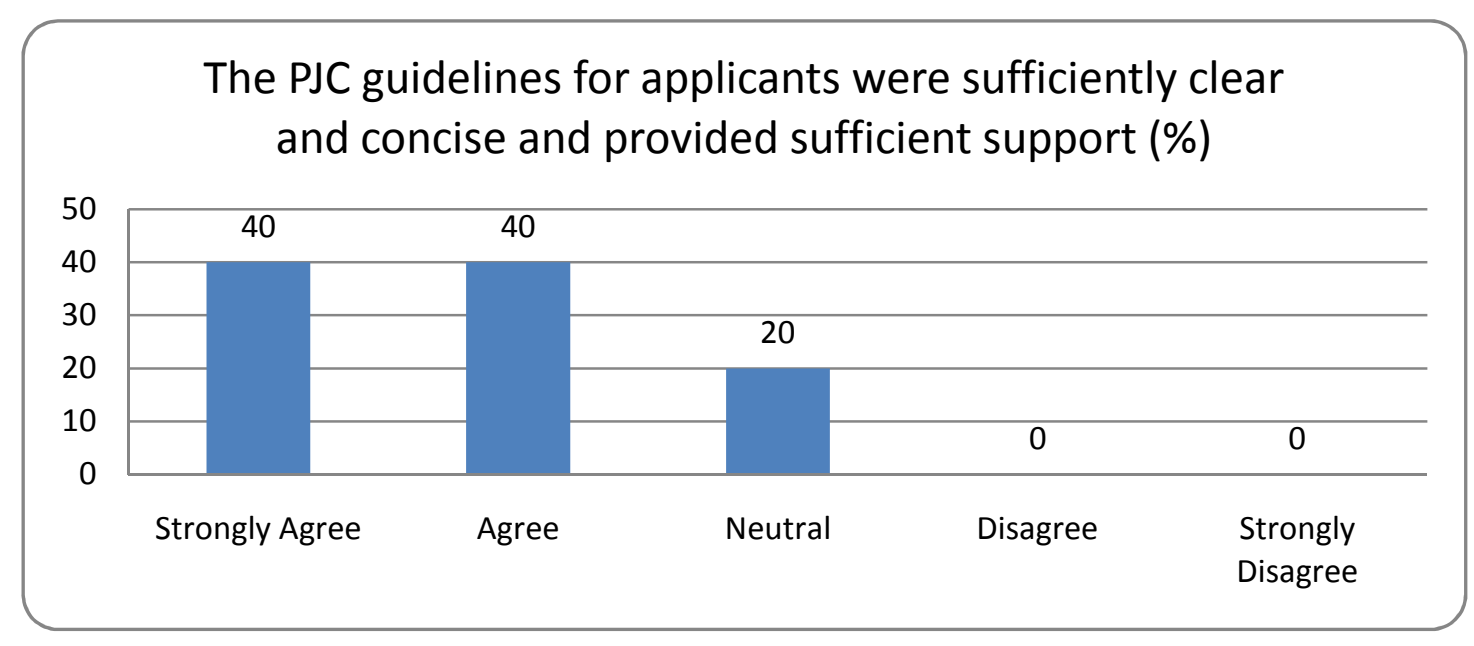

Conclusion 5: The documents of the Pilot Joint Call (terms of reference, guidelines for applicants) were detailed, sufficiently clear and concise and provided sufficient support to potential applicants. There is room for improvement, such as to include in the terms of reference the ways that the applicants could be informed on the results and especially the reviewers' comments of their proposal.

Most of the applicants as well as the members of the funding parties have a positive view concerning the documents of the Pilot Joint Call

\subsubsection{The NCPs performance in the preparation phase.}

\subsubsection{The NCPs activities in the preparation phase}

The National Contact Points have shown remarkable and varied activities during the preparation phase. 
Had you explained by any means (phone, e-mail etc) to potential applicants, the concept of the BS ERA.net and the scope and the modalities of the Pilot Joint Call

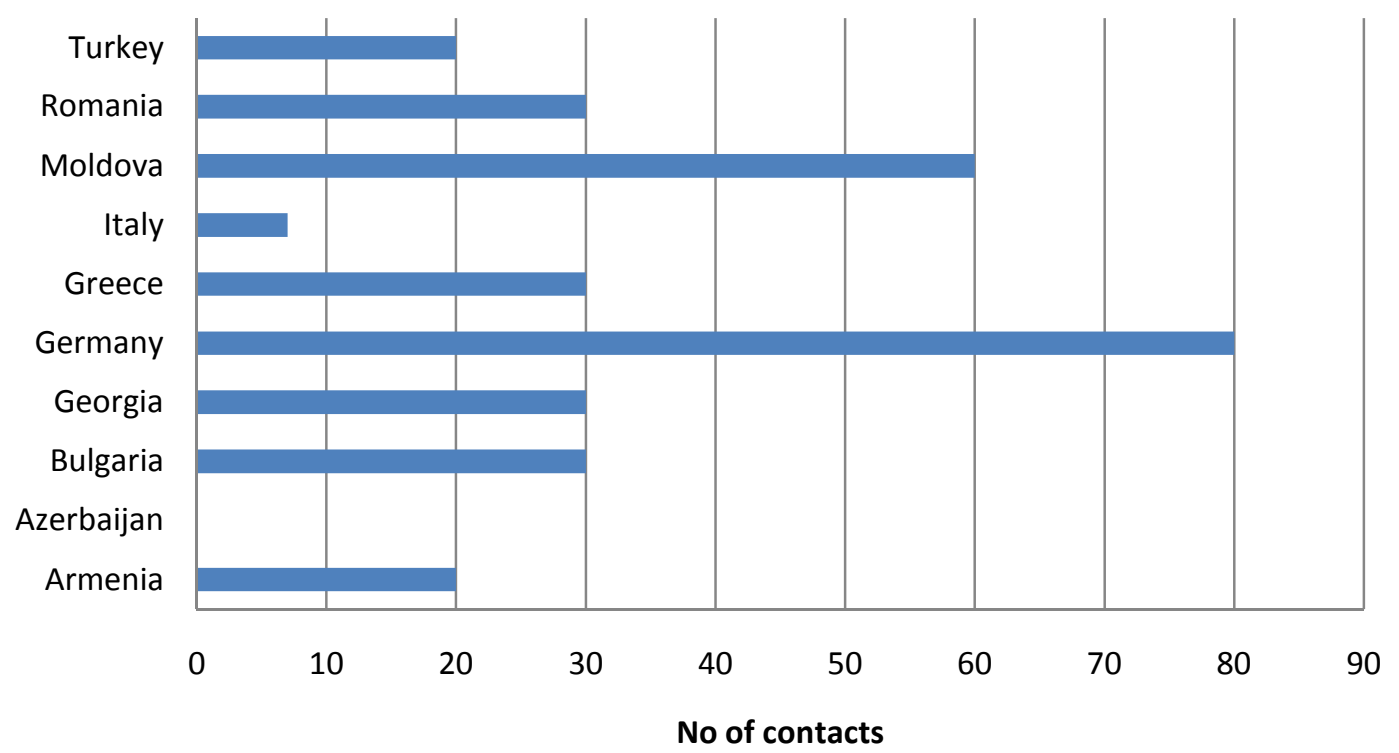

Had you advised on administrative procedures and legal issues by any means (phone, e-mail etc) (e.g. national eligibility of participants, role and responsibilities of participants in a consortium, costs, rights and obligations of participants)

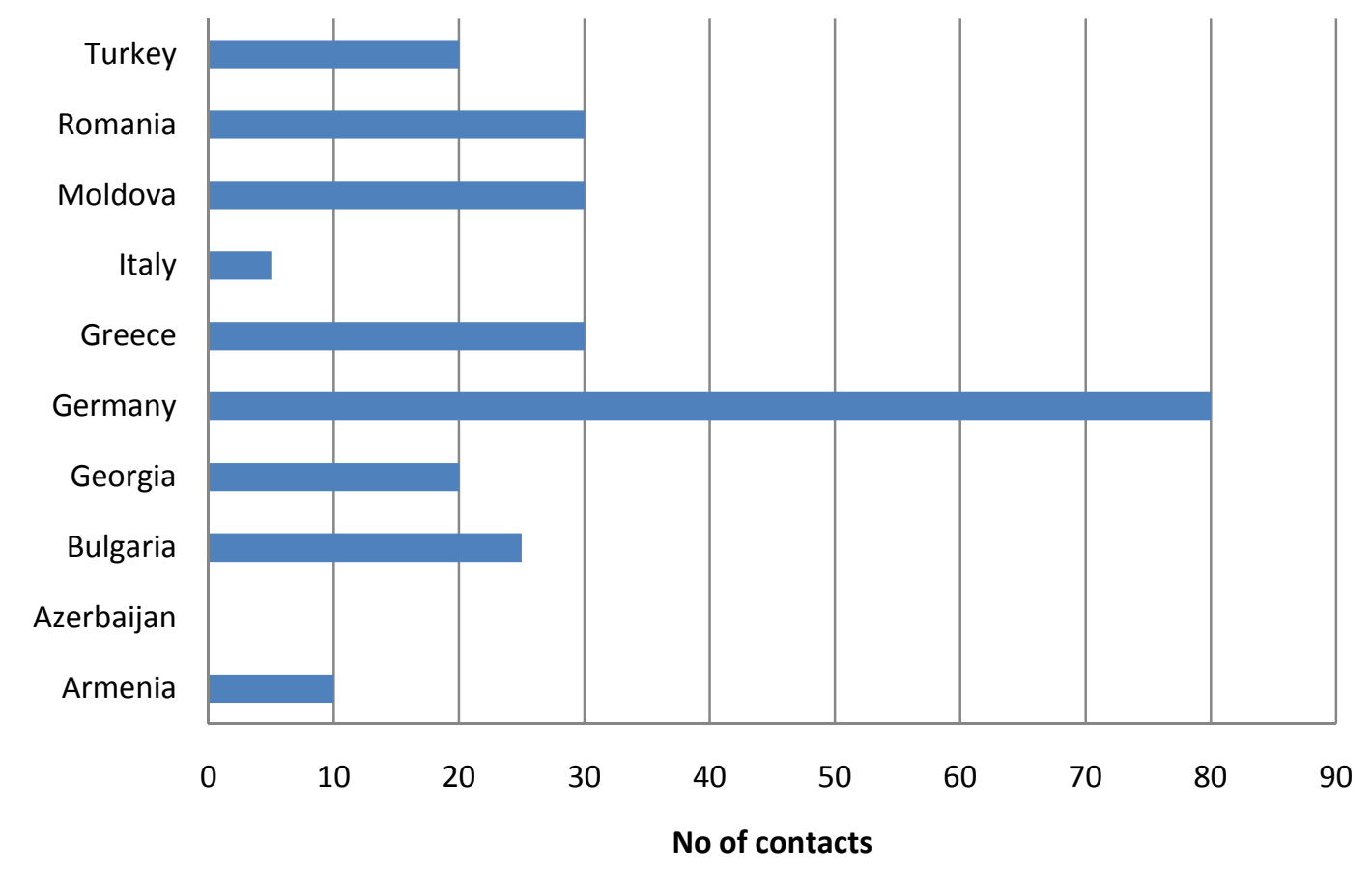


Had you assisted in partner searching by contacting the BS ERA.net NCP's network

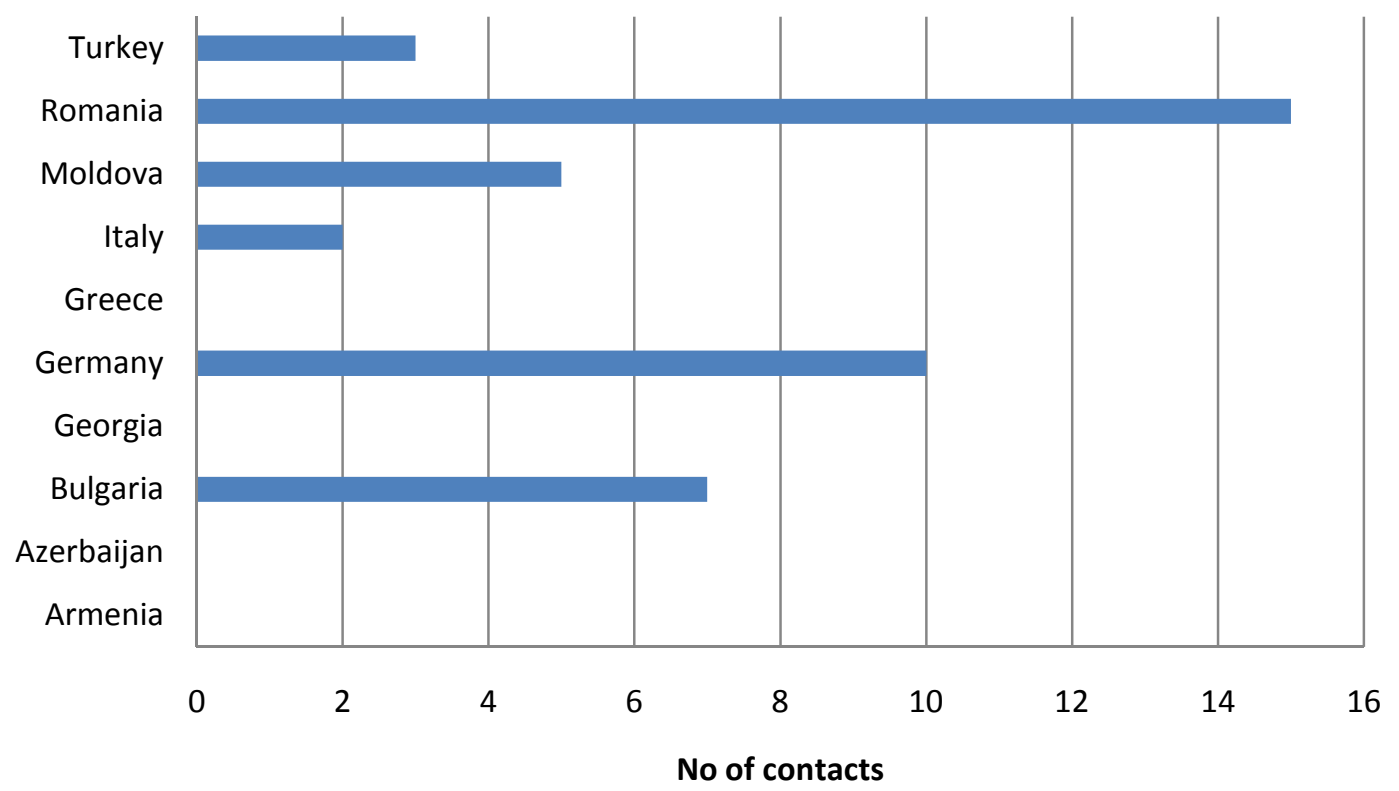

Had you organised training sessions or seminars on specific topics on the PJC proposals preparation issues (i.e. legal aspects, modalities for participation, research areas covered, submission system)

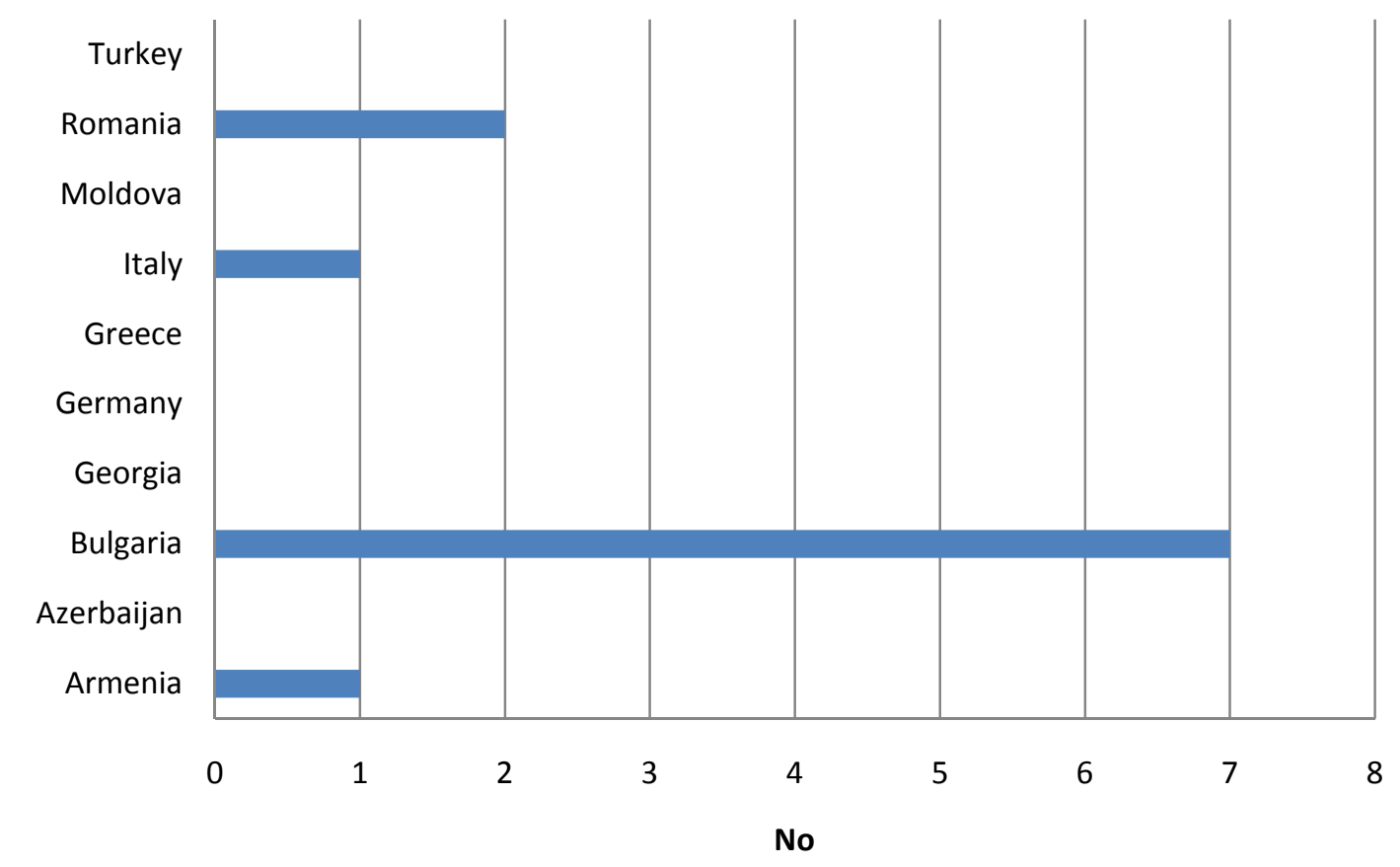


Conclusion 6: The National Contact Points has shown significant efficiency during the preparation phase of the Pilot Joint Call. More specifically, most of the NCPS explained to potential applicants the concept of the BS ERA.net and the scope and the modalities of the Pilot Joint Call and advised on administrative procedures and legal issues. Some of the NCPS moved forward and assisted in partner searching by contacting the BS ERA.net NCP's network and last but not least organized training sessions or seminars on specific topics on the PJC proposals preparation issues

\subsubsection{The view of the applicants and the funding parties regarding NCPs performance in the preparation phase}

A significant percentage of the unsuccessful applicants was not satisfied with the NCPs guidance and support during the preparation phase.

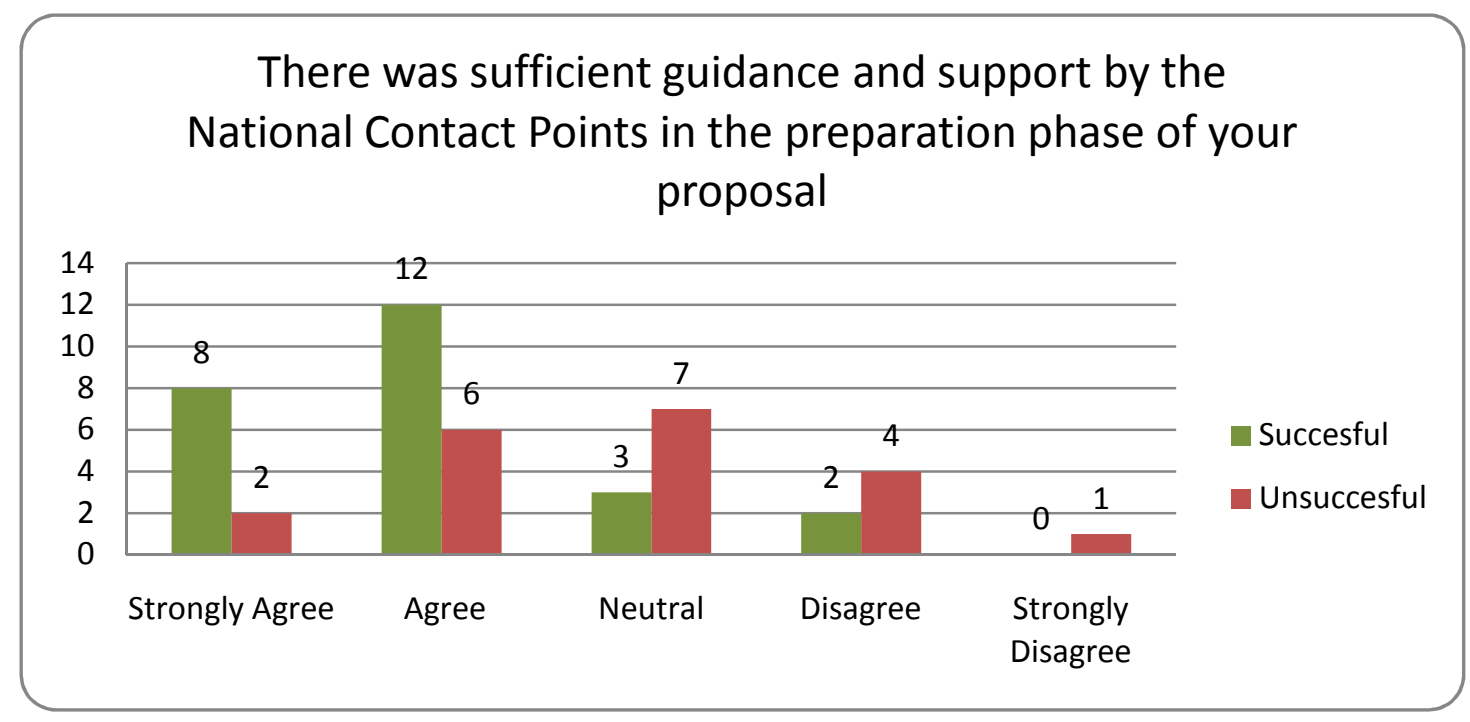

The NCPs performance in the preparation phase is appreciated by the funding parties. 


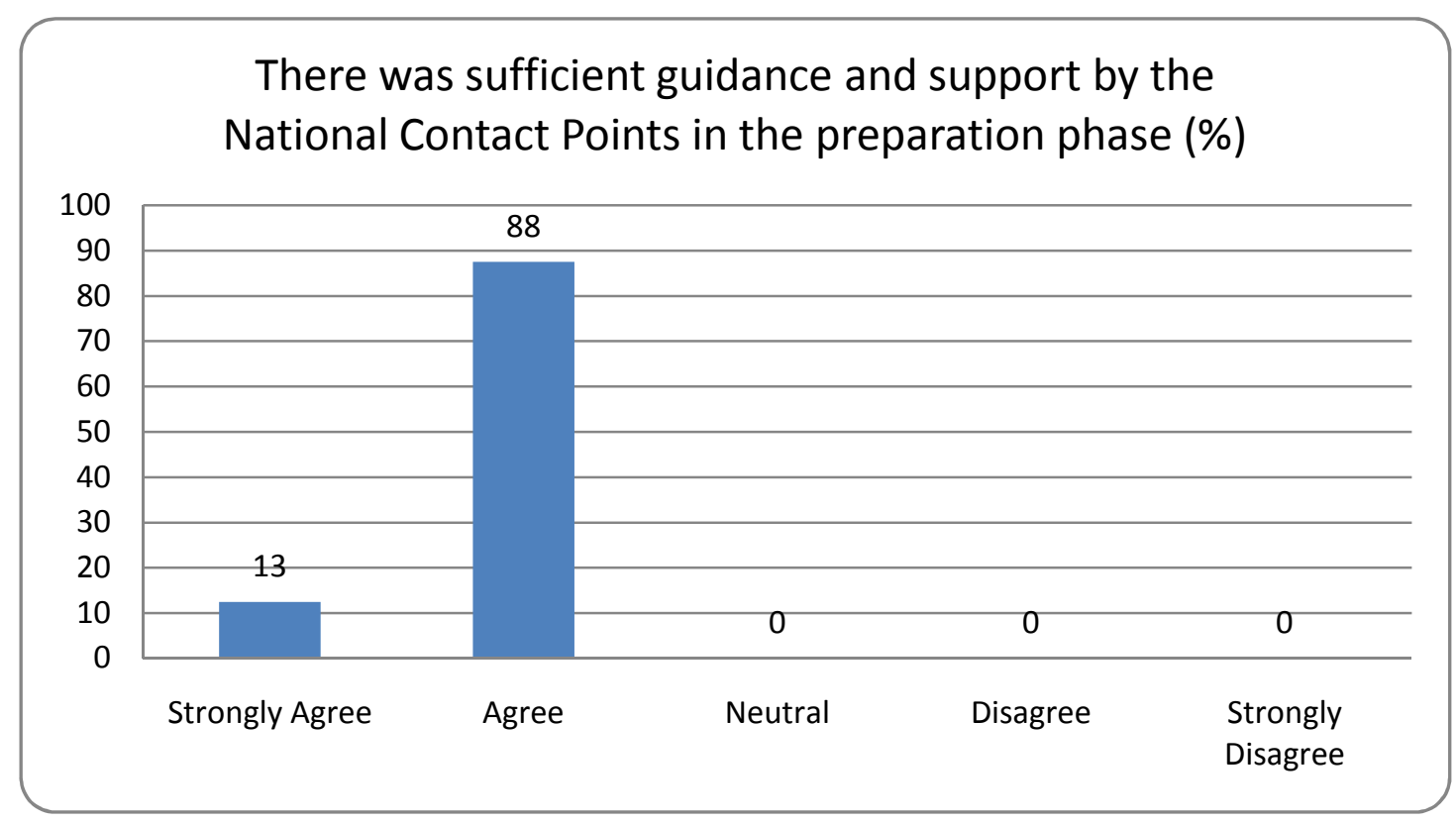

Conclusion 7: The National Contact Points performance during the preparation phase was not appreciated by a significant percentage of unsuccessful applicants. It is possible that they were expecting better guidance and support during the preparation phase and this is something that should be taken over as a remark. On the other hand the successful applicants and the funding parties are mostly satisfied. It should be noticed that in many cases individual officers from the funding parties and the national contact points are one and the same.

\subsubsection{The Joint Call Secretariat's performance in the preparation phase.}

The applicants as well as the funding parties are mostly satisfied with the performance of the Joint Call Secretariat

There was sufficient guidance and support by the Joint Call Secretariat in the preparation phase of your proposal

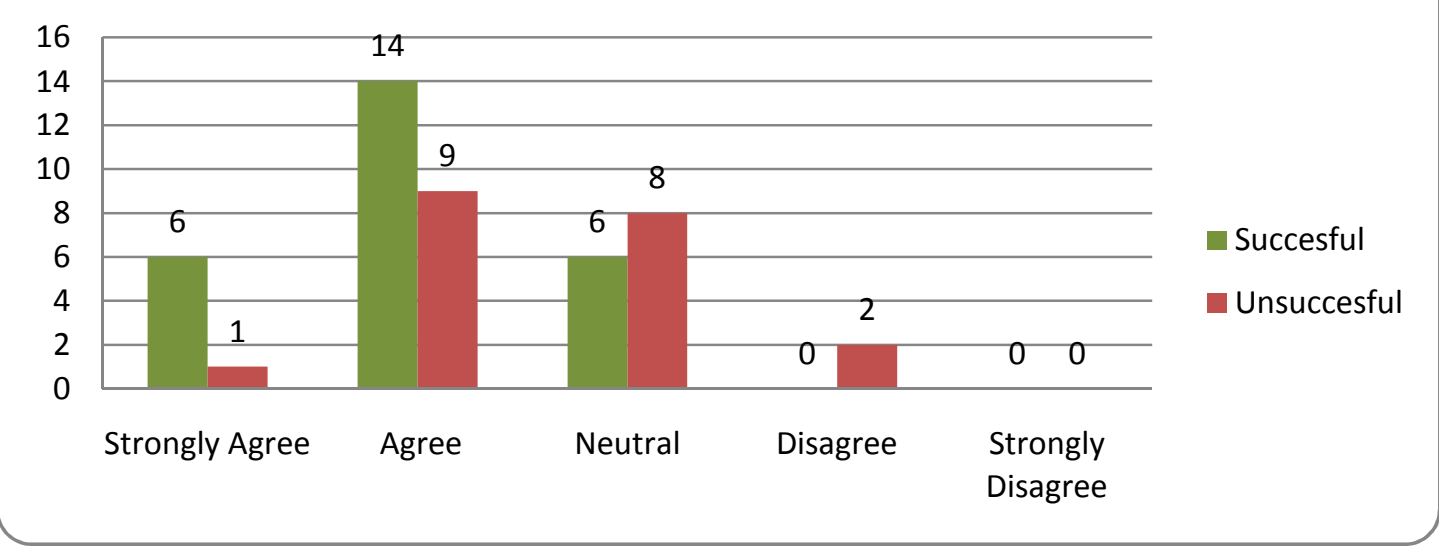




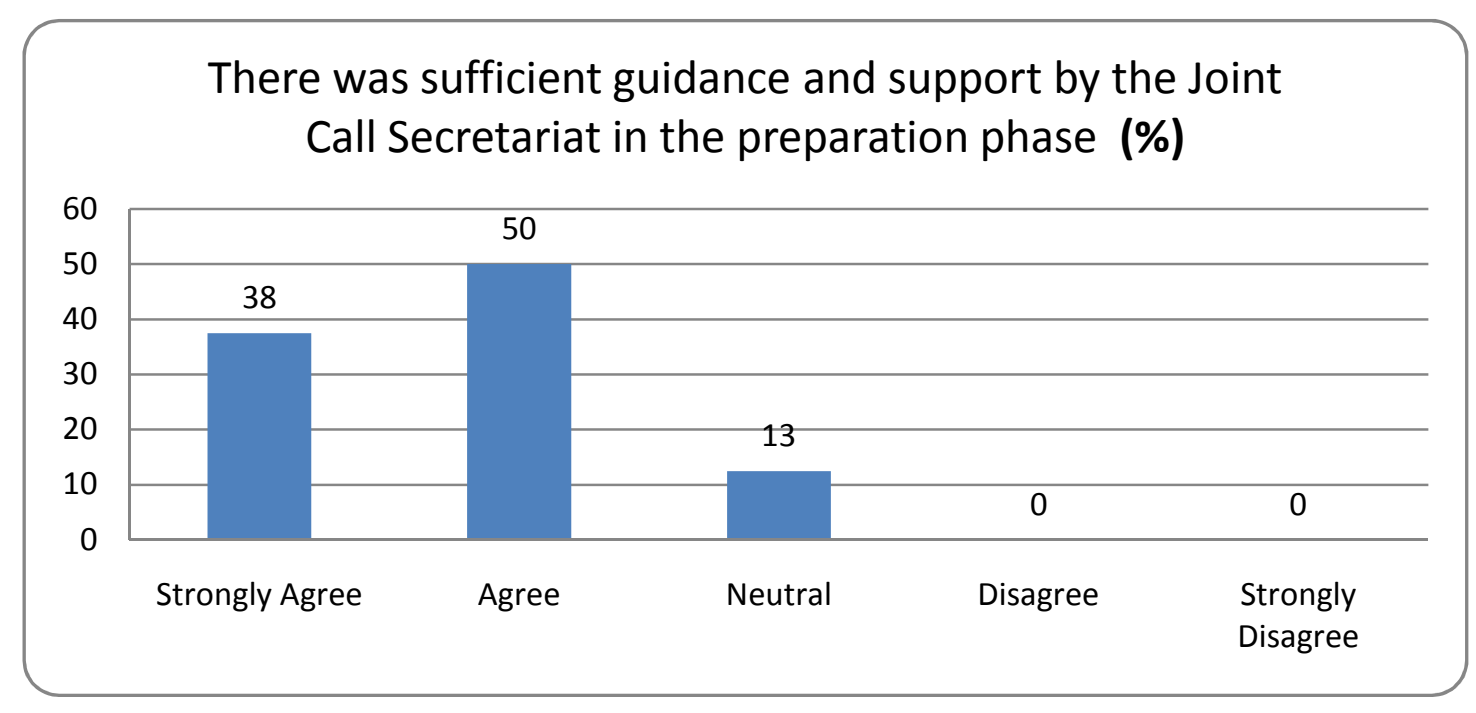

Conclusion 8: The Joint Call Secretariat's performance in the preparation phase is appreciated by the majority of the applicants and the funding parties.

\subsection{Submission phase}

\subsubsection{Setting up the partnerships}

A notable number of applicants pointed out that they needed more time to set up their consortium and submit their proposal. 


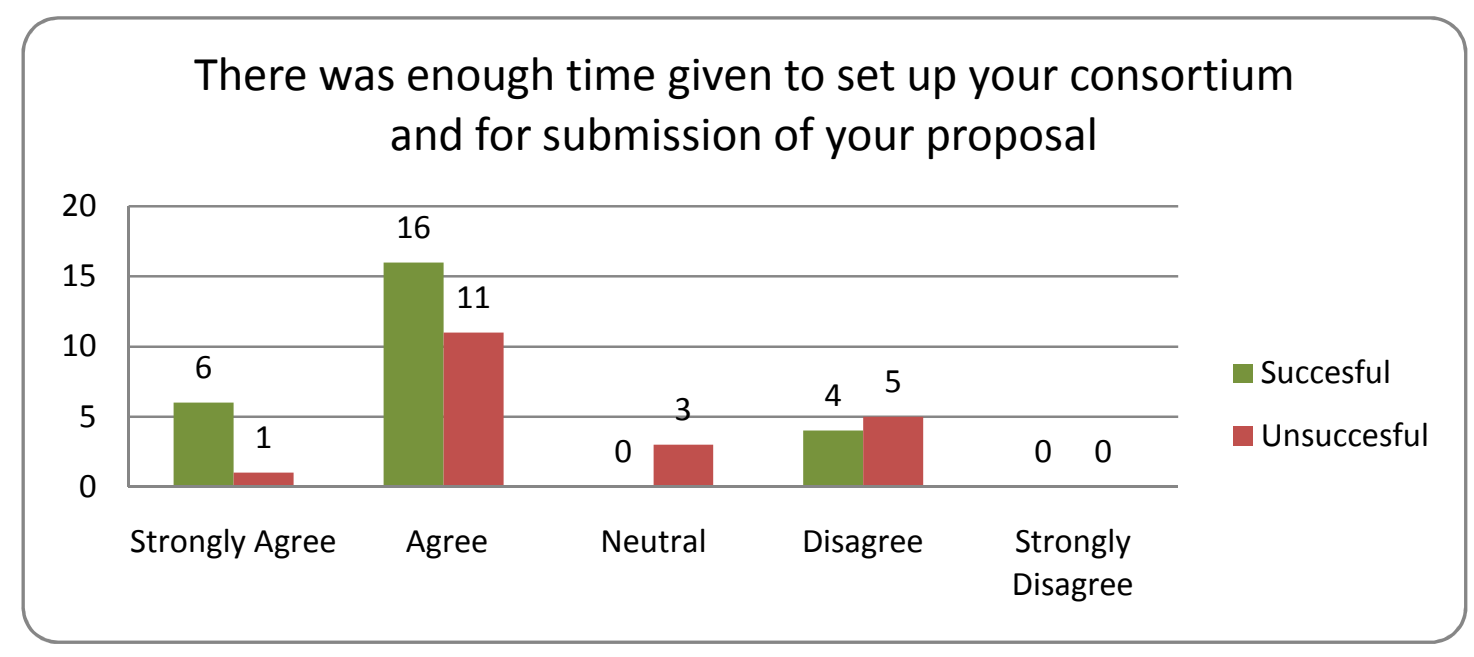

The funding parties are fully satisfied with the given time to set up partnerships and submit proposals.

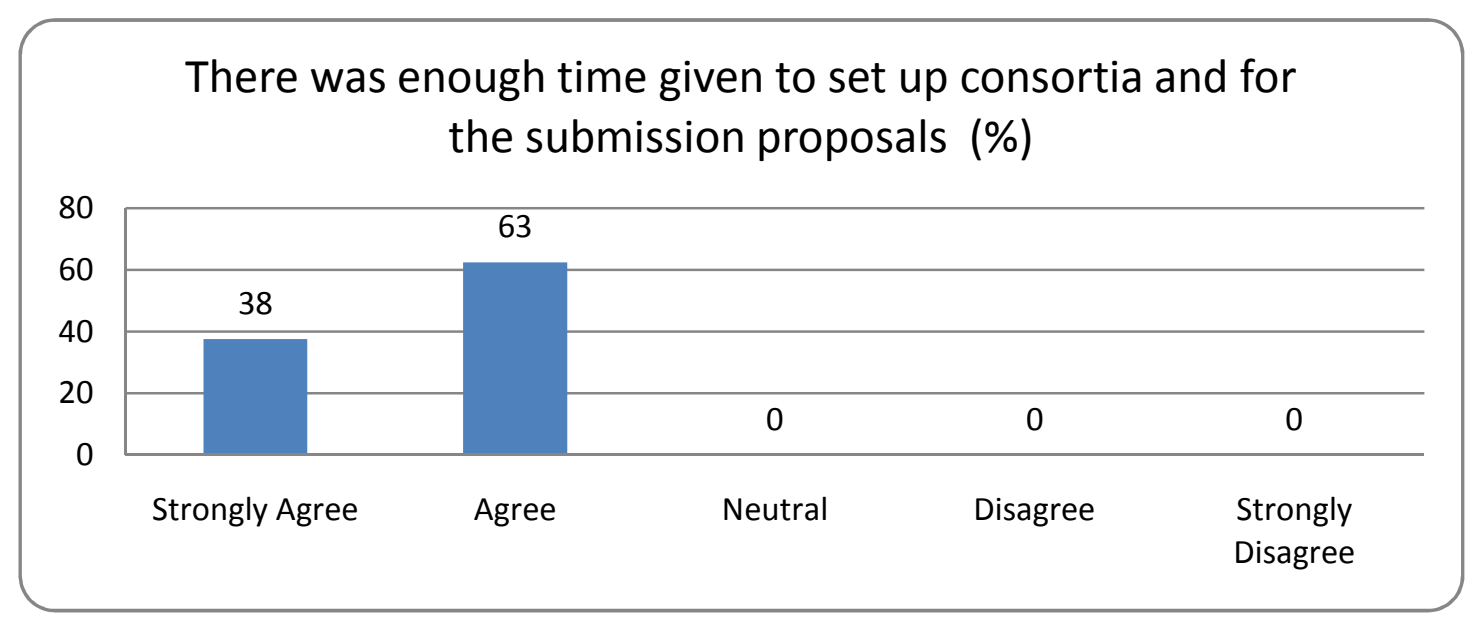

Conclusion 9: A notable number of applicants pointed out that they needed more time to set up their consortium and submit their proposal. This is a suggestion that should be taken into account. Another issue to pay attention is that more time is needed in cases when after the launching of the call there are public holidays that delay the contact and partnership processes. 


\subsubsection{The submission process}

\subsubsection{The proposal form}

The proposal form was well accepted by most of the applicants

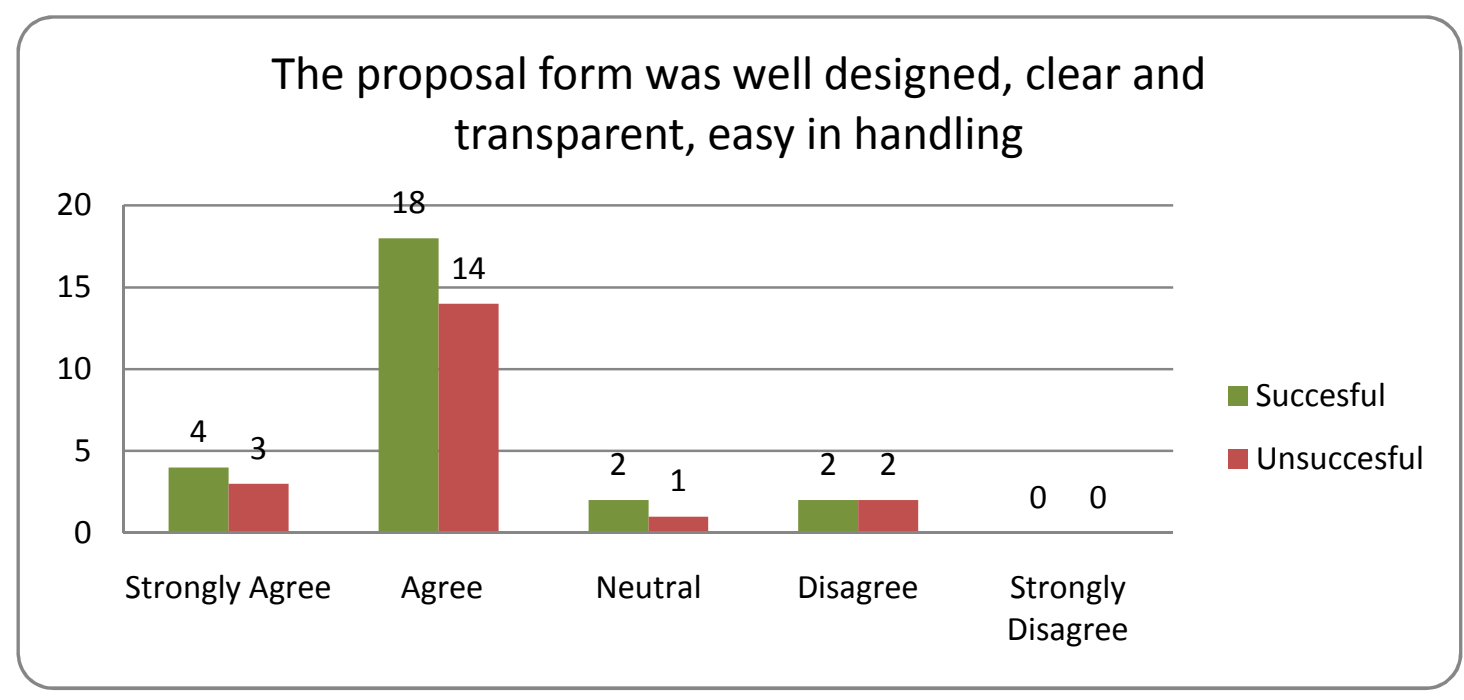

It is worth noting the neutral approach of a significant percentage of the group of funding parties regarding the functionality of the proposal form

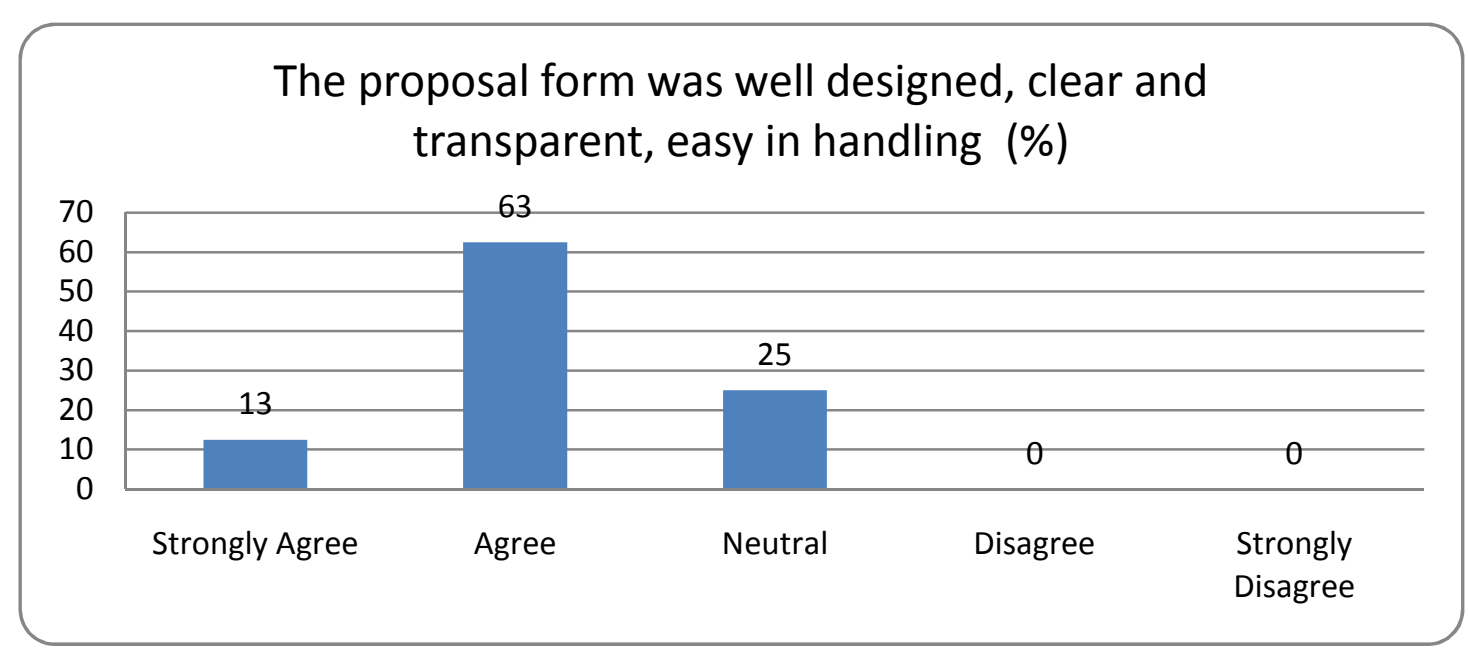

The Scientific Council appreciated the proposal form 


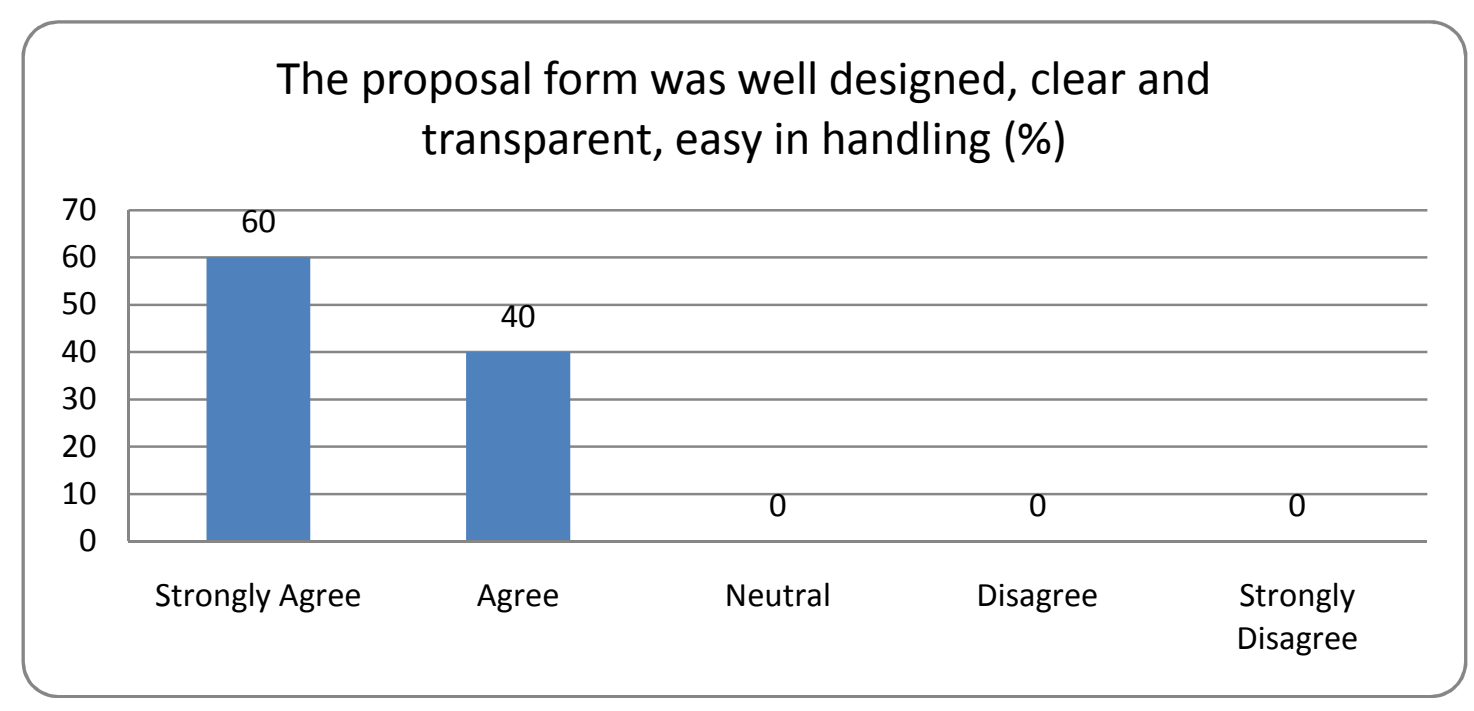

Conclusion 9: The proposal form was simple, clear and easy in handling. Most of the applicants had a positive attitude regarding the proposal form. It was well accepted by the members of the scientific council. This is quite important since the Scientific Council members are very experienced scientists deeply involved in such processes.

It is worth noting the neutral approach of some members of the group of funding parties regarding the functionality of the proposal form

\subsubsection{The web-based Call Management System PT-Outline}

The Call Management System PT-Outline was developed by the German Agency IKT (Informations und Kommunikationstechnologien). The system consists of the submission tool, the management tool and the evaluation tool. It was used for the first time for the management of the calls of the German Thematic Programmes and later its usage was expanded to almost all national calls. In these days the succesful web-based Call Management System is used for the joint calls of several international cooperation ERA-NETS as well as for joint calls in the framework of bilateral programmes. The system is administrated by the IKT management agency, which is located in Berlin.

Most of the applicants, during the submission of their proposal, found the web based tool efficient and functional 


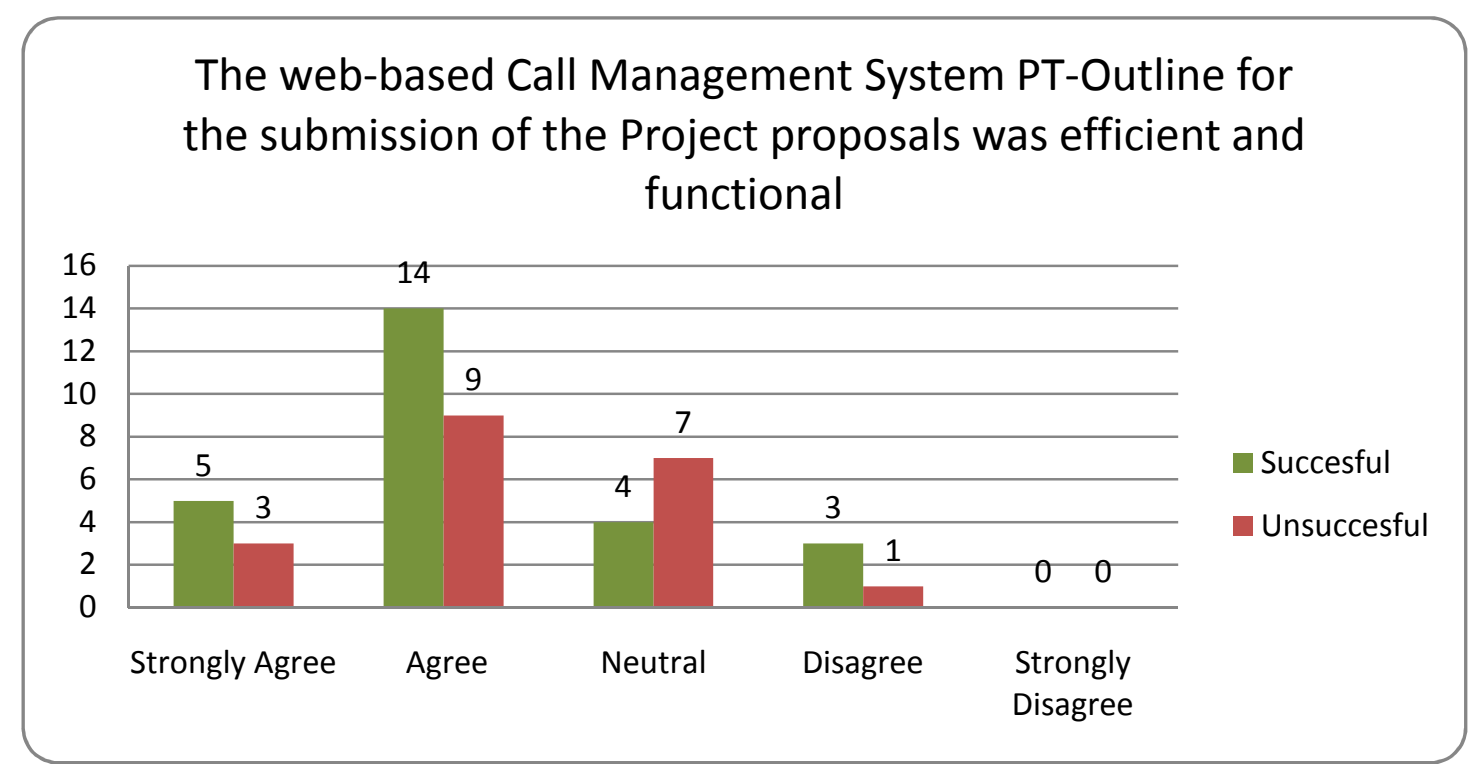

All the funding parties with the exception of the Italian one find the PT-outline system both efficient and functional for the purposes of the PJC

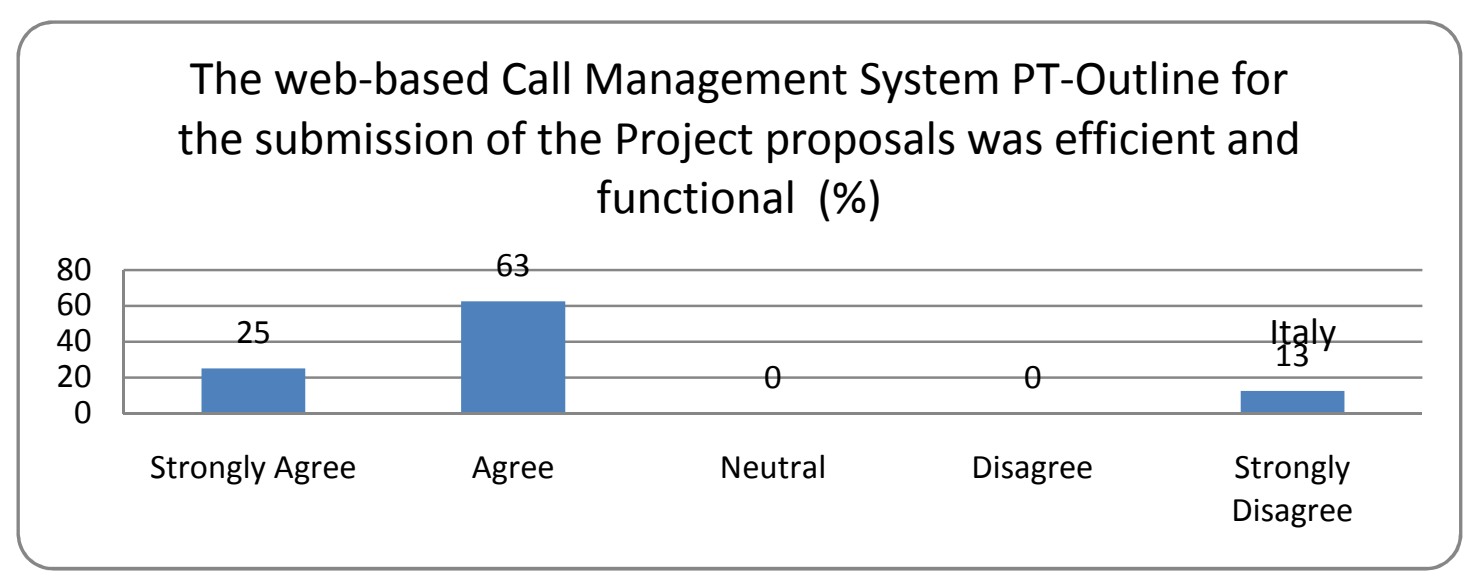

The opinion of the Scientific Council members is positive

The web-based Call Management System PT-Outline for the submission of the Project proposals was efficient and functional

(\%)

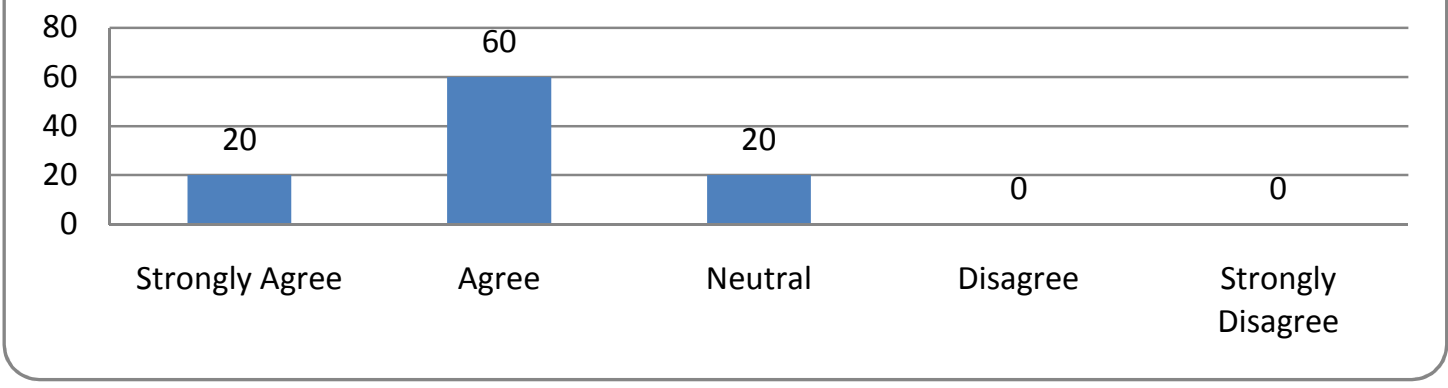


Conclusion 10: Without doubt the use of the PT-Outline system was a great advantage for the Pilot Joint Call. This web based call management system is well known for its efficiency and functionality from the past, since it was used for several transnational cooperation calls. The system functions were tested by the external expert in operation in the framework of the German Turkish bilateral cooperation.

Most of the applicants during the submission of their proposal, found the web based tool efficient and functional. Positive also is the opinion of the Scientific Council members. All the funding parties with the exception of the Italian one, found that the PT-outline system was efficient and functional for the purposes of the PJC

\subsubsection{The application procedure}

The greater majority of successful as well as unsuccessful applicants reported positive experiences during the application procedure, finding it clear and transparent

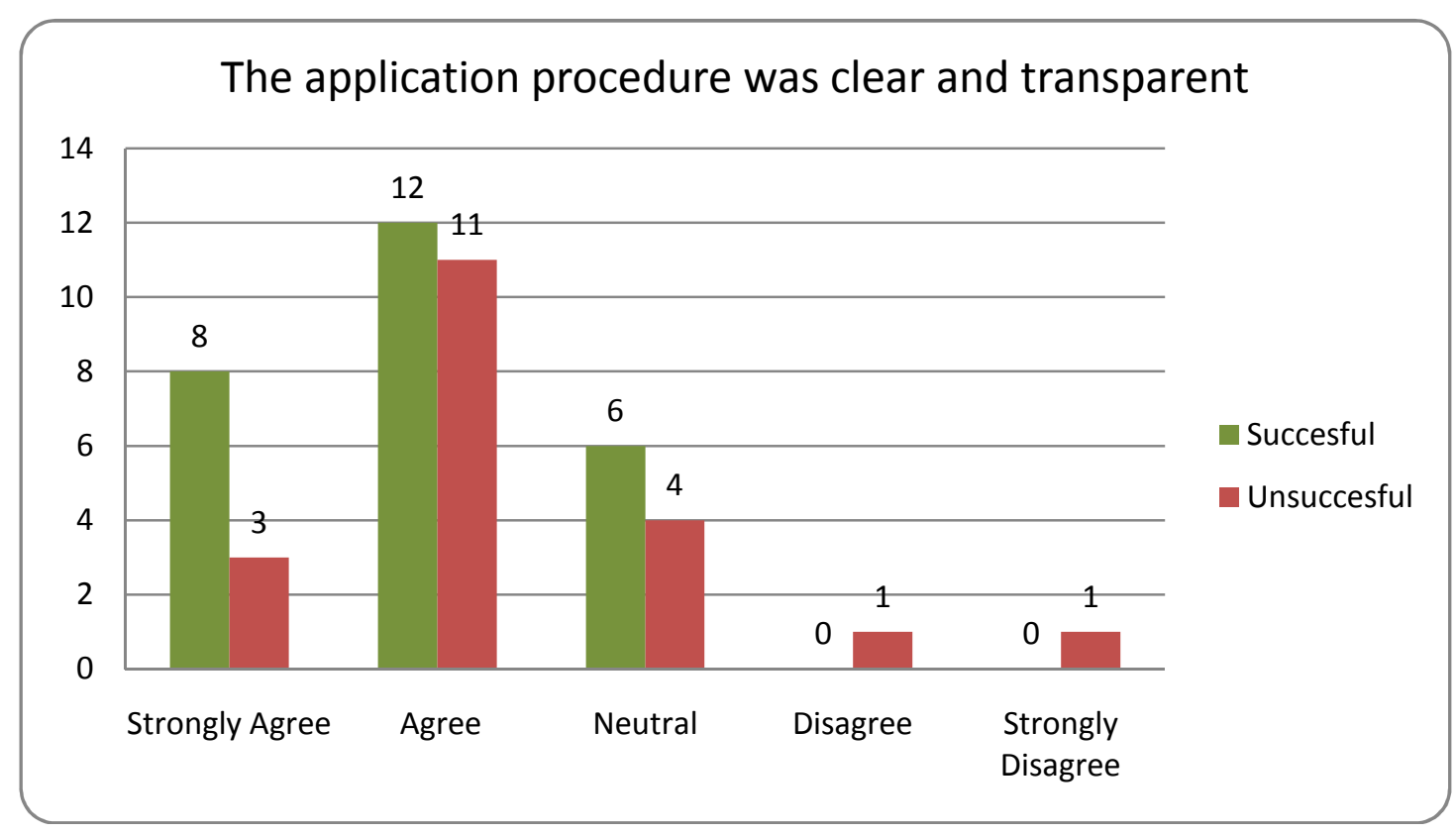

The opinion of the members of the group of funding parties is positive 


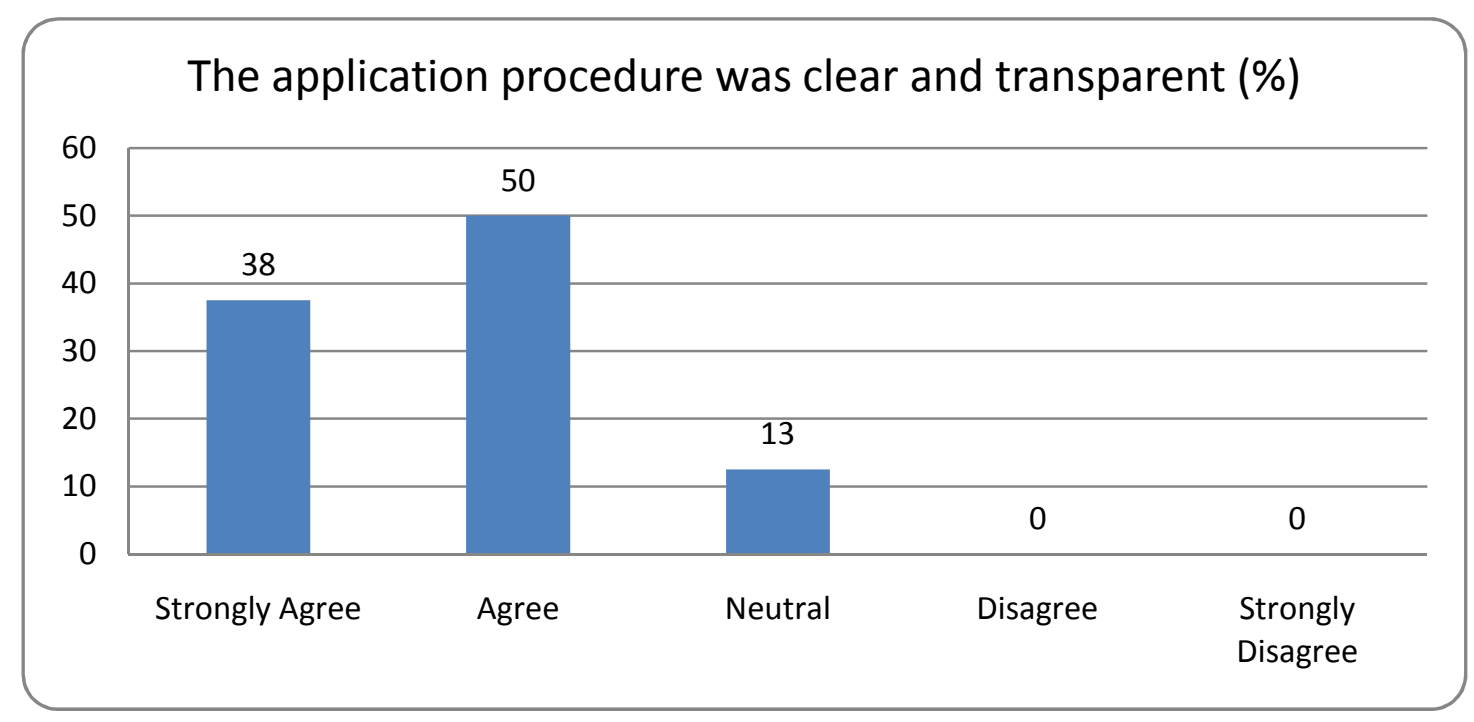

The same view was expressed by the Scientific Council members

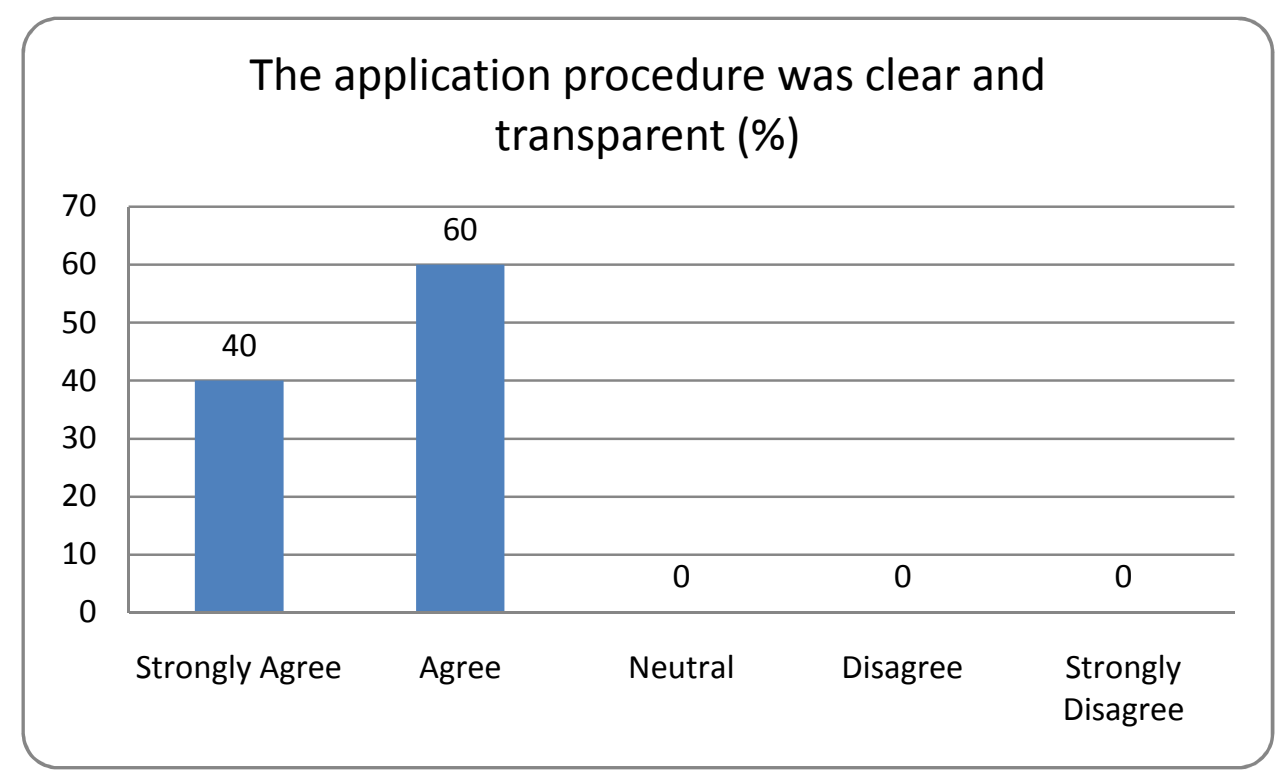


Few negative answers were received by the applicants regarding the non bureaucratic and straight forward submission of the proposals

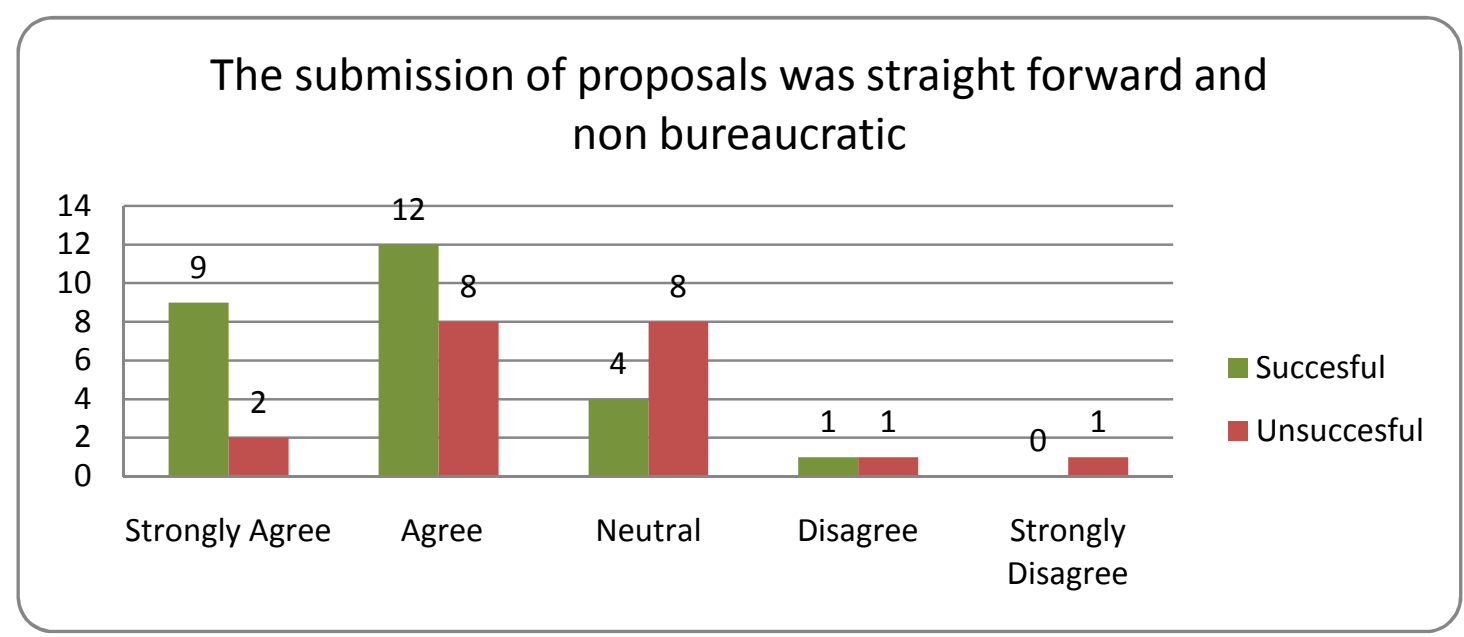

The Italian funding party pointed out the bureaucratic and complicated procedure during the submission of the proposals. All the other partners considered the process straight forward and non-bureaucratic.

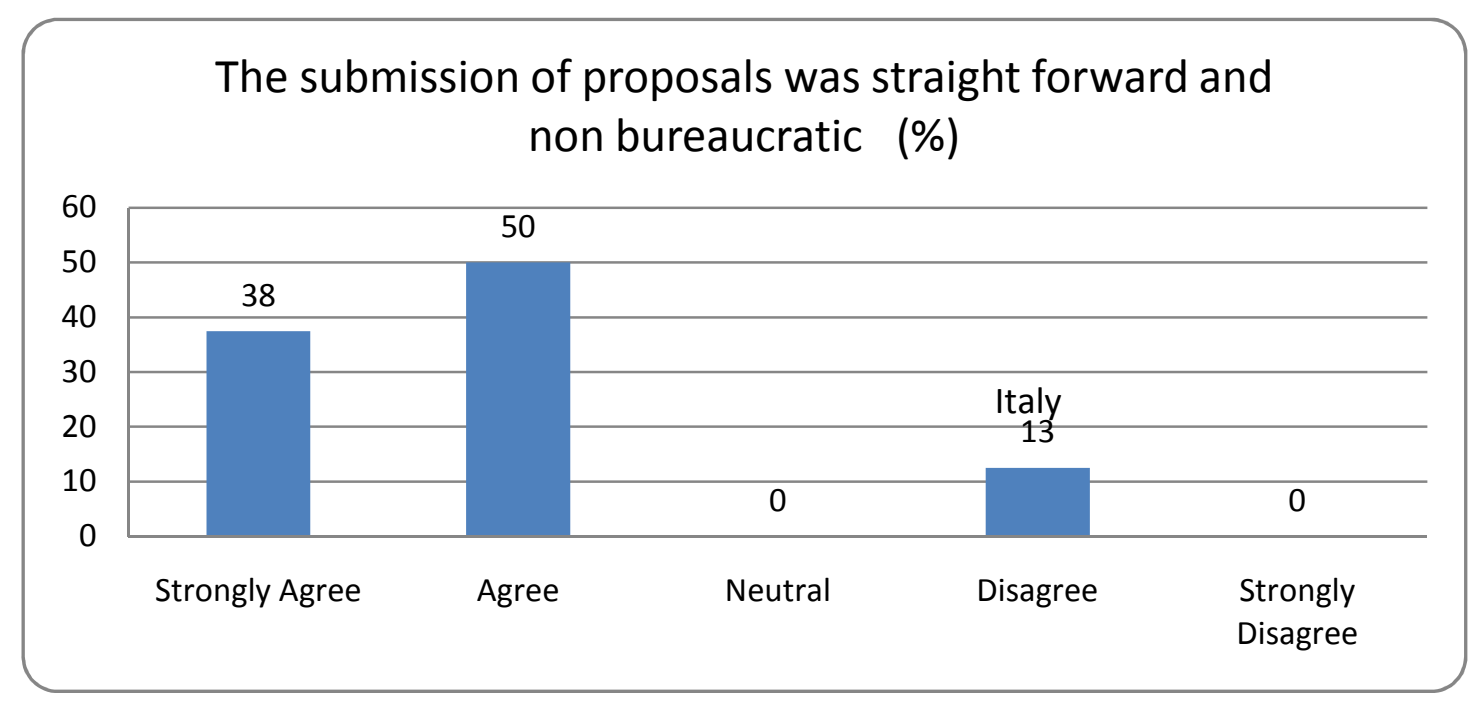

Conclusion 11: The greater majority of successful as well as unsuccessful applicants reported positive experiences during the application procedure, finding it clear and transparent. Moreover they found the submission of their proposals non bureaucratic and straight forward. The group of funding parties and the scientific council are in line with the view of the applicants.

However, it should be noted that the Italian funding party disagreed with the opinion that the submission of proposals was straight forward and non-bureaucratic. 


\subsubsection{The NCPs performance in the submission phase.}

\subsubsection{The NCPs activities in the submission phase}

The National Contact Points have been contacted by the scientific communities in order to provide support in the submission phase

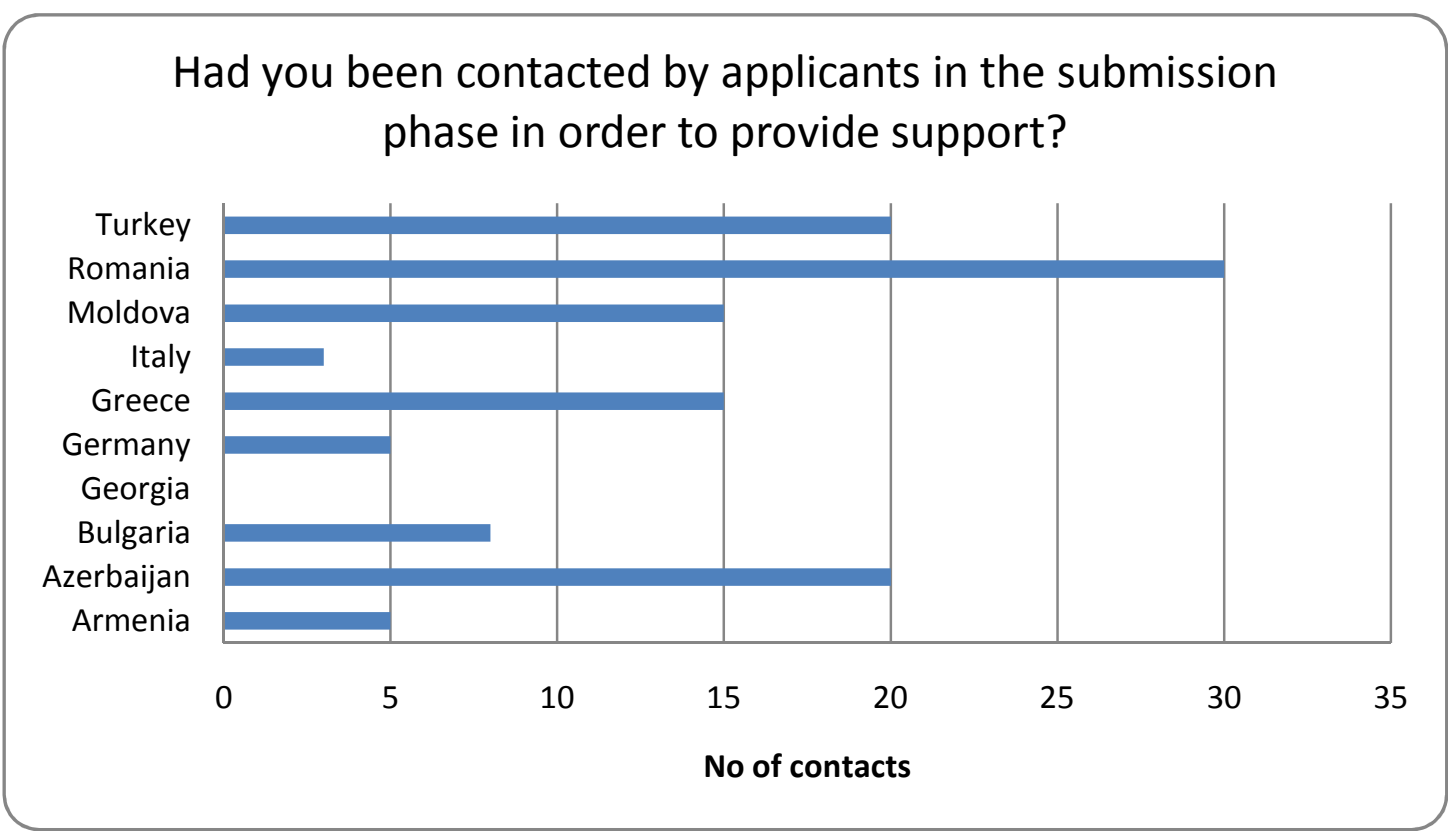

The content of the contacts with the applicants in the submission phase was: The proposal form which was not easy to handle and help was needed

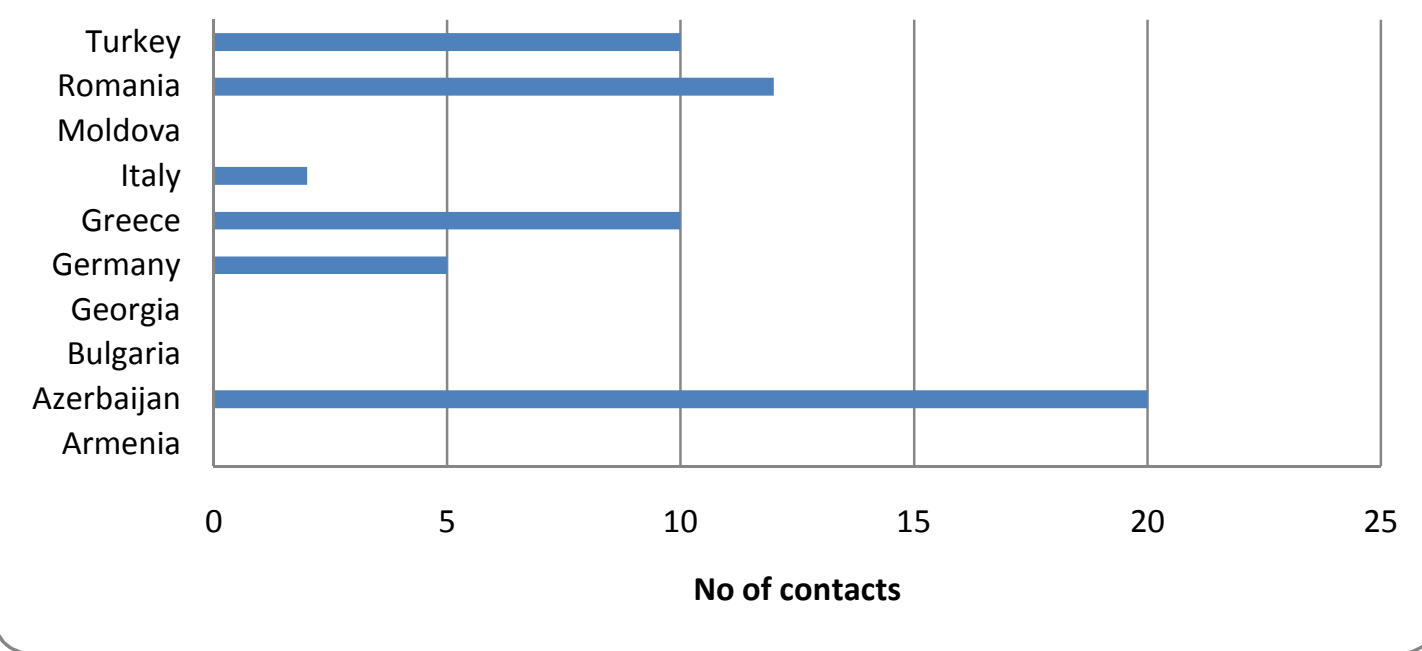




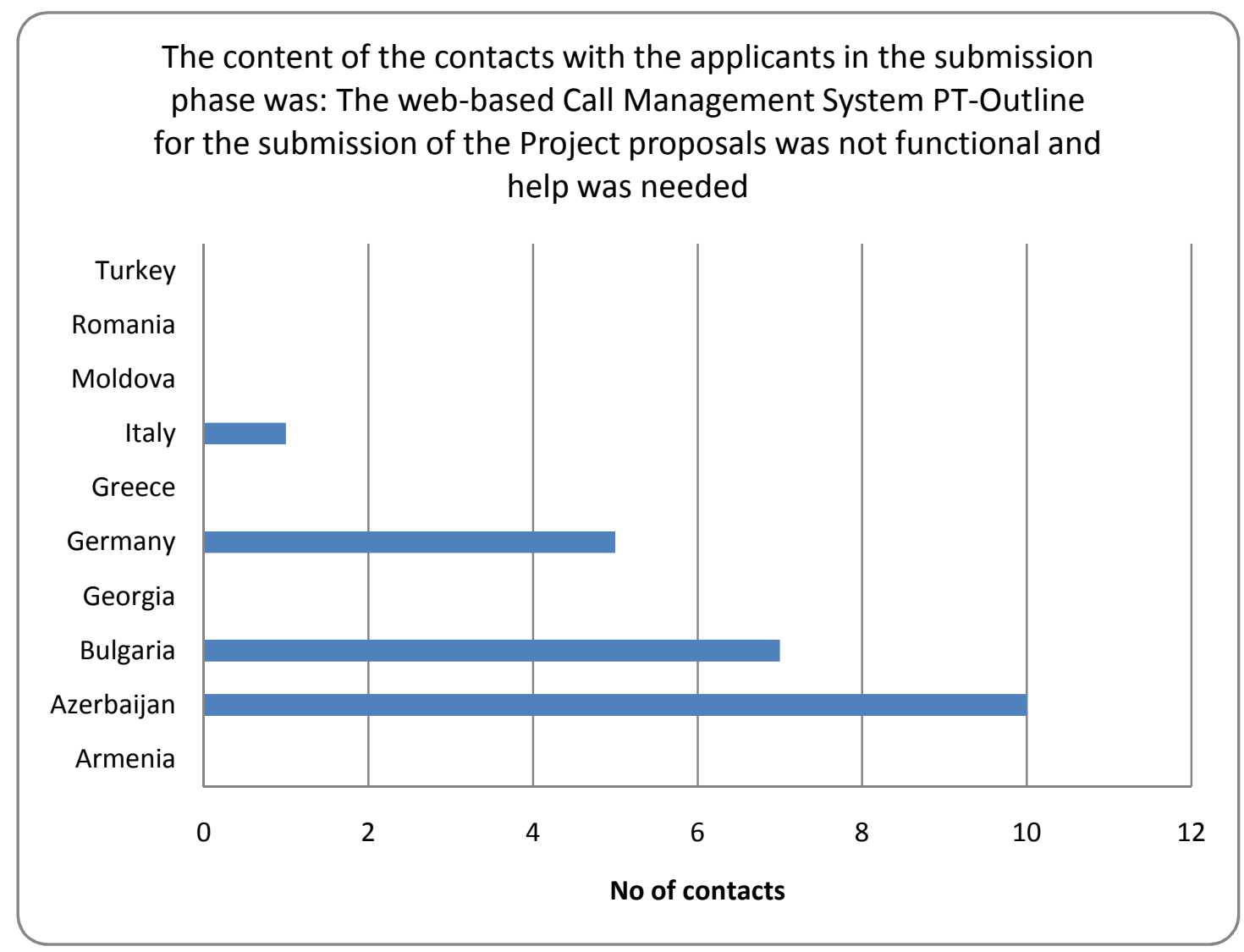

Conclusion 12: The National Contact Points reported that they had been contacted by the applicants during the submission phase mainly because the proposal form was not easy to handle and help was needed or in less cases because the web-based Call Management System PT-Outline for the submission of the Project proposals was not functional and help was needed. A possible explanation for this could be that some potential applicants were not familiar with such on-line submission systems, taking into account that the very strong majority of applicants reported their positive experience of the PT outline

\subsubsection{The view of the applicants and the funding parties regarding NCPs performance in the submission phase}

Many of the unsuccessful applicants are not satisfied with the NCPs guidance and support during the submission phase. 


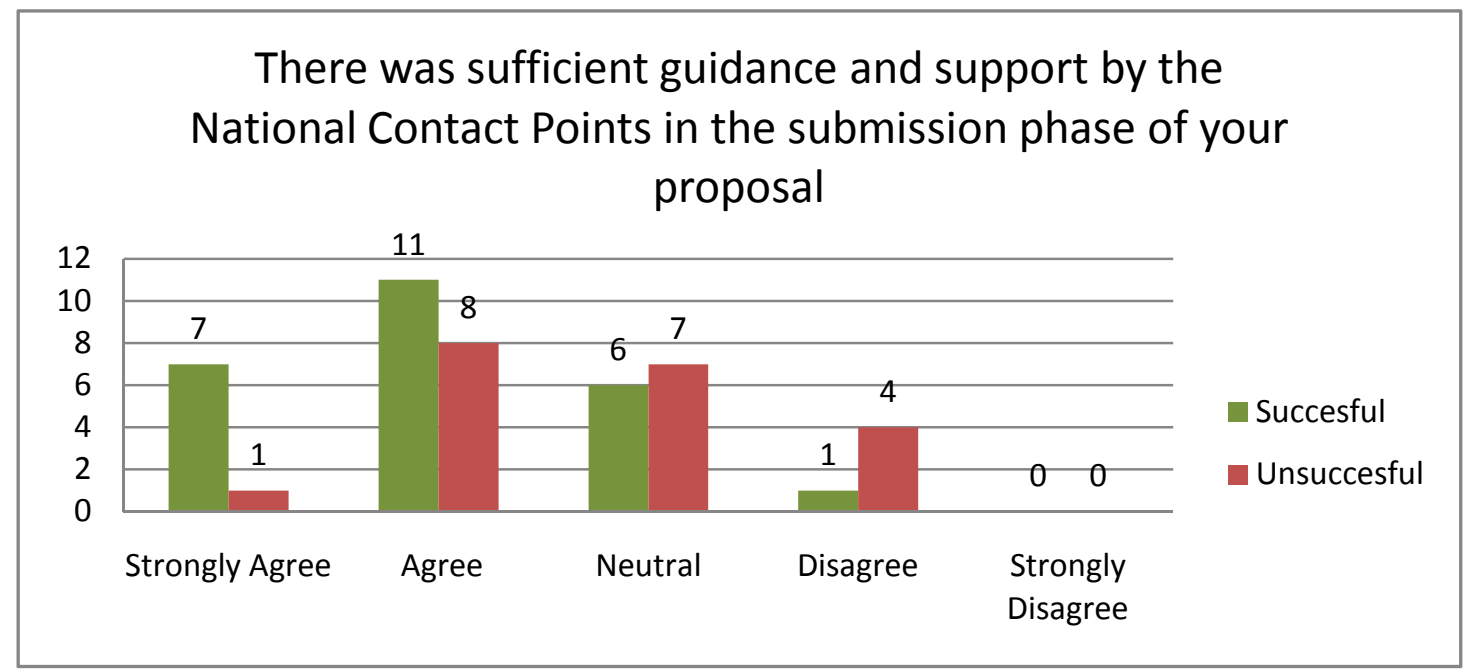

The funding parties are satisfied with the NCPs performance in the submission phase.

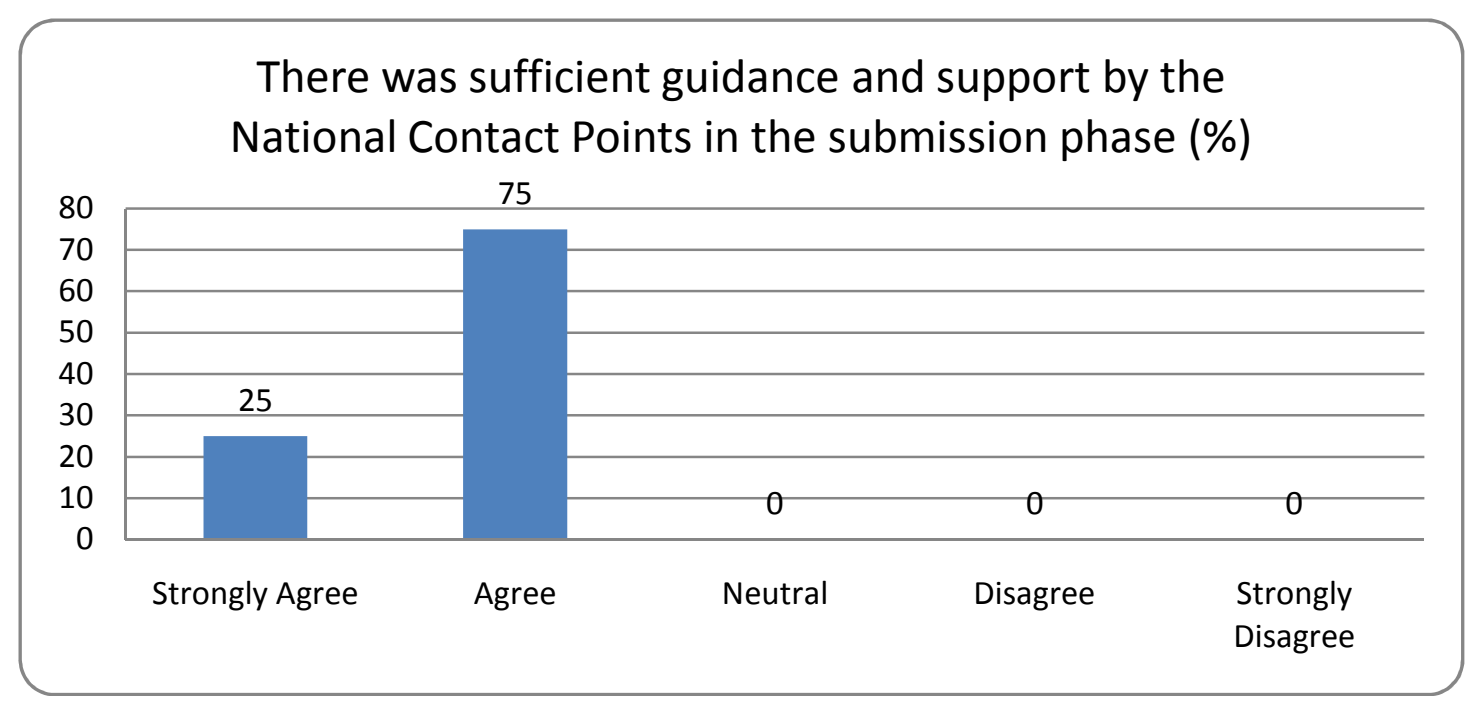

Conclusion 13: The National Contact Points performance during the submission phase was not appreciated by many unsuccessful applicants who were not satisfied with the NCPs guidance and support. Probably they were expecting better guidance and support during the preparation phase and this is something that it should be taken over as a remark. On the other hand the successful applicants and the funding parties are mostly satisfied. It should be noticed that in many cases the individual officers from the funding parties and the national contact points are one and the same. 


\subsubsection{The Joint Call Secretariat's performance in the submission phase.}

Both the applicants and the funding parties are mostly satisfied with the performance of the Joint Call Secretariat.

There was sufficient guidance and support by the Joint Call Secretariat in the submission phase of your proposal
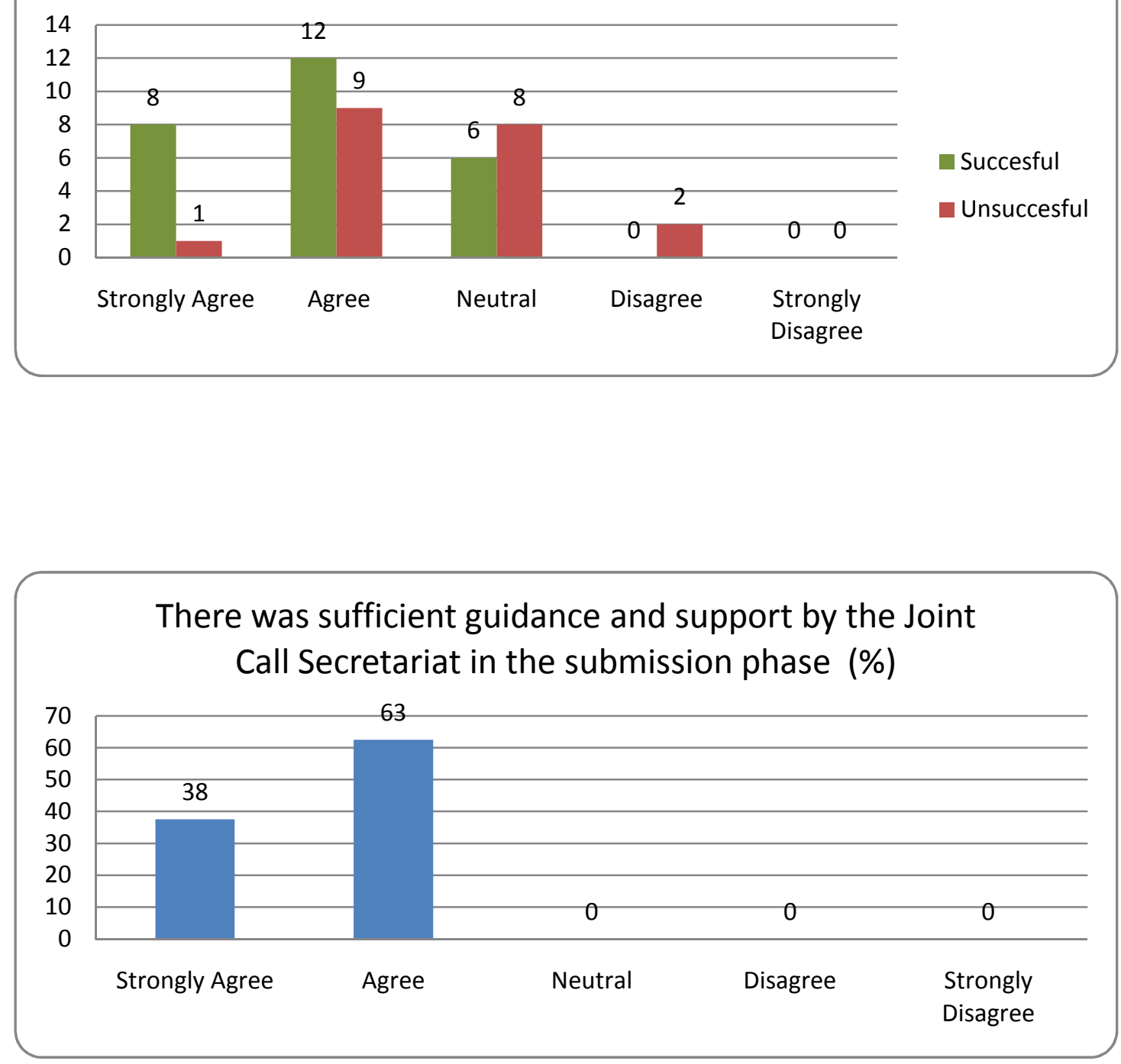

Conclusion 14: The Joint Call Secretariat's performance in the submission phase is appreciated by the majority of the applicants and the funding parties 


\subsection{Evaluation phase}

3.3.1. The proposals that have been submitted in the frame of the Pilot Joint Call.

The Romanian scientific community has been very active submitting the higher number of proposals by far.

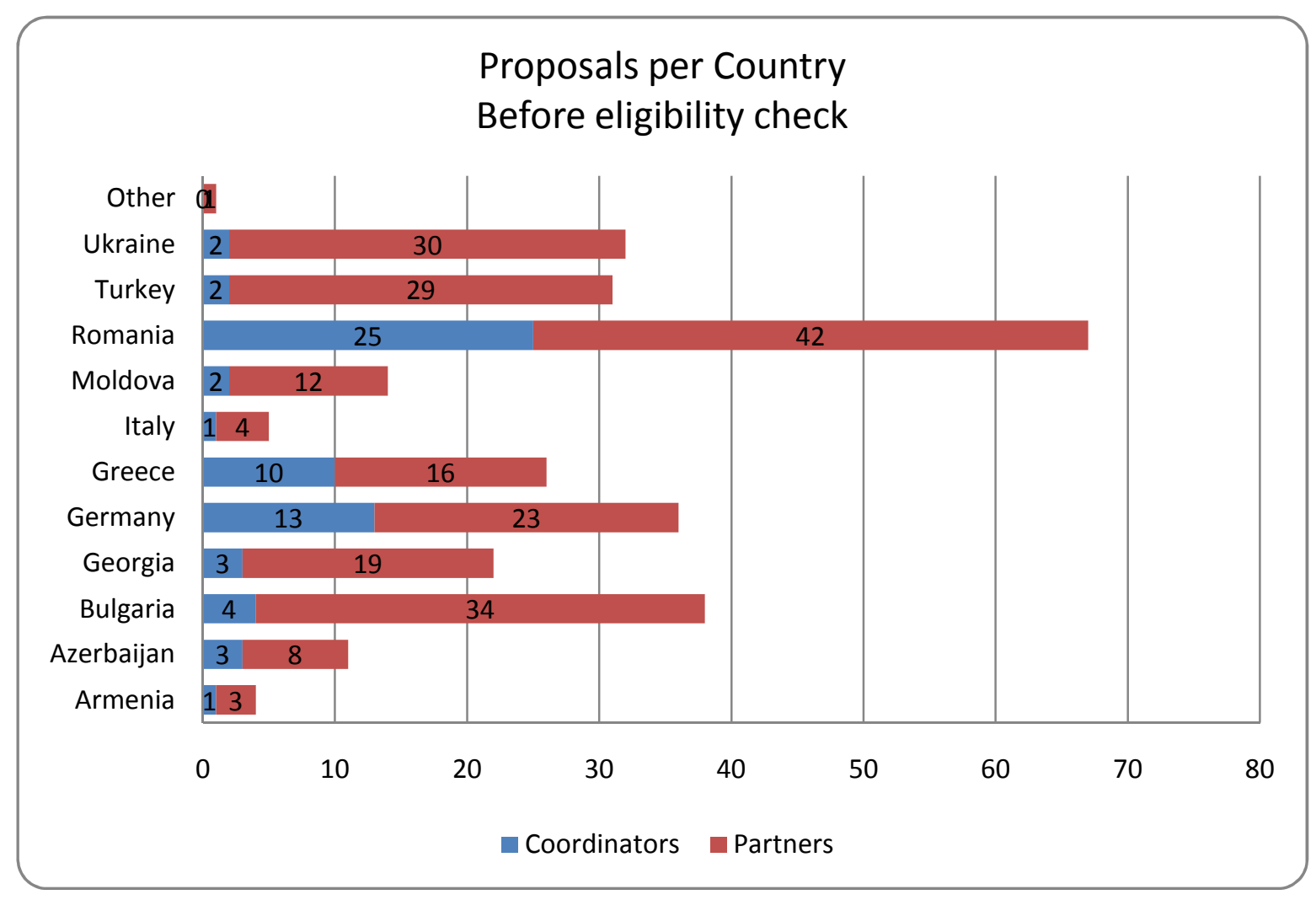




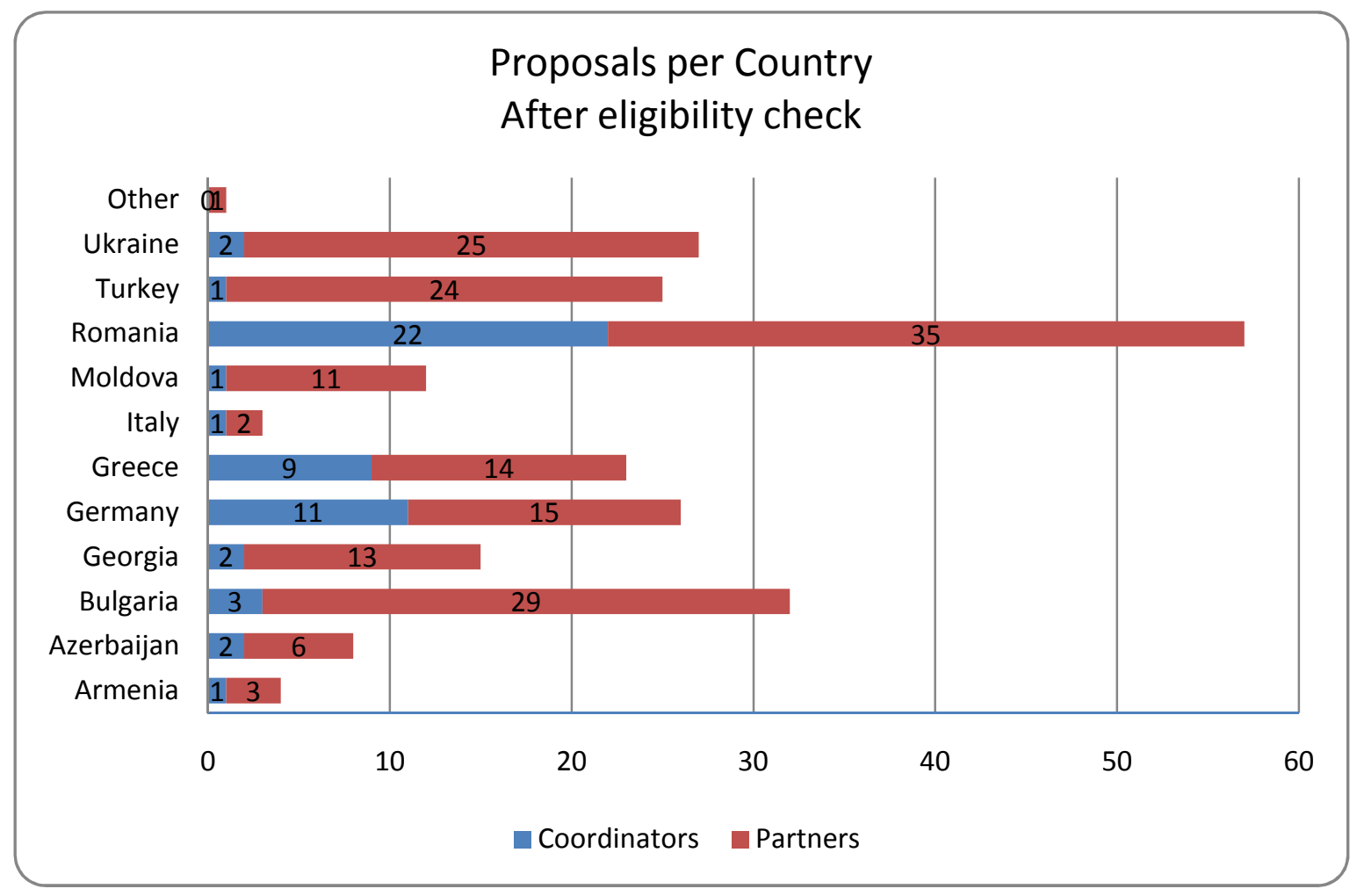

Concerning the topics, most of the proposals fall within the field of water pollution

\section{Proposals per Topic (after final national eligibility check)}

CO2 capture and storage technologies for zero emission power generation in the Black Sea region.

Hydrogen production from $\mathrm{H} 2 \mathrm{~S}$ rich Black Sea Water

Water pollution prevention options for coastal zones and tourist areas

Exploitation and transport of mineral resources: impact on environment

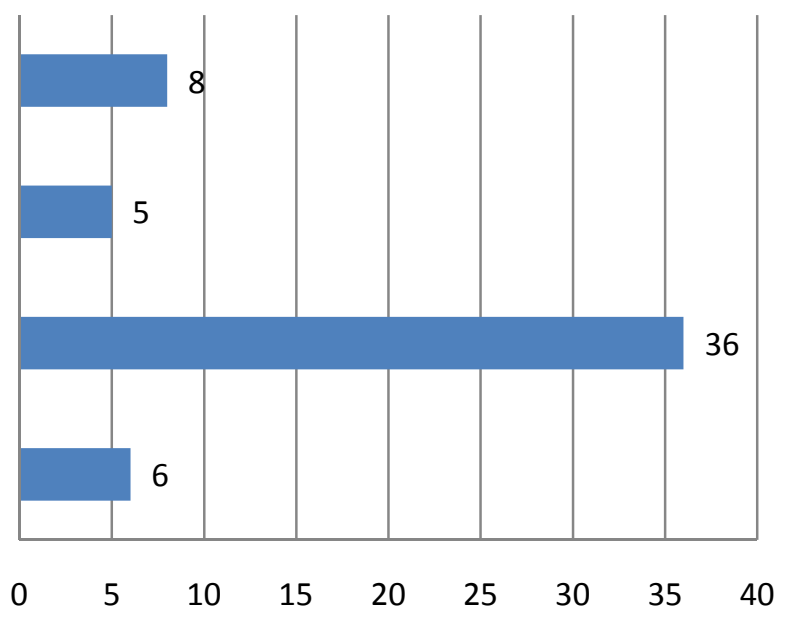


The group of funding parties is mostly satisfied with the number of proposals that have been submitted.

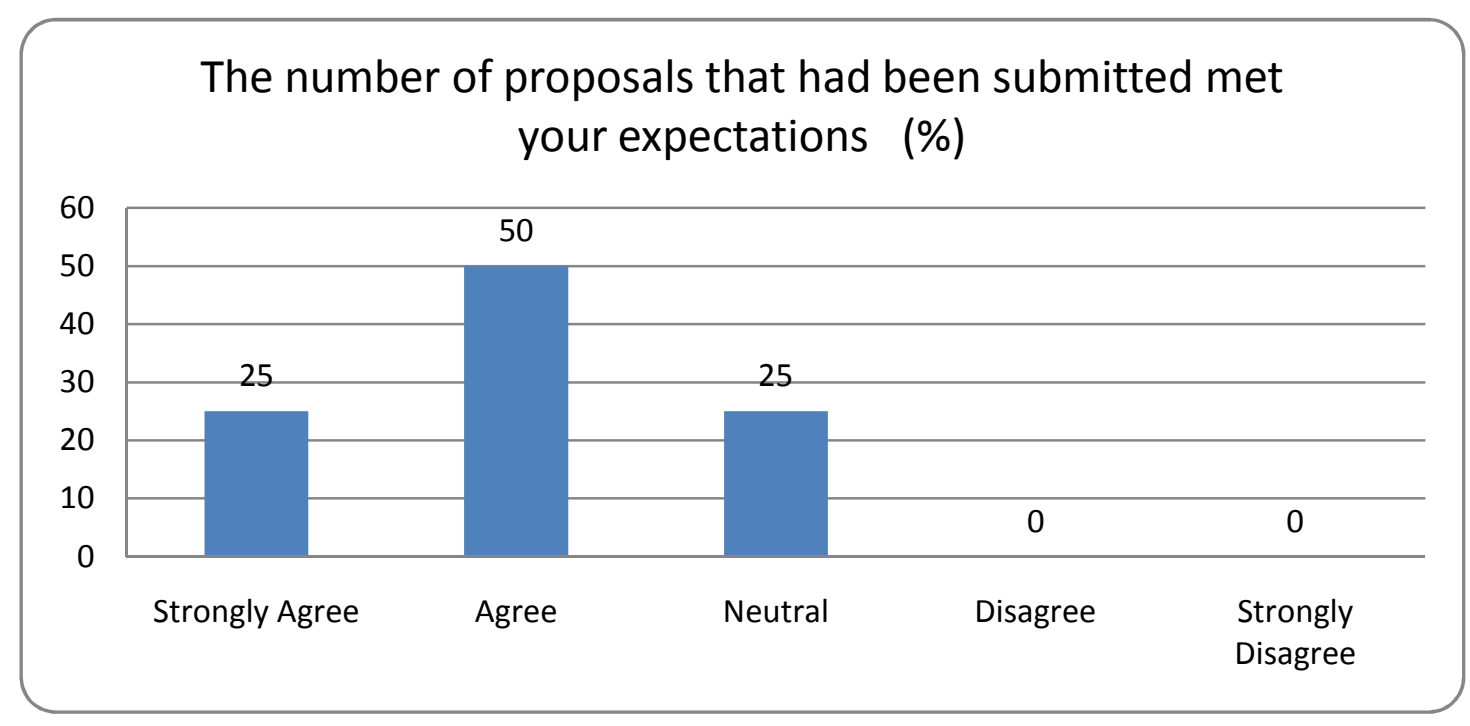

Conclusion 15: Of the 66 proposals submitted, 11 were approved for funding. So they were submitted 6 times more proposals than the ones that could be funded. This is a common ratio in similar calls and the oversubscription rate is deemed normal. On the other hand the number of projects submitted for funding indicates that there was a mobilization in the research communities in the region but not equally so in all the participating countries. Consequently Romanian partners were by far the more active as opposed to the Italian and Armenian partners. The lack of substantial participation could be explained by the failures in the dissemination of the joint call or by the absence of interest of the researchers due to the rules of participation, the topics, the budget or the timing of the call.

The water pollution topic dominates the submitted projects. This is an indication of the scientific and environmental importance of this discipline in the Black Sea.

The majority of the group of funding parties is mostly satisfied with the number of proposals that have been submitted.

\subsubsection{The way that the evaluation of proposals has been organized}

The evaluation procedure consisted of a number of steps:

a. Eligibility check by the Joint Call Secretariat.

The Joint Call Secretariat checked that proposals met the eligibility criteria as set in the Terms of Reference BS-ERA.NET Pilot Joint Call. Non-eligible proposals were rejected.

b. Eligibility check by the Group of Funding Parties.

Once a proposal met the basic eligibility criteria, the Joint Call Secretariat asked the Group of Funding Parties to check and confirm the eligibility at the level of partner 
institutions according to their national regulations. Proposals that met all eligibility criteria underwent the evaluation and selection procedure that follows.

c. Individual evaluation of proposals.

For most of the proposals, three independent evaluators, of which at least one was from a Black Sea country participating in the BS-ERA.NET Pilot Joint Call, were selected by the Joint Call Secretariat from the pool of evaluators (Eval-Inco database). Keywords and free words specified in the proposal helped selecting the most suitable evaluators in the field of the proposal. Only $75 \%$ of the initially selected evaluators declared their availability and capacity to evaluate the chosen proposals. Under these circumstances the Joint Call Secretariat had to find alternative solutions or to asses some proposals with less than 3 evaluators. The evaluation was performed on-line, using the on-line submission and evaluation system PT-Outline. Each evaluator received access to the proposal and submitted on-line the results of her/his evaluation. The evaluators were ignorant of the other experts evaluating the same proposal. Each evaluator therefore assessed each proposal independently without exchanging views with the other evaluators. The quality of the evaluators' reviews was standing at quite high level, although there was a small number of reviews ( 25 to 220 ) that needed to be returned to evaluators for improvement (i.e. better justification of the marks, irrelevant justification etc)

\section{d. Ranking List}

From the total scores xi given by each evaluator the average score <xi> of each proposal was calculated and retained to assemble a preliminary ranking list.

\section{e. Scientific Council}

The preliminary ranking list prepared by the Joint Call Secretariat was reviewed by the Scientific Council. This Council was appointed by the Joint Call Secretariat based on the nominations of the Group of Funding Parties and consisted of high level scientific experts. The aim of the Council was to consolidate the results of the evaluation and make recommendations to the Group of Funding Parties. In practice the Scientific Council reviewed proposals that had less than 3 independent evaluations, or the already given evaluations by the independent evaluators had significant differences in their scores.

f. The final funding decision rested with the Group of Funding Parties.

Conclusion 16: The followed steps in the evaluation of the projects are in line with the international practice and had also been applied in other joint calls of ERA-NETs. Still there is room for a number of improvements:

a. There were 2 preliminary eligibility checks, one by the Joint Call Secretariat and the other at national level by the Funding Parties. It is obvious that the rationale for this double check is that the submitted projects should be checked against the eligibility criteria of the call itself (terms of references) but at the same time should fulfill the national eligibility criteria for funding, given that the virtual common pot scheme is applied. However, the double check causes delays in the evaluation phase. 
b. A key issue is the database of evaluators for the independent evaluation of proposals. The Eval-Inco database is the successor of the well known INTAS database which at different stages through time was enriched with new entries mainly by ERANET initiatives (i.e. SEE-ERA-NET). It is still an old database that needs to be updated and cleaned of reviewers that are not active anymore. Additionally, in these types of experts' databases the expertise of the evaluators is based on what is self-proclaimed without any crosscheck and "evaluation" of the enlisted evaluators. This issue directly affects the quality standards of the database. For example it had been reported by the officers in the Joint Technical Secretariat that almost 25\% of the initially selected evaluators from the pool of Eval-Inco database did not reply to the call to evaluate or declared that they were not capable of evaluating the particular projects. Moreover, 25 out of 220 evaluation reports needed to be returned to evaluators in order to be improved (i.e. better justification of the marks, irrelevant justification etc).

c. It has been reported that the time given to the scientific council was very short and there was insufficient time to review the whole preliminary ranking list prepared by the Joint Call Secretariat. In practice, the Scientific Council reviewed proposals that had less than 3 independent evaluations or the already given evaluations by the independent evaluators had significant differences in their scores. Under these circumstances the Council was not able to achieve its aim, which according to the TOR was to consolidate the results of the evaluation and make recommendations to the Group of Funding Parties.

\subsubsection{The view of the applicants, the funding parties and the Scientific Council regarding the evaluation procedures}

\subsubsection{Time duration of the evaluation procedures}

Most of the applicants found the time span from the submission of their proposal to the announcement of the results reasonable, however some successful and unsuccessful applicants declared a complaint. 


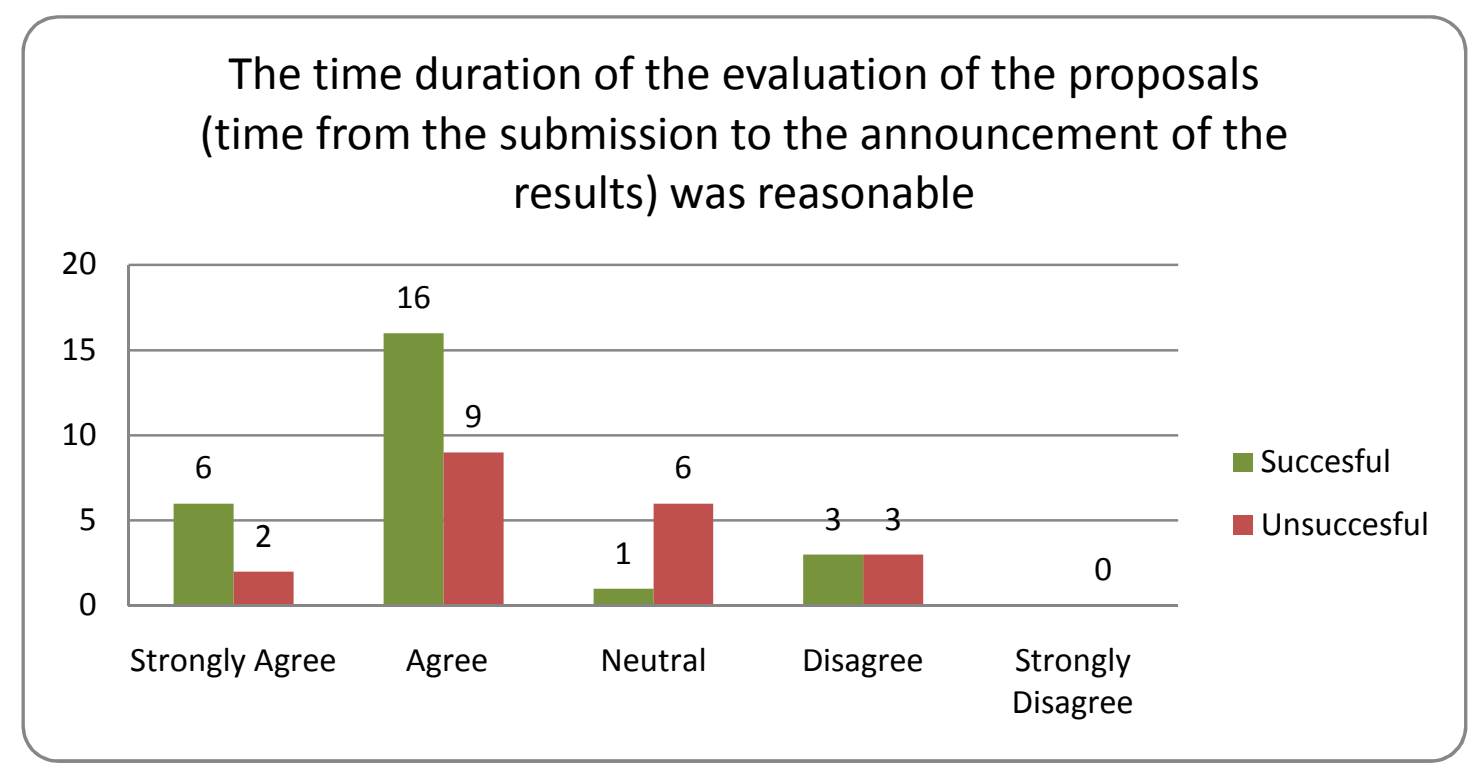

The group of funding parties was rather satisfied with the time span of the proposals' evaluation

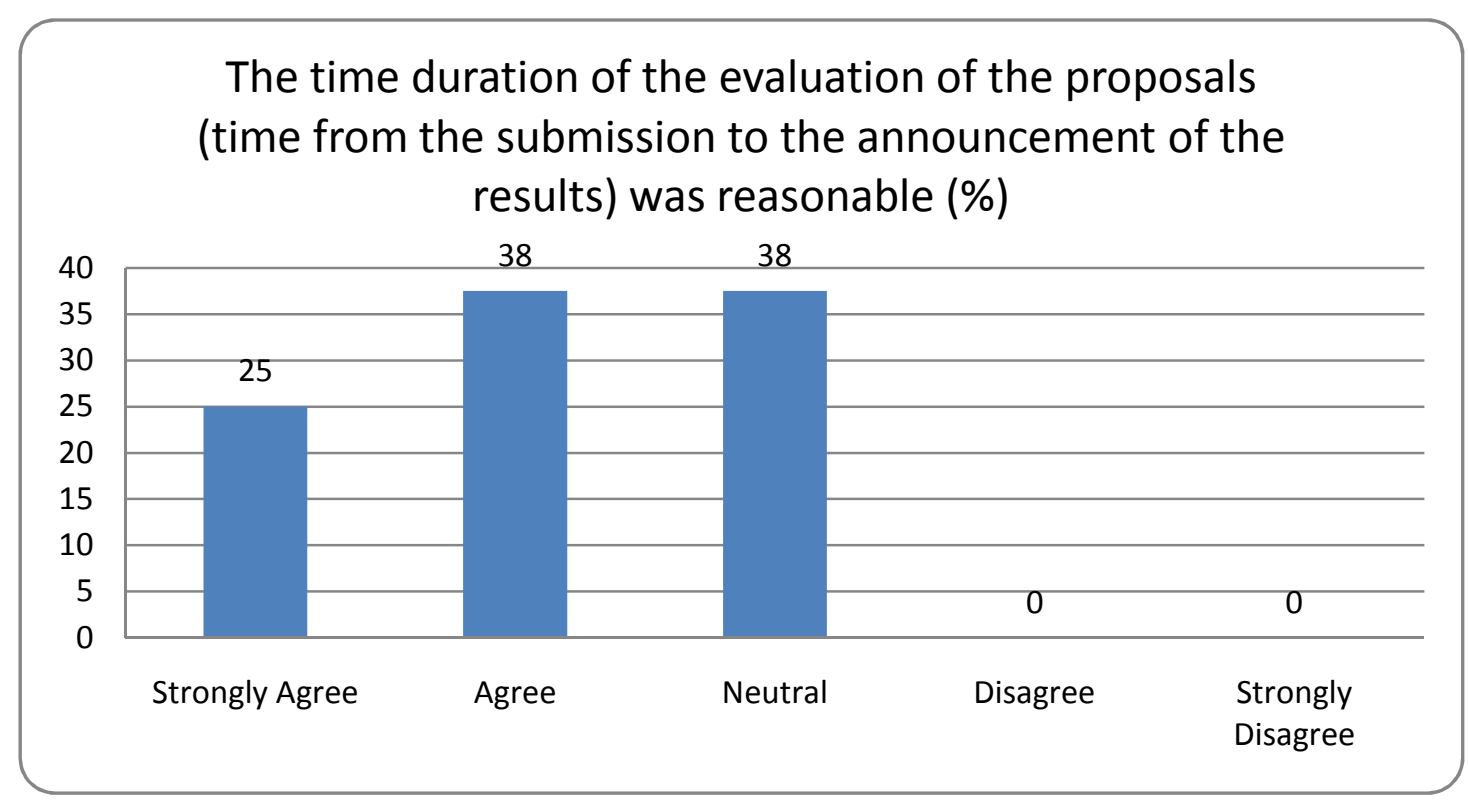

The Scientific Council members showed a neutral approach regarding the time span of the evaluation of the proposals. 


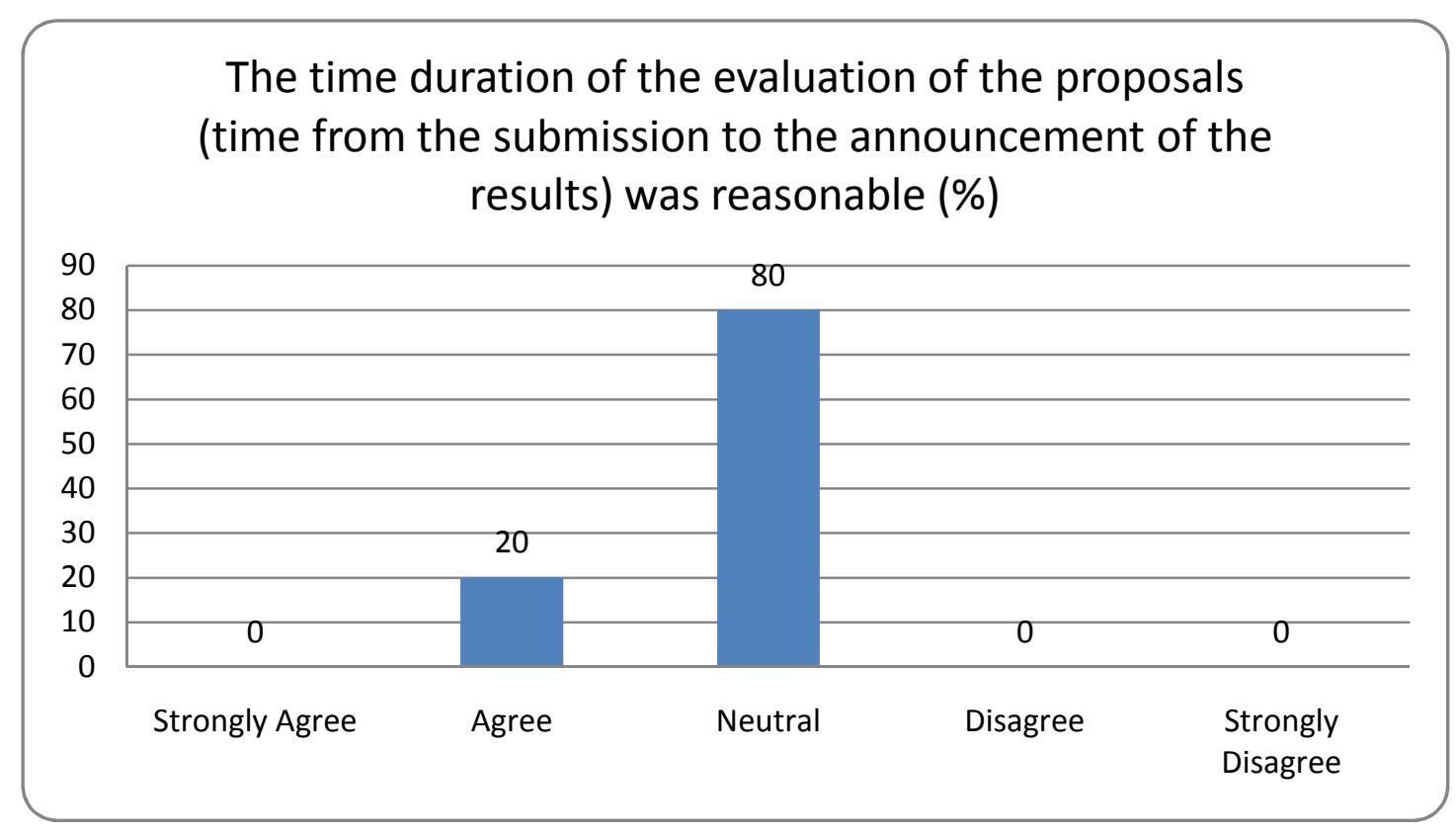

Conclusion 17: The time span of the evaluation of the proposals (time from the submission to the announcement of the results) could be reduced basically on the stage of the preliminary check of the national eligibility criteria.

It is interesting that most of the applicants found the time from the submission of their proposal to the announcement of the results reasonable, however some successful and unsuccessful applicants declared their disagreement and complained.

\subsubsection{Quality standards of the evaluation}

Many unsuccessful applicants expressed their concerns regarding the evaluation standards and principles. 


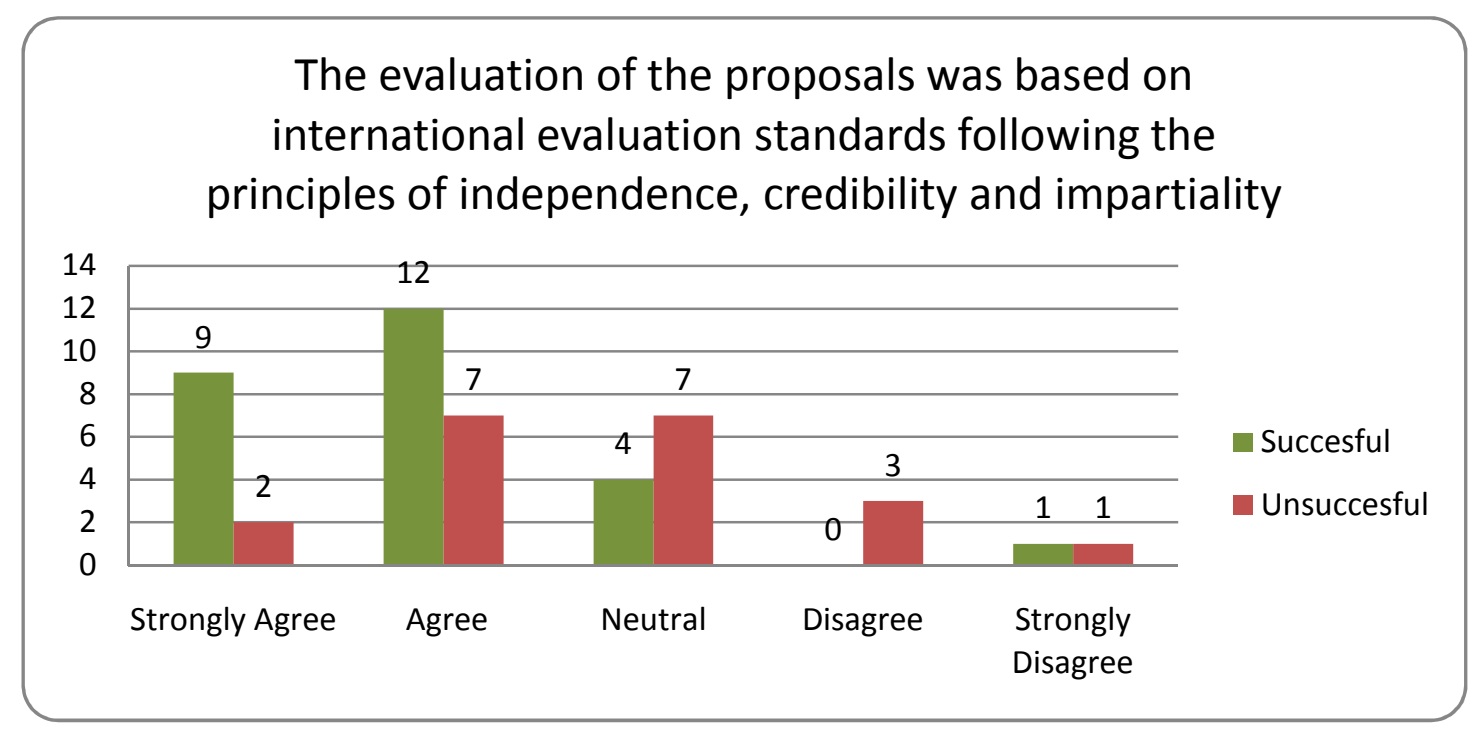

The funding parties are mostly satisfied with regard to the quality standards of the evaluation

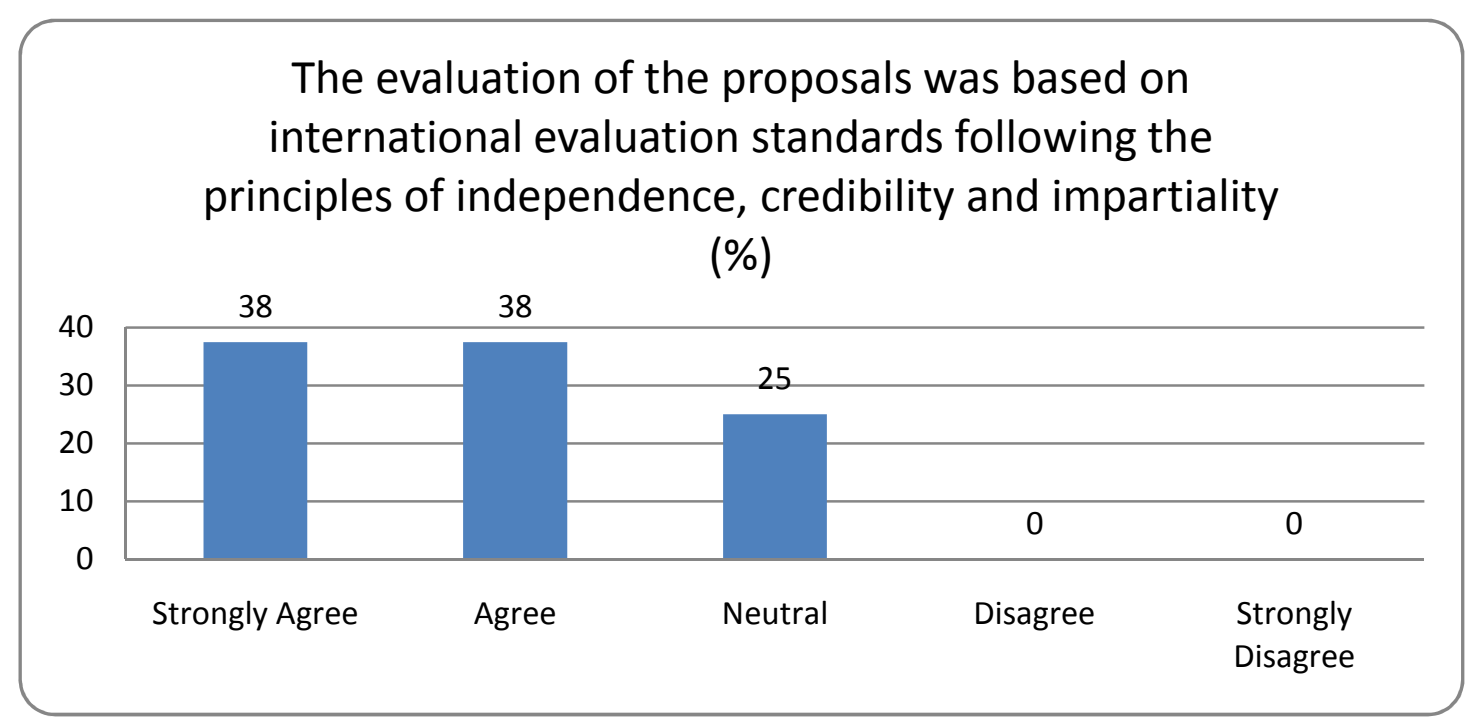

Although the majority of the members of the Scientific Council agreed that the evaluation of the proposals was based on international evaluation standards, there is a percentage that is not similarly convinced. 
The evaluation of the proposals was based on international evaluation standards following the principles of independence, credibility and impartiality

(\%)

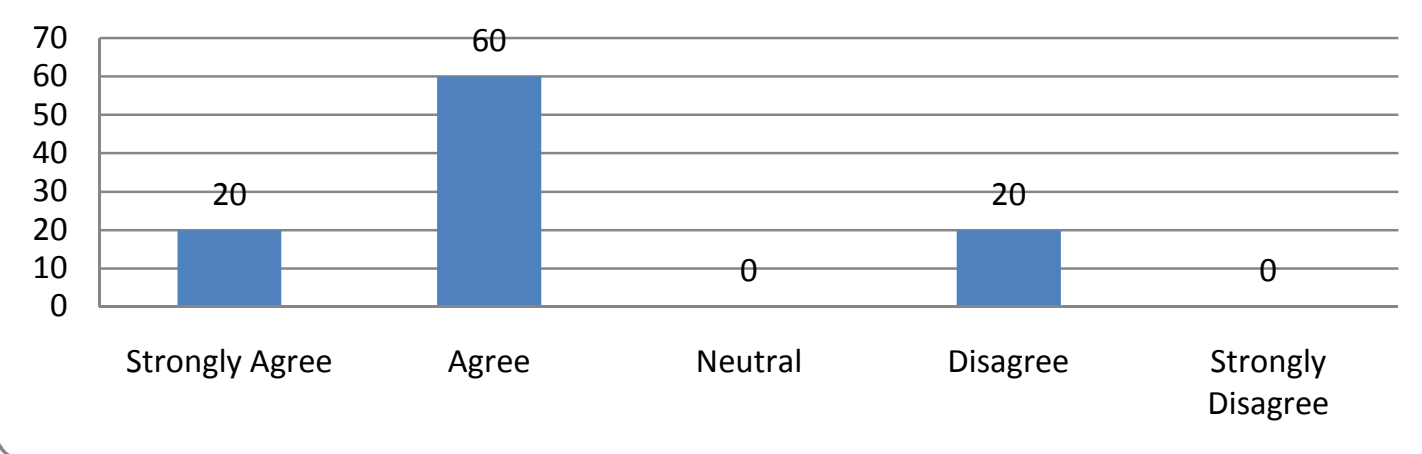

Moreover, some Scientific Council members have expressed reservations as to the fulfillment of the three fundamental principles governing the evaluation of project proposals.

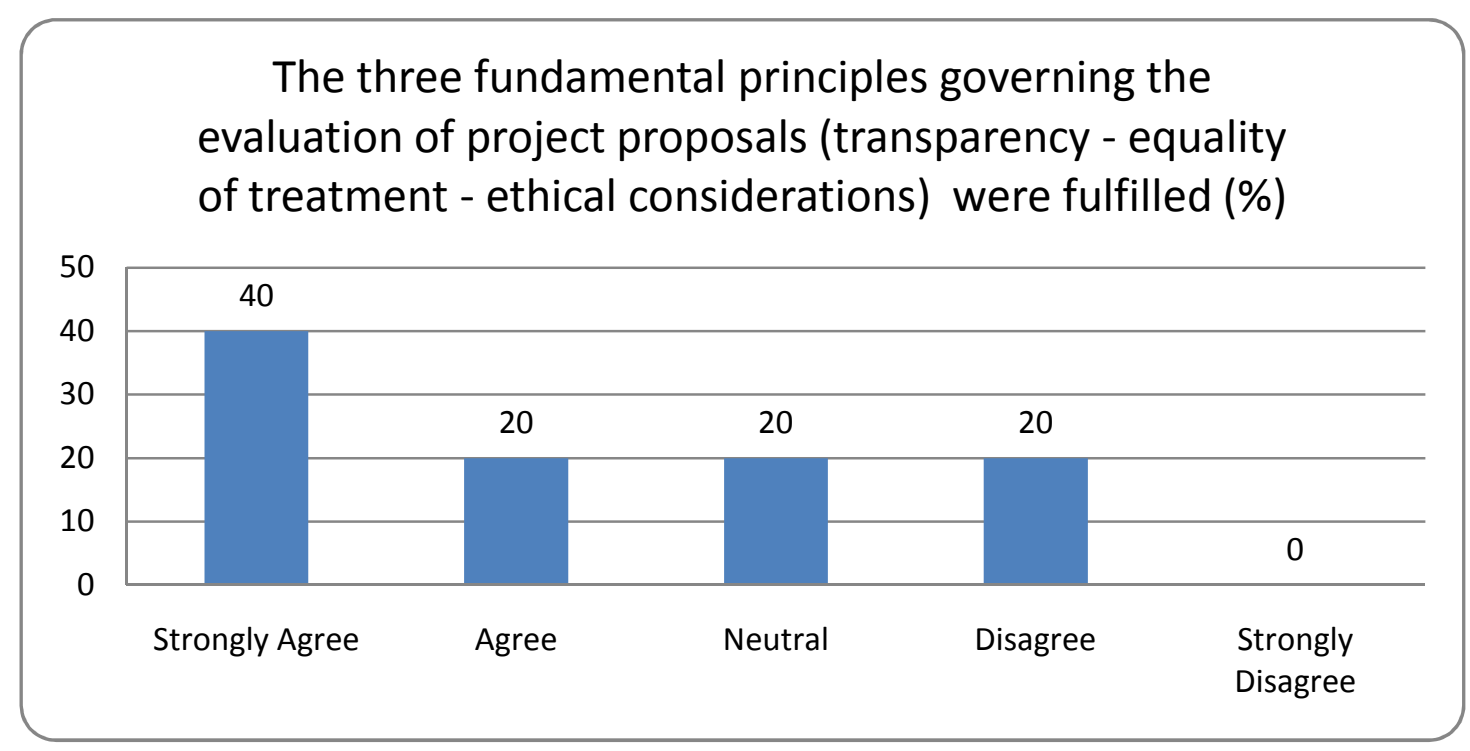

The Scientific Council members agreed on the high scientific competence and experience of the independent evaluators of the proposals. 


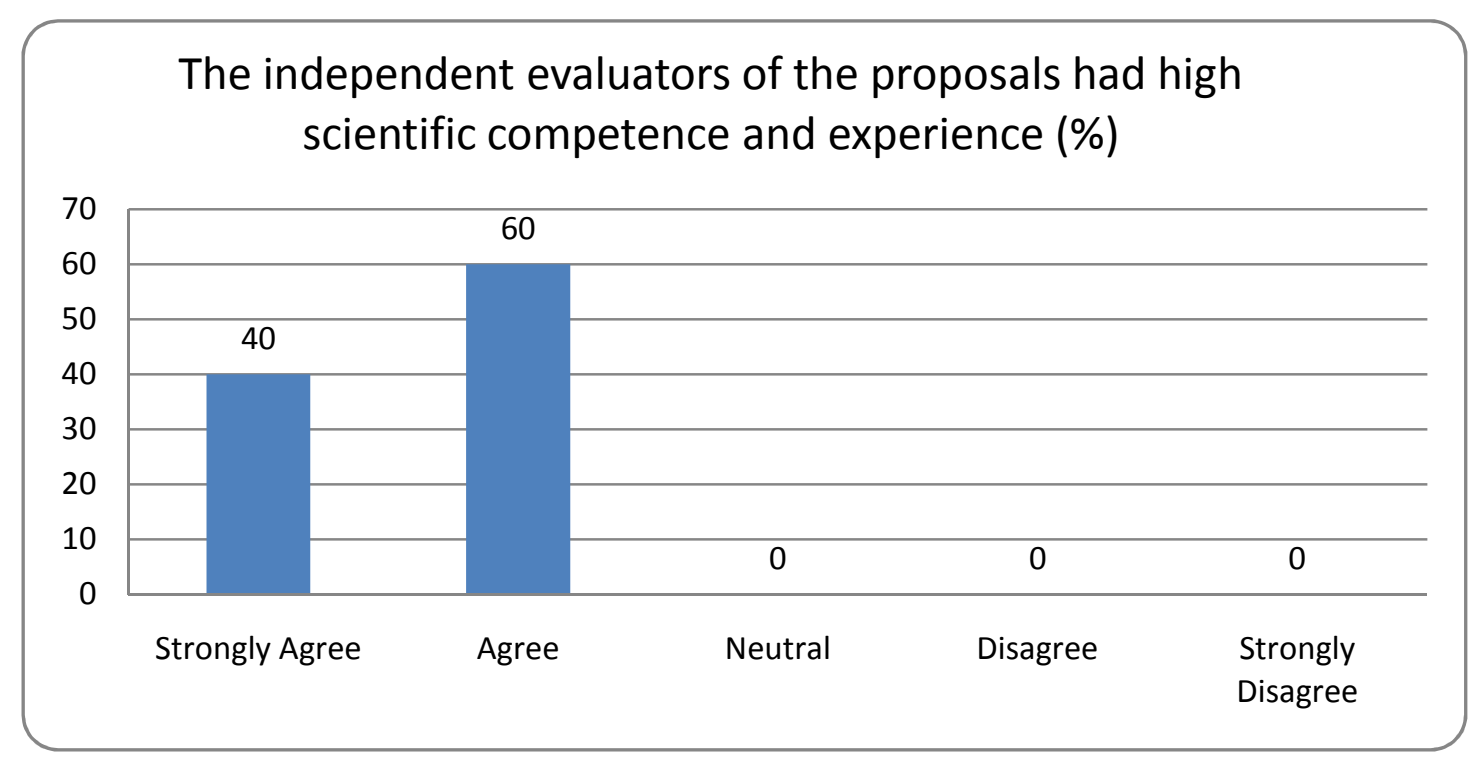

The Scientific Council members agreed that the individual evaluation forms (with the given scores and justification of the scores for each evaluation item) that had been delivered by the independent evaluators had high international scientific quality standards.

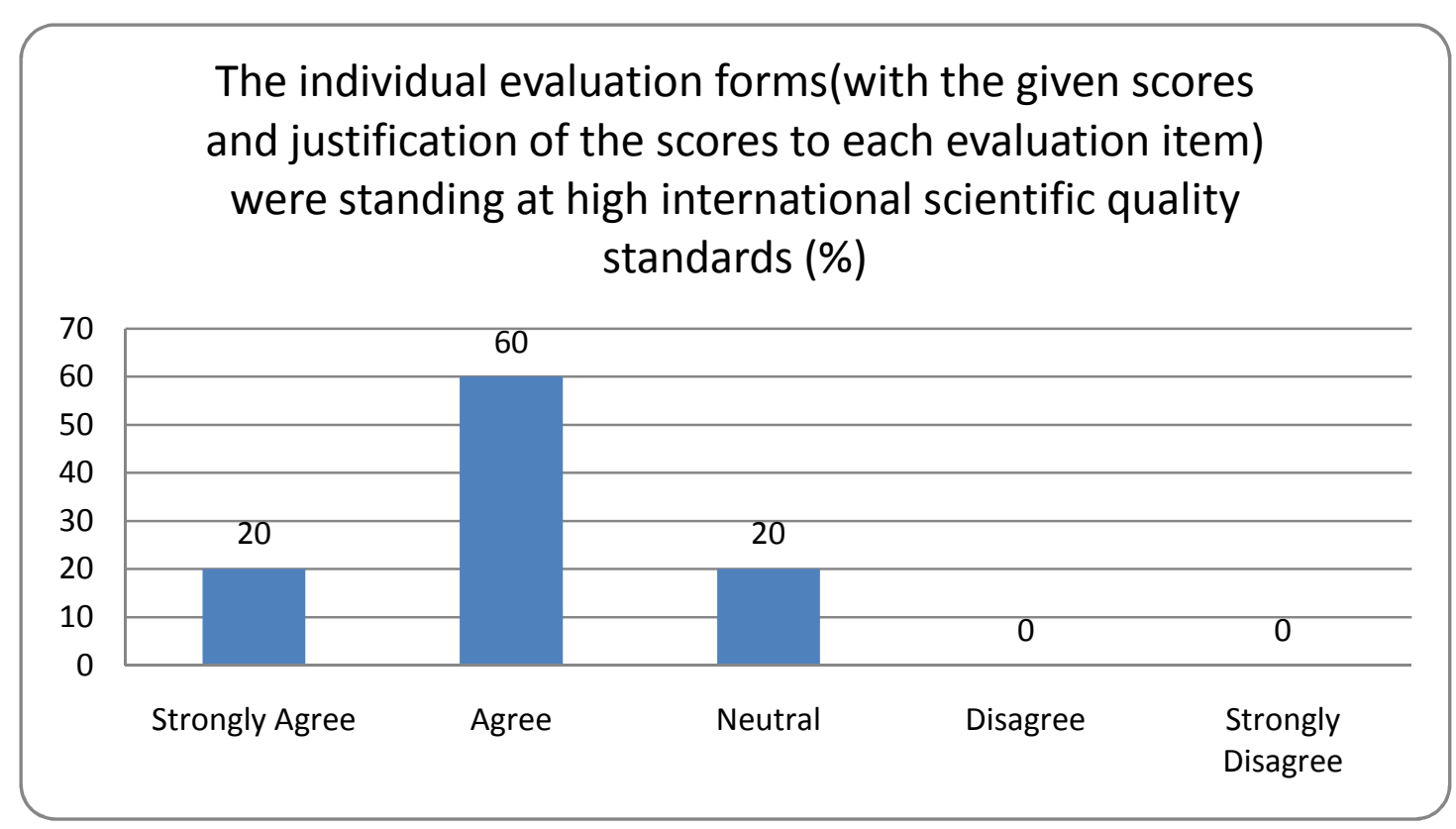


Conclusion 18: Many unsuccessful applicants expressed concerns about the application of evaluation standards and principles during the evaluation of their proposal. This is considered a justified reaction given the fact that they have been rejected. The funding parties are mostly satisfied with respect to the quality standards of the evaluation.

It is a very interesting fact to note that although the majority of the members of the Scientific Council consider that the evaluation of the proposals was based on international evaluation standards, there is a percentage that is not convinced about that. Moreover, some Scientific Council members have expressed reservations as to the fulfilment of the three fundamental principles governing the evaluation of project proposals. This is in line with what is mentioned at the conclusion 17 of this report. The Scientific Council members found the independent evaluators of the proposals to have high scientific competence and experience.

The Scientific Council members found that the individual evaluation forms (with the given scores and justification of the scores to each evaluation item) that were delivered by the independent evaluators had high international scientific quality standards. It is worth mentioning at this point that even a small number of inadequate evaluation forms due to the efforts and capacity of the Joint Call Secretariat were returned for improvement before being finally submitted to the Scientific Council.

\subsubsection{The feedback provided regarding the scientific evaluation of the proposals}

It is more than interesting that it has been confirmed by the Joint Call Secretariat that it had not provided any feedback to the unsuccessful applicants regarding the reasons of their failure. Moreover, marks, evaluation comments and recommendations have never been disclosed to the applicants.

However, many answers given by the responders through the questionnaires are in disagreement with the above-mentioned.

Some of the unsuccessful applicants complained about the inadequate feedback on the scientific evaluation of their proposal. 


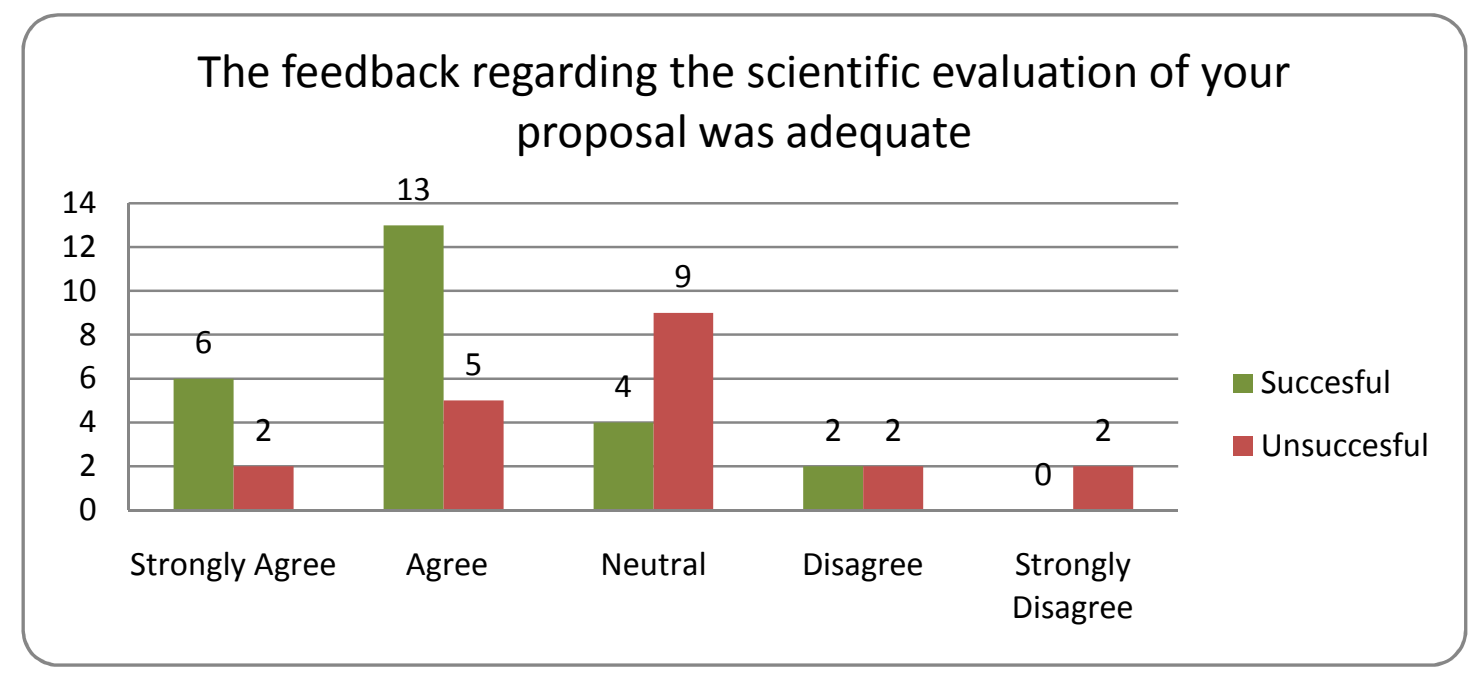

The same concerning the evaluation comments

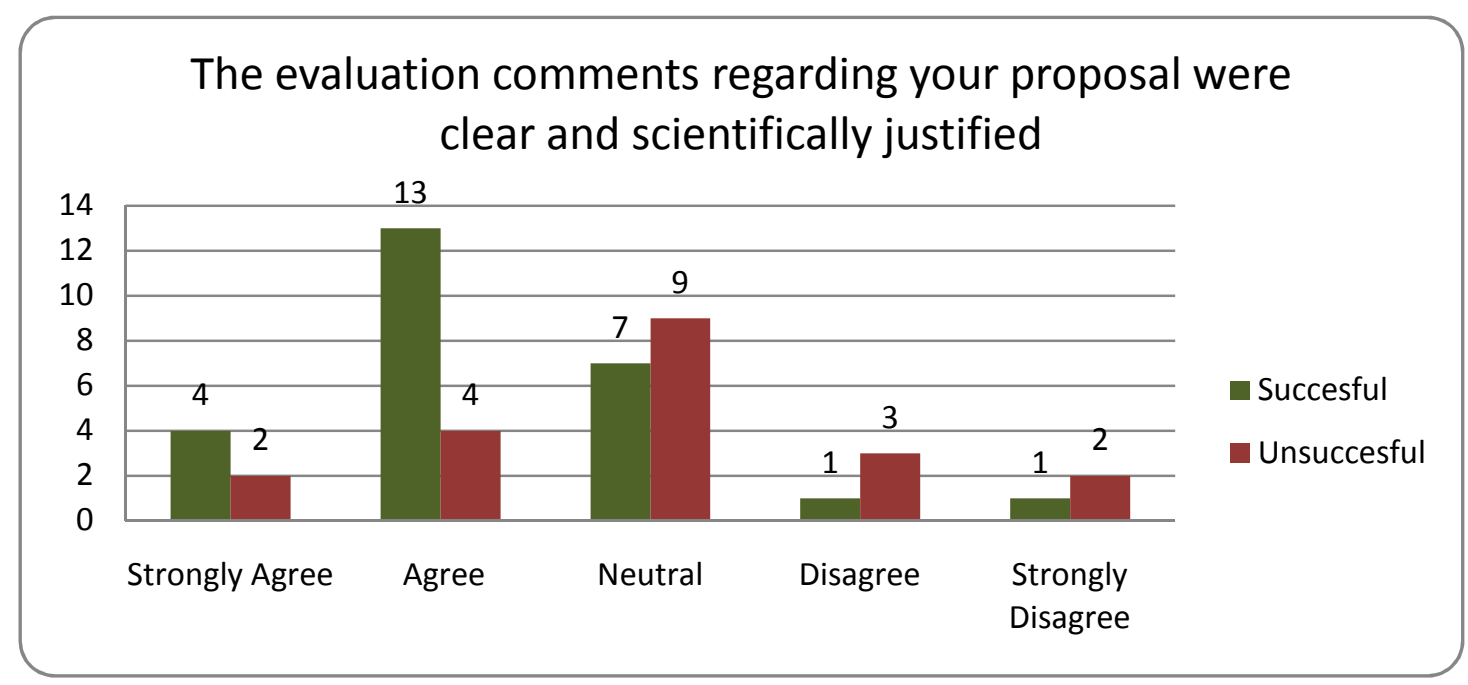

The funding parties have expressed satisfaction with regard to the feedback on the scientific evaluation of the proposals. However, a significant percentage retains a neutral position on the subject. 


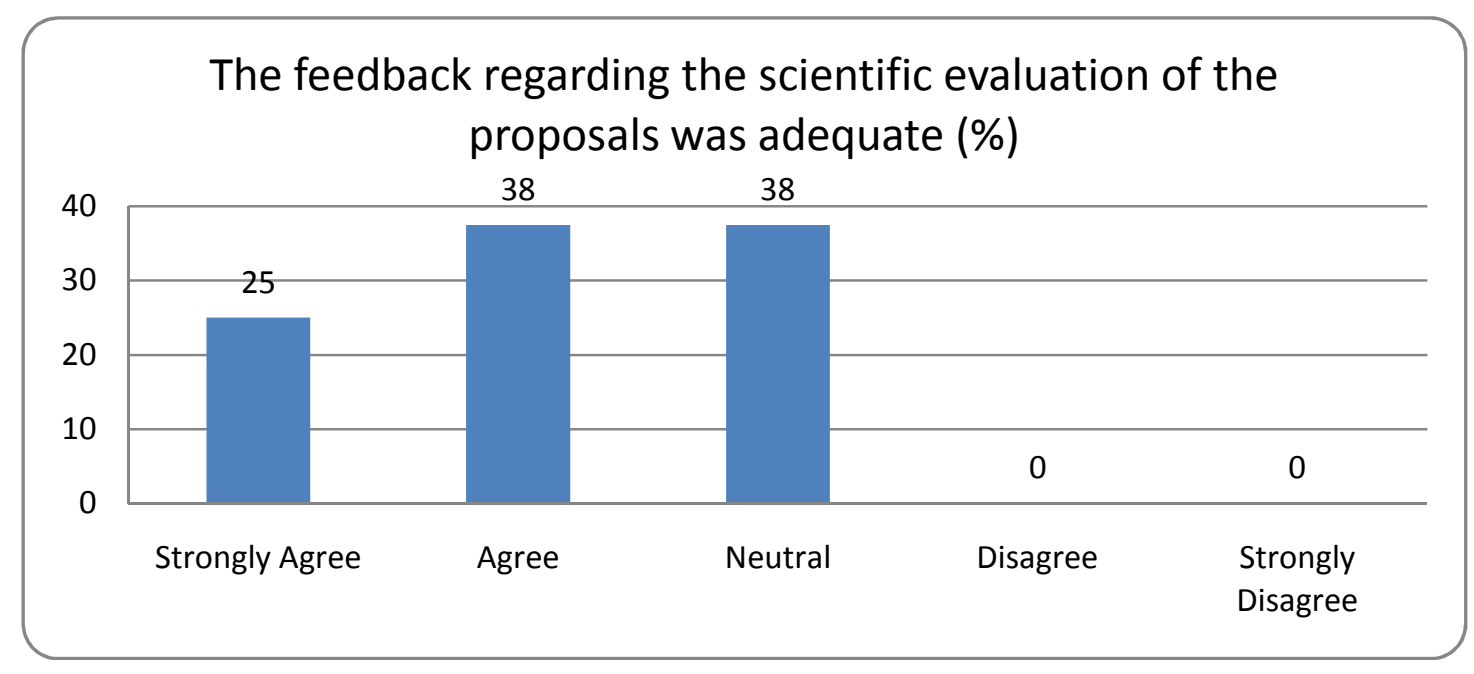

The same concerning the evaluation comments

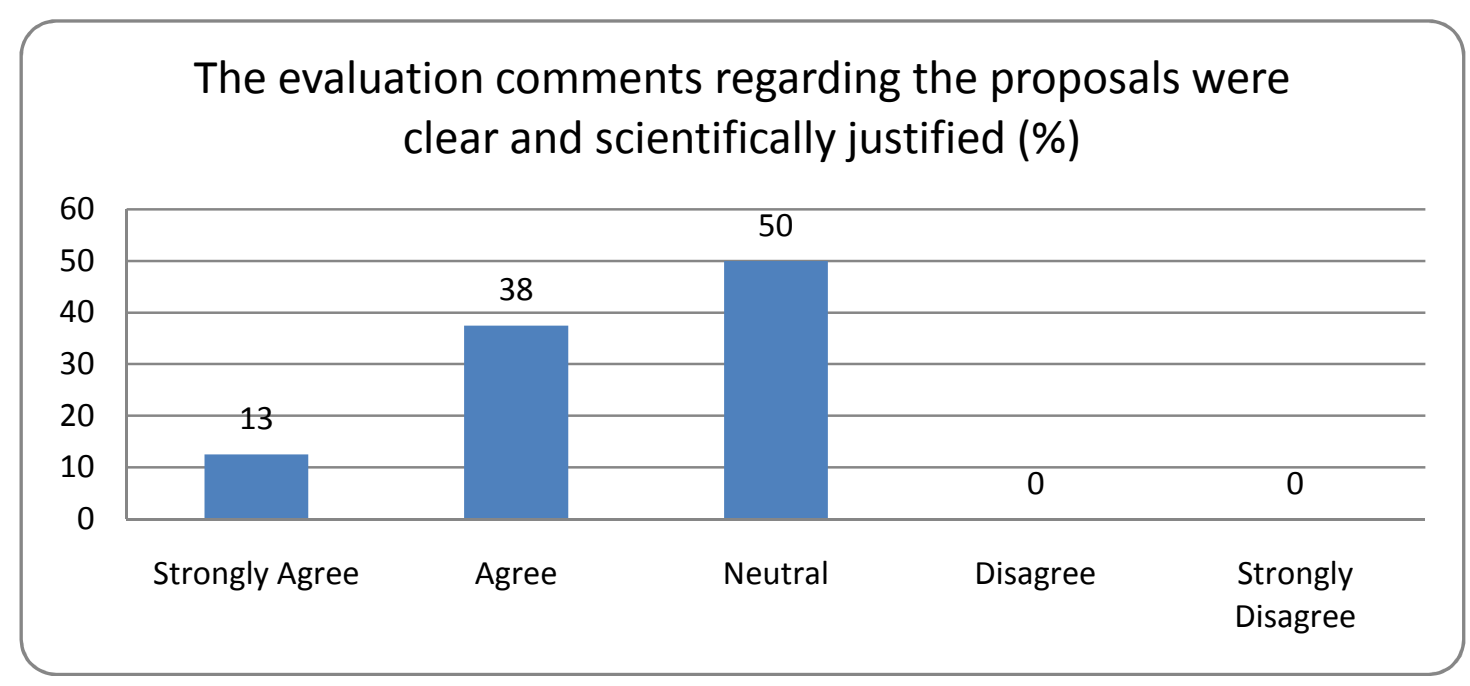

Reservations by some Scientific Council members have been expressed regarding the feedback to the applicants concerning the scientific evaluation of the proposals. 


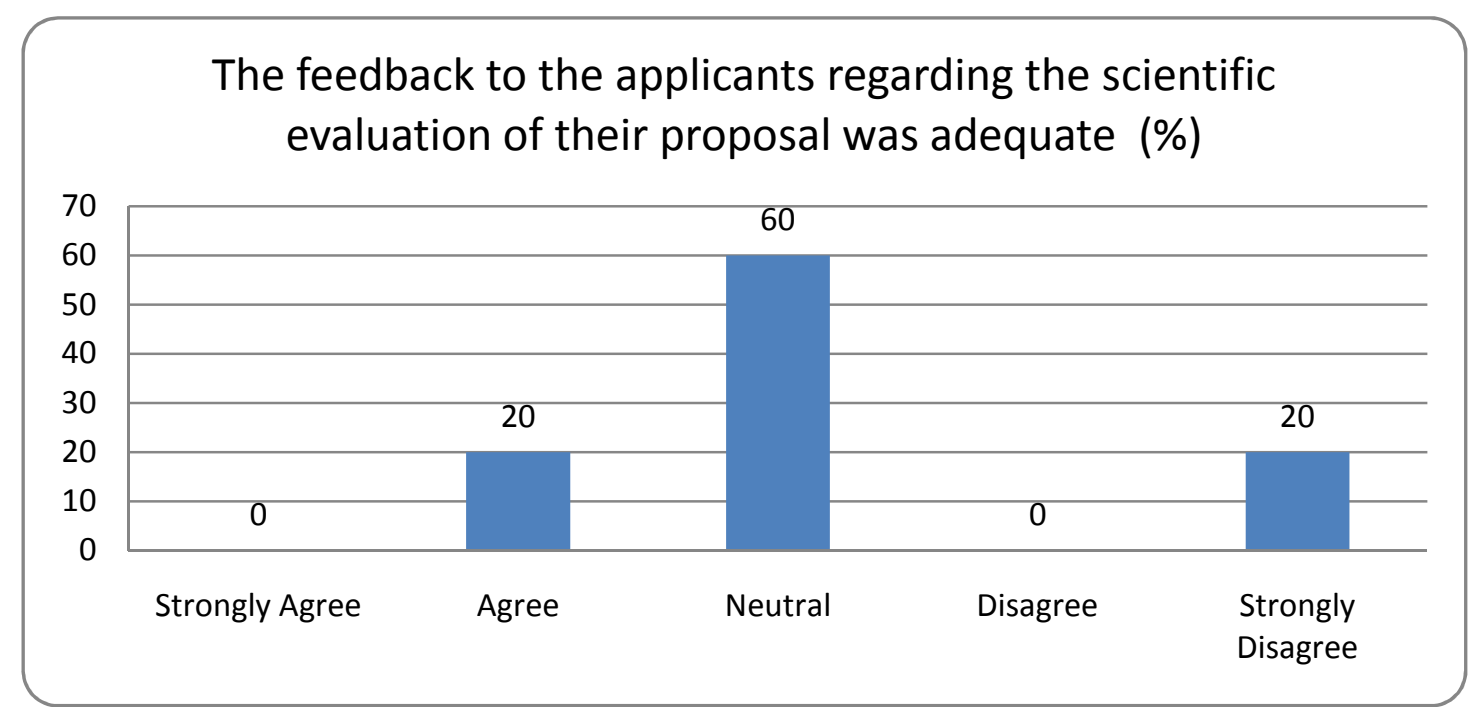

The Scientific Council members found the evaluation comments regarding the proposals clear and scientifically justified.

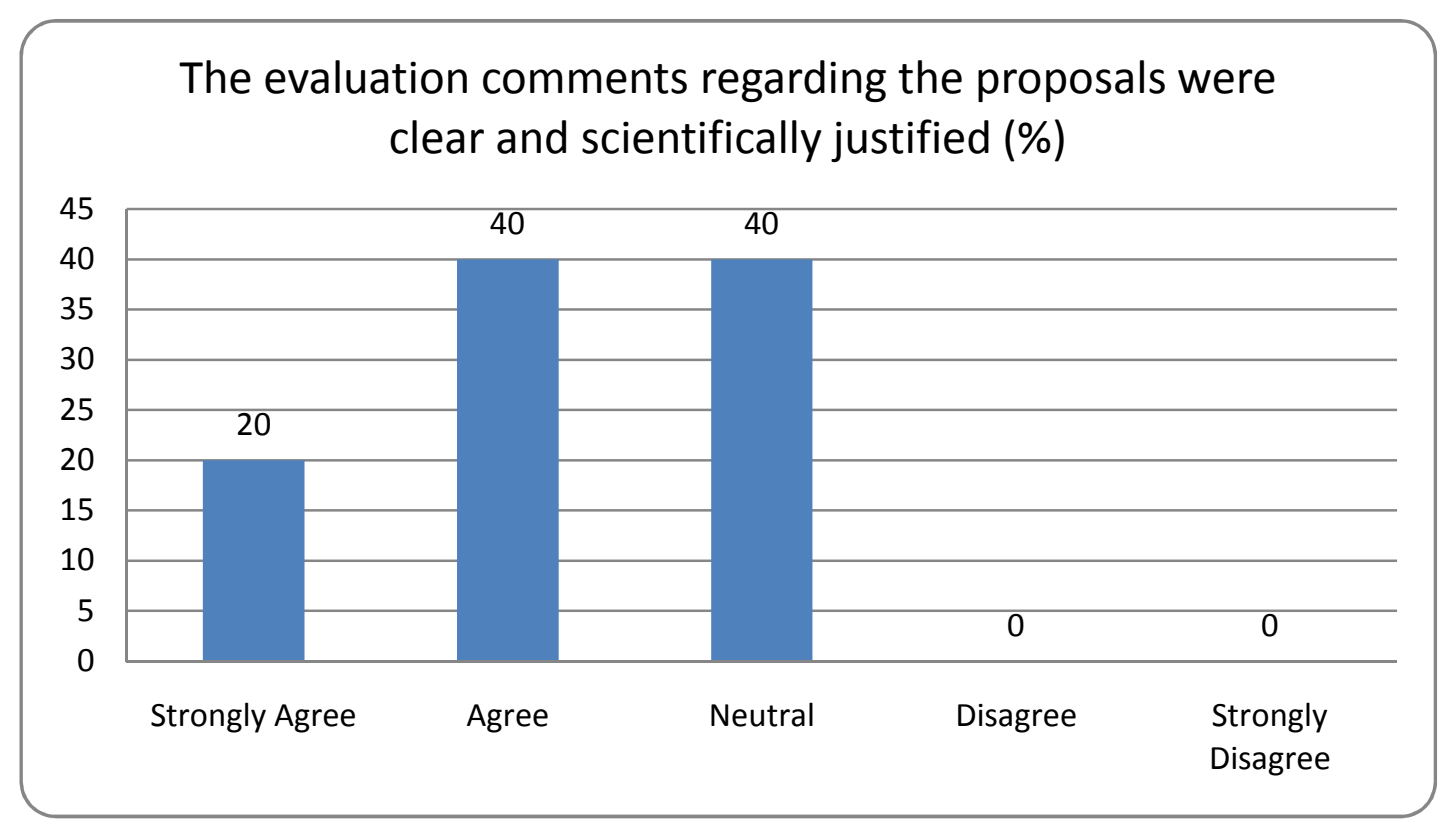

The Scientific Council members are divided on how efficient and adequate in effort the administrative procedures of the Joint Call Secretariat are concerning the evaluation of the project proposals. 


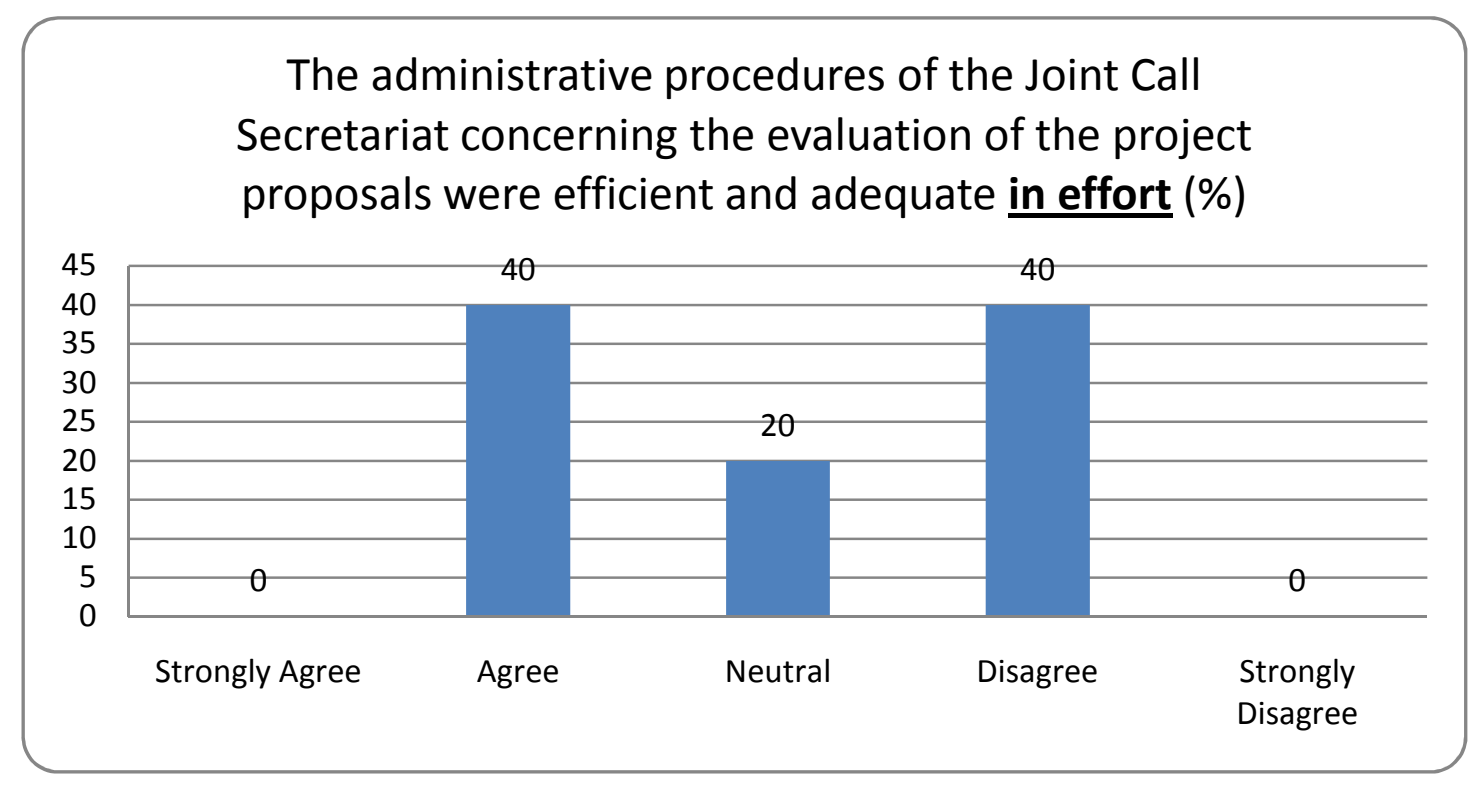

The Scientific Council members found the administrative procedures of the Joint Call Secretariat concerning the Evaluation of the project proposals to be efficient and adequate in time

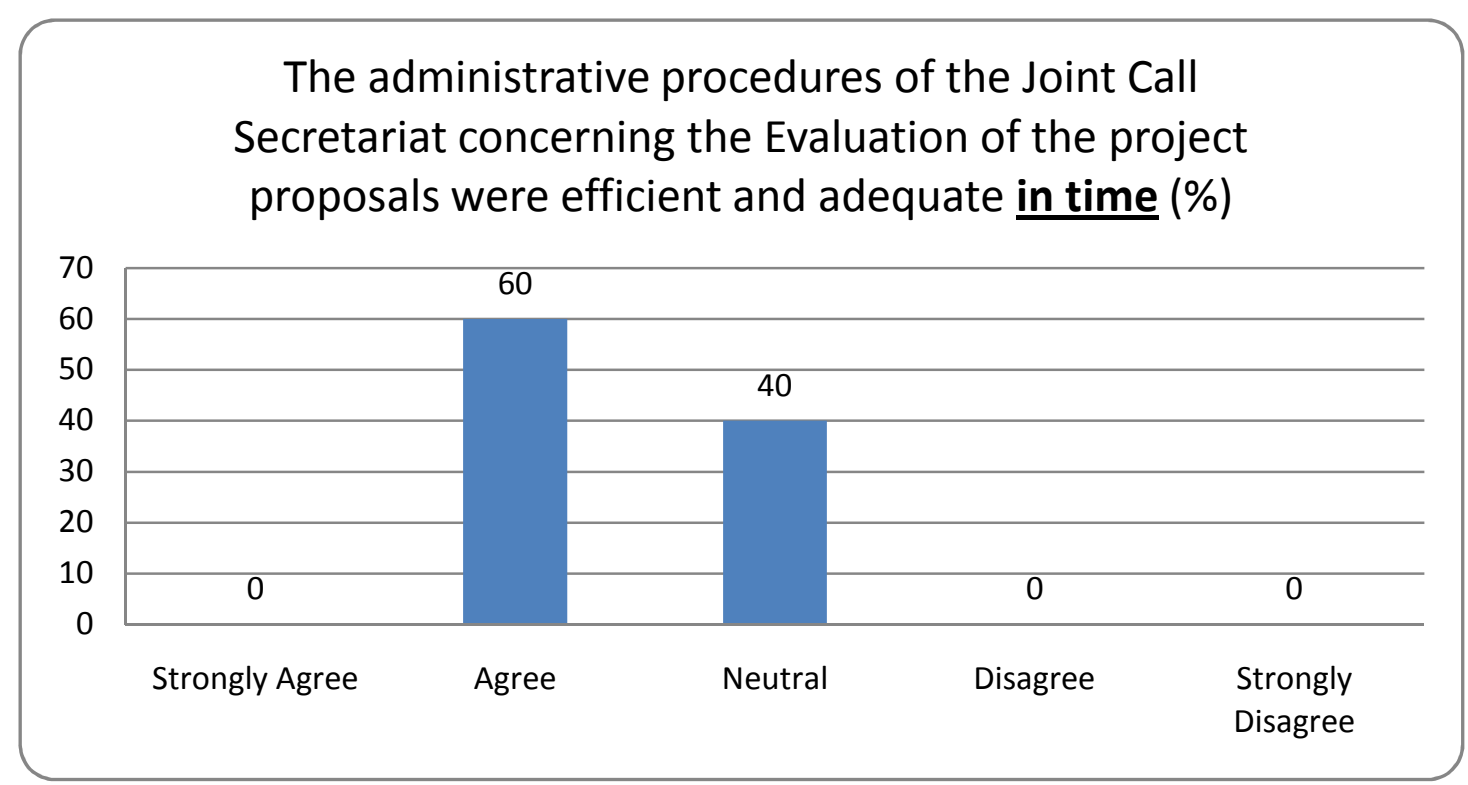

The Scientific Council members had a positive opinion on the web-based Call Management System PT-Outline for the evaluation of the Project proposals 


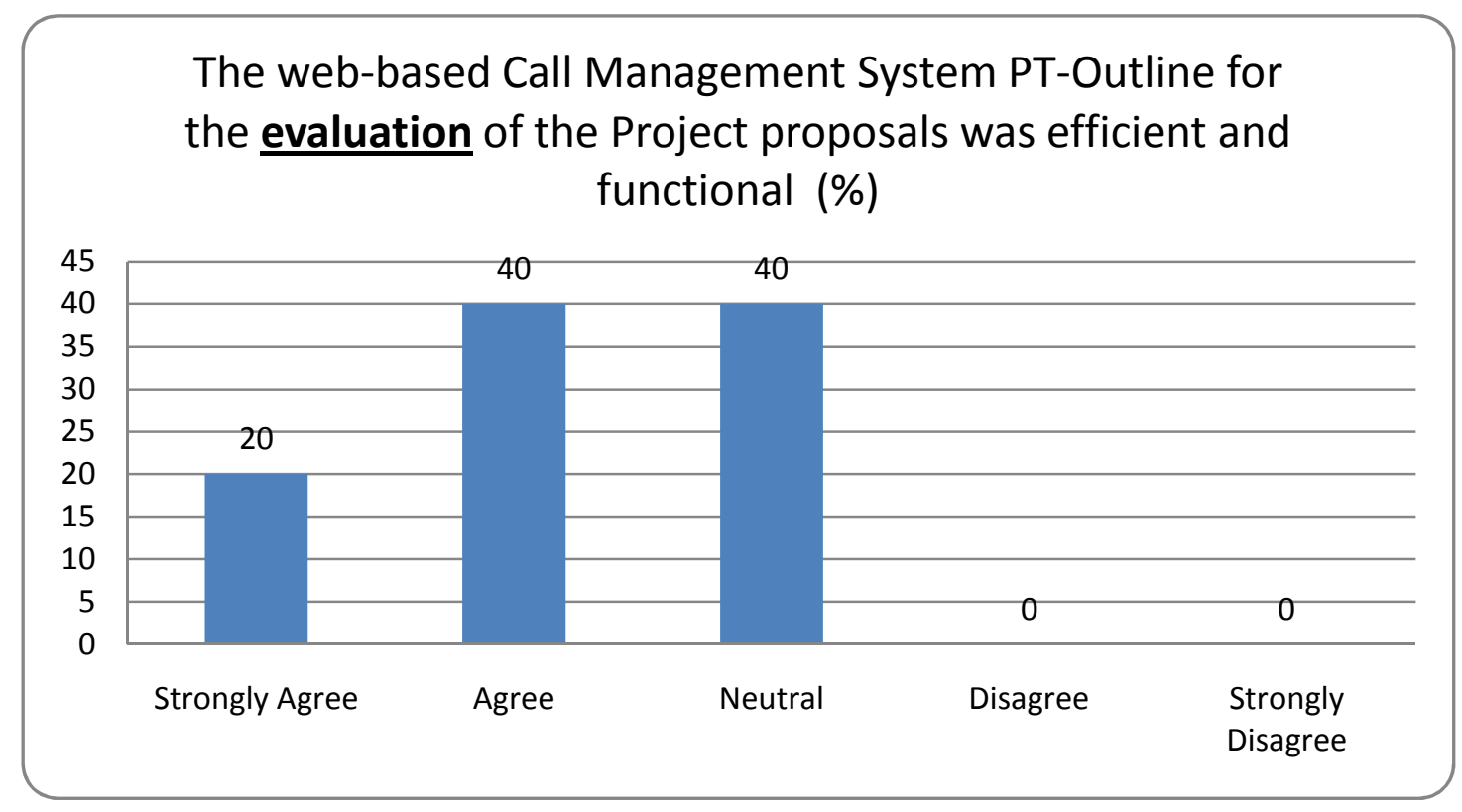

It is worth noting that there is a non-unanimous consensus that the task of the Scientific Council to review the preliminary ranking list prepared by the Joint Call Secretariat and to prepare a final list of all project proposals recommended for funding together with their tentative budgets, was fulfilled.

The task of the Scientific Council to review the preliminary ranking list prepared by the Joint Call Secretariat and to prepare a final list of all project proposals recommended for funding together with their tentative budgets was fulfilled (\%)

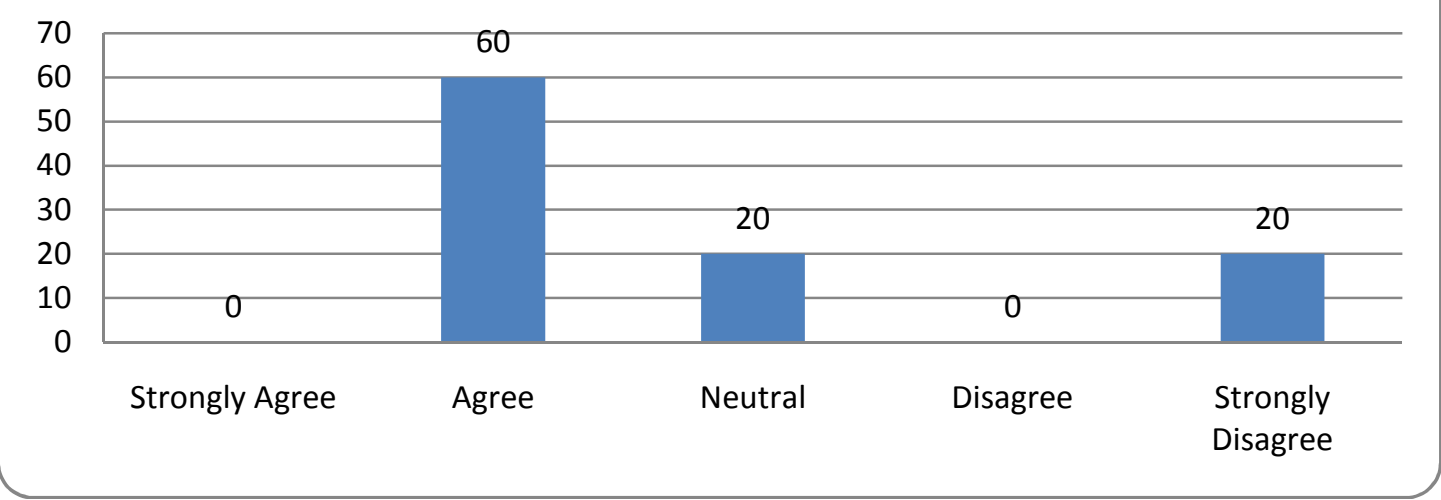


Conclusion 19: It was reported both by unsuccessful applicants and the Joint Call Secretariat that there was lack of feedback to the unsuccessful applicants explaining the reasons of their failure. The usual practice is to be sent an informative letter with the relevant marks by criterion and an adapted summary of the comments of the reviewers attached. This is a principal that assures the transparency of the evaluation procedure and more importantly aids the applicant to improve in future project proposal submissions. It is more than interesting that the funding parties were quite satisfied about the level of feedback on the scientific evaluation of the proposals. The same applies about the evaluation comments that were not given.

Some Scientific Council members have expressed reservations regarding the feedback on the scientific evaluation of the proposals to the applicants. Moreover, the Scientific Council members are divided on how efficient and adequate in effort the administrative procedures of the Joint Call Secretariat are concerning the evaluation of the project proposals. Concerning the time are more positive. Finally, the Scientific Council members had a positive opinion on the web-based Call Management System PT-Outline for the evaluation of the Project proposals

It is worth mentioning here that there was a non-unanimous consensus that the task of the Scientific Council to review the preliminary ranking list prepared by the Joint Call Secretariat and to prepare a final list of all project proposals recommended for funding together with their tentative budgets was fulfilled. This is in line with what is mentioned in conclusion 16.

\subsubsection{The NCPs performance in the evaluation phase.}

Some of the National Contact Points had been contacted by the scientific communities in order to provide support in the evaluation phase. 
Had you been contacted by applicants in the evaluation phase in order to provide support?

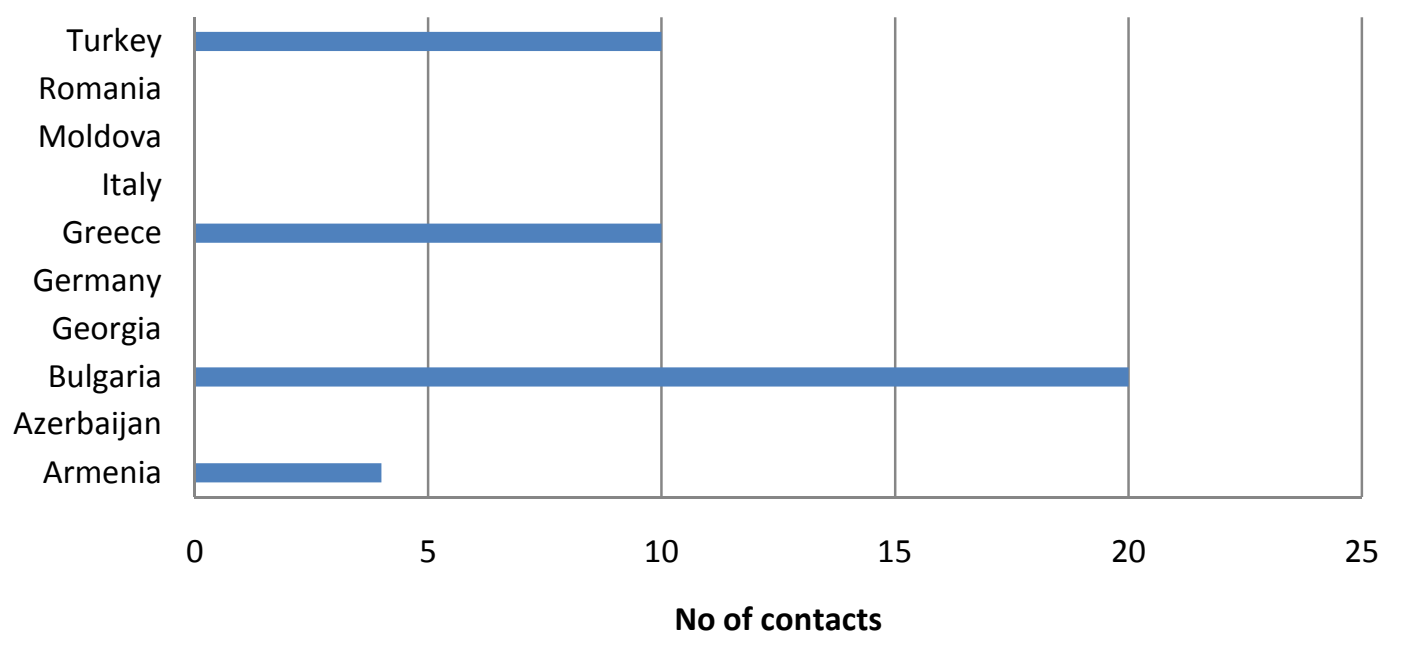

The content of the contacts with the applicants in the evaluation phase was:

The time duration of the evaluation of the proposals (time from the submission to the announcement of the results) was not reasonable

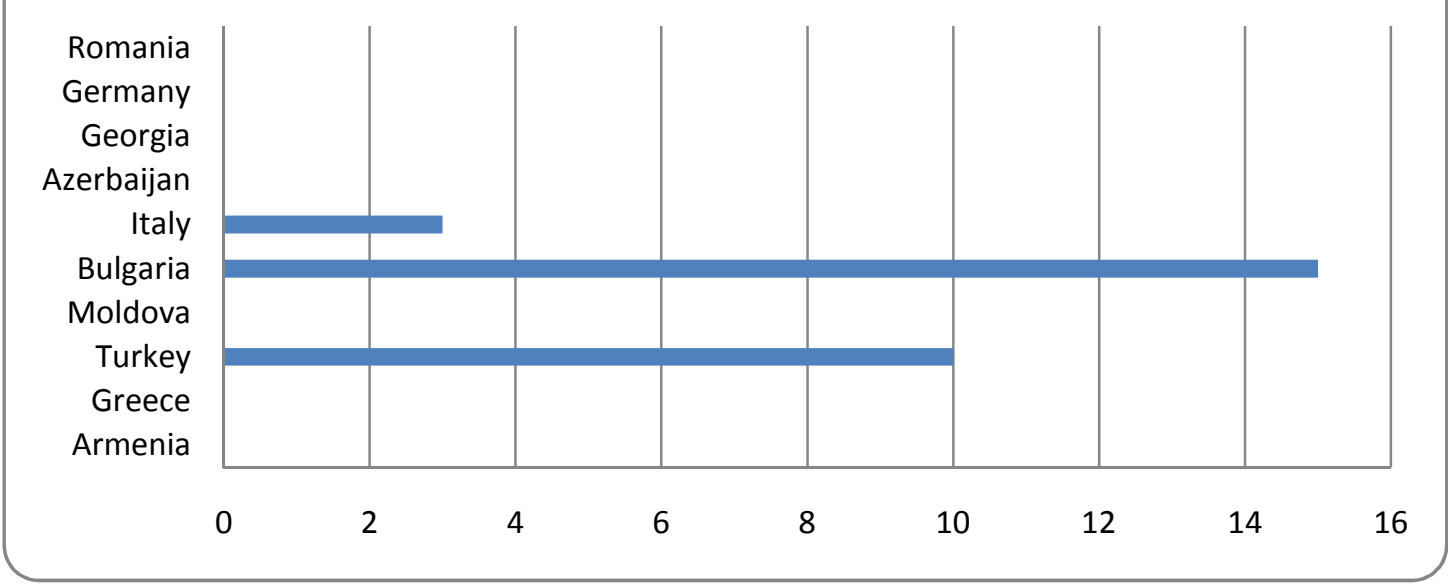

Conclusion 20: Some of the National Contact Points were contacted by the applicants in the evaluation phase in order to complain about the long time duration of the evaluation of their proposals. This is in line with conclusion no 17. 


\subsection{Contracting phase}

\subsubsection{The virtual common pot and the availability of national funds.}

The Pilot Joint Call was implemented through a coordinated funding scheme whereby each funding party funded their own teams within a multilateral project ("Virtual Common Pot"), with a view to harmonize the funding contributions in order to guarantee the funding of as many as possible of the projects selected through a peer review process.

The financial contributions of each Funding Party were topped-up by contribution based on a transfer of INTAS financial assets to the funding parties from the Joint Call Secretariat. The principle was on a pro-rata basis depending on the total actual contribution of each Funding Party in relation to the total financial contribution of the Group of Funding Parties.

The Group of Funding Parties met at Chisinau, Moldova in order to finalize the list of the funded projects based on the ranking list that had been provided by the Scientific Council and the availability of national funds.

Given the fact that for certain countries the allocated national funds were quickly exhausted, the group of funding bodies was forced to skip several highly ranked projects in the ranking list.

More specifically, 11 projects, were finally approved for funding in places $1,2,3,4,5,6,7,8,10,12,20$ down the ranking list.

\begin{tabular}{|l|l|}
\hline Ranked & Funded \\
\hline 1 & Yes \\
\hline 2 & Yes \\
\hline 3 & Yes \\
\hline 4 & Yes \\
\hline 5 & Yes \\
\hline 6 & Yes \\
\hline 7 & Yes \\
\hline 8 & Yes \\
\hline 9 & No \\
\hline 10 & Yes \\
\hline 11 & No \\
\hline 12 & Yes \\
\hline 13 & No \\
\hline 14 & No \\
\hline 15 & No \\
\hline 16 & No \\
\hline 17 & No \\
\hline 18 & No \\
\hline 19 & No \\
\hline 20 & Yes \\
\hline 21 & No \\
\hline
\end{tabular}


The majority of the Scientific Council members remained neutral on the decision of the Group of Funding Parties for the final list of projects to be funded.

The decision of the Group of Funding Parties on the final

list of projects to be funded and on a reserve list of projects eligible for funding was in line with the recommendations of the Scientific Council (\%)

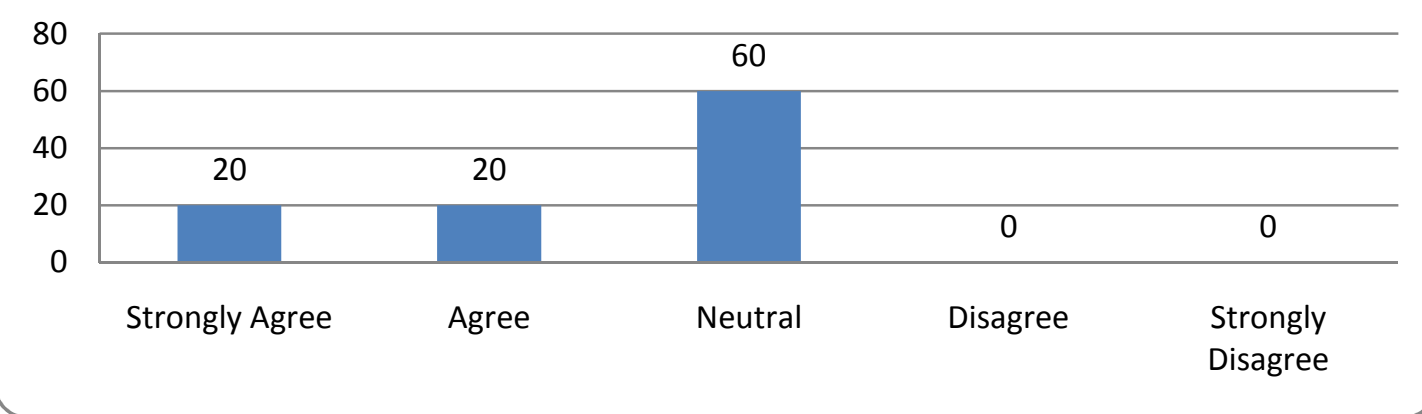

Conclusion 21: Skipping highly ranked projects because of lack of available funds by the funding parties is most usual in all the virtual common pot schemes. Certainly this is unfair for the scientists that were successfully evaluated, they are above the threshold but they can't be funded. There are 2 possible solutions in order to overcome the specific issue:

a. To substitute the virtual common pot with a real common pot where the funding of a project will be dependent exclusively on the scientific excellence.

$b$. Due to the fact that the first solution is difficult to be accepted by almost all the national funding parties, in the future a combination of real and virtual common pot could be used. More specifically, it could be agreed that a standard percentage of the national contributions (i.e. 20\%) will be allocated to a pot that will be used to fund projects which are highly ranked but there is a lack of national funding.

It is very interesting that the majority of the Scientific Council members remain neutral with regard to the decision of the Group of Funding Parties on the final list of projects to be funded. This could be explained in relation with what is mentioned in conclusion 16.

\subsubsection{The successful proposals of the Pilot Joint Call.}

A total number of 66 proposals were submitted in the BS-ERA.NET Pilot Joint Call. After eligibility checks, 55 proposals underwent the evaluation, out of which 11 excellent projects were finally recommended for funding. 
The success rate of the applications in the Pilot Joint Call reached $17 \%$ (taking into account all the submitted proposals before the eligibility checks). The success rate increased to $20 \%$ taking into account the proposals that underwent evaluation after the eligibility checks.

Analyzing the number of successful applicants per country, Romania is leading (11 partners) followed by Germany and Bulgaria (7 partners).

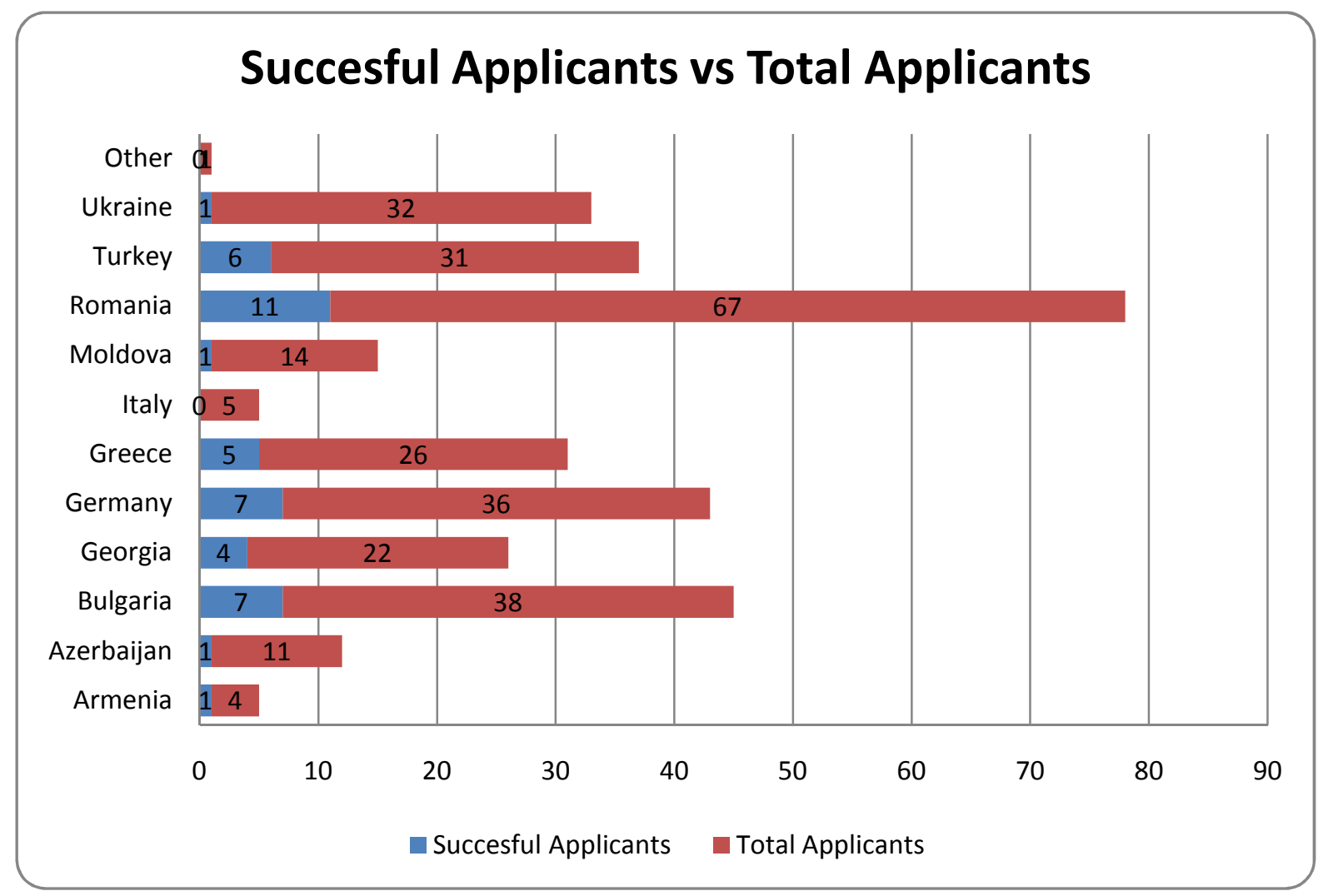

Calculating the success rate as the number of successful applicants over the number of total applicants, Armenia is leading (25\%) followed by Germany, Greece and Turkey (19\%). 


\section{Success Rate (\%)}

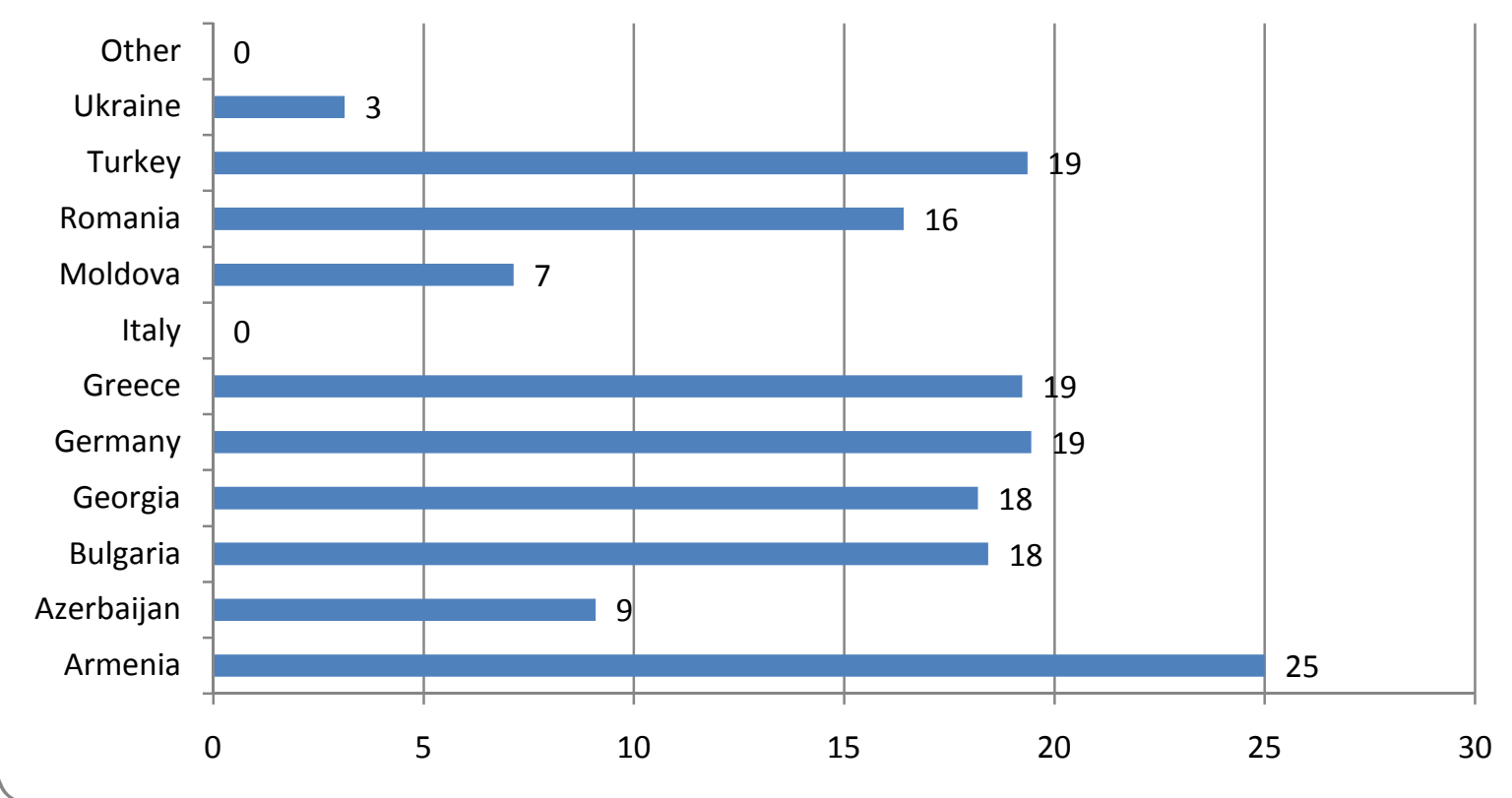

The distribution per topic of the approved proposals is dominated by the water pollution prevention for coastal zones and tourist areas

\section{Approved vs Total Proposals per Topic (after final national eligibility check)}

CO2 capture and storage technologies for zero emission power generation in the Black Sea...

Hydrogen production from $\mathrm{H} 2 \mathrm{~S}$ rich Black Sea Water

Water pollution prevention options for coastal zones and tourist areas

Exploitation and transport of mineral resources: impact on environment

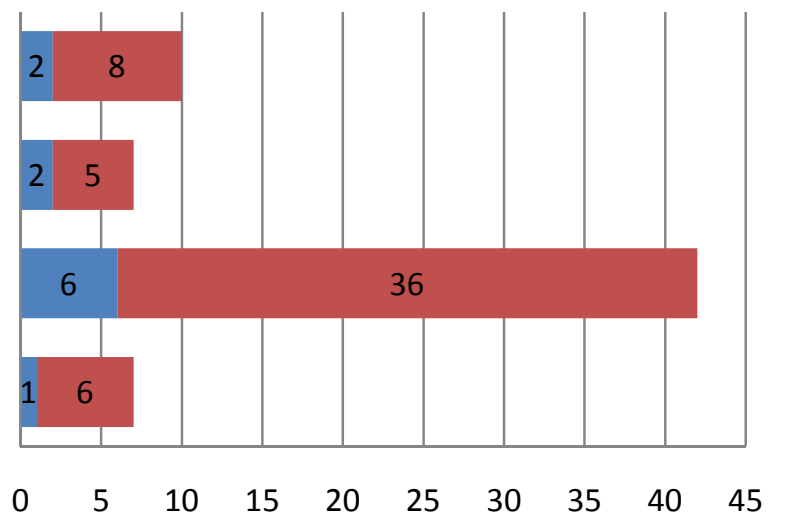

- approved total

Conclusion 22: Analyzing the number of successful applicants per country, Romania is leading (11 partners) followed by Germany and Bulgaria (7 partners). Calculating the success rate as the number of successful applicants over the number of total applicants, Armenia is leading (25\%) followed by Germany, Greece and Turkey (19\%). The distribution per topic of the approved proposals is dominated by the water pollution prevention for coastal zones and tourist areas. 


\subsubsection{The quality of the approved for funding projects of the Pilot Joint Call.}

The Scientific Council found the Scientific Merit of the projects recommended for funding to be high.

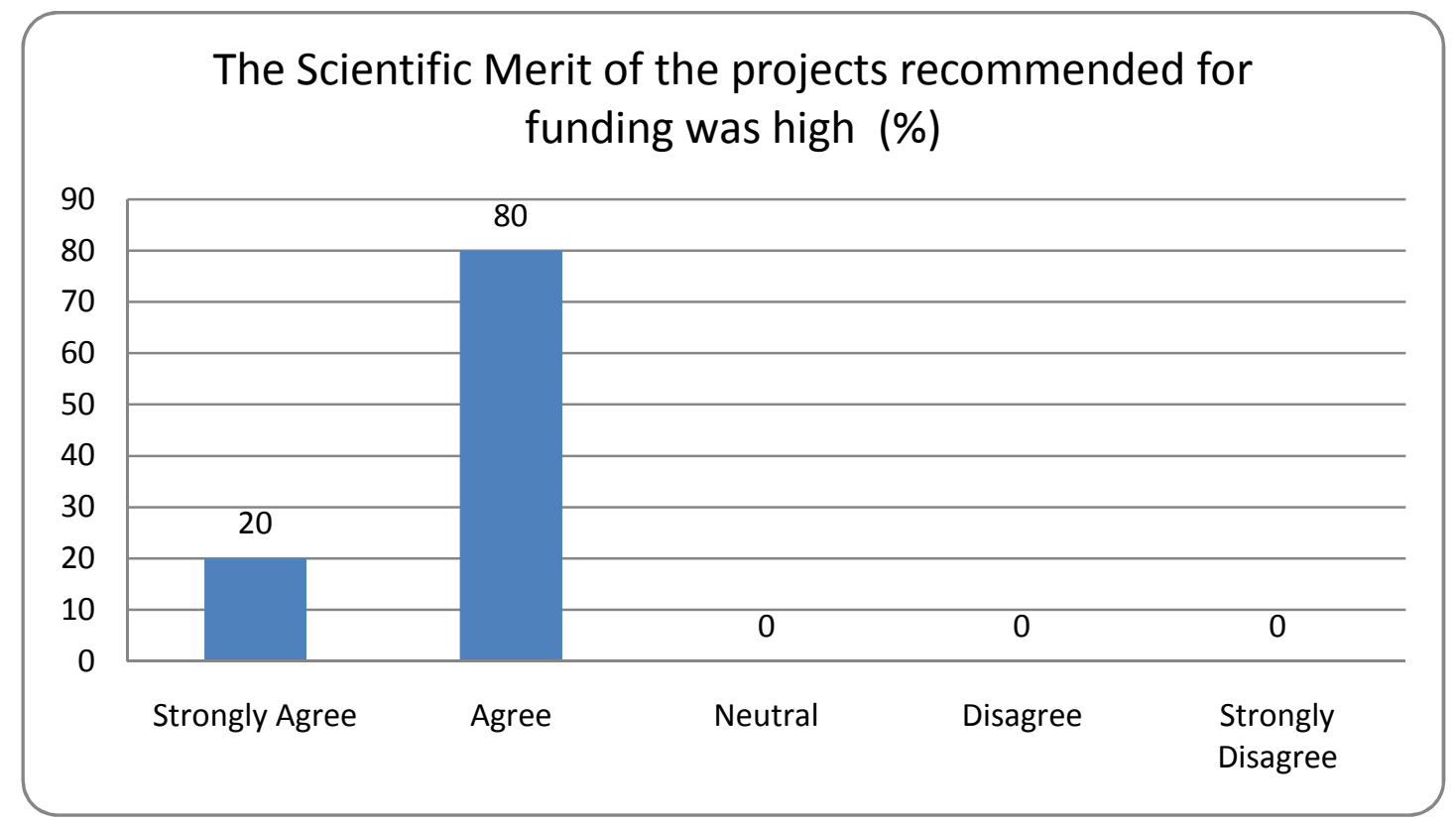

The Scientific Council pointed out that the expected impact of the projects recommended for funding was high.

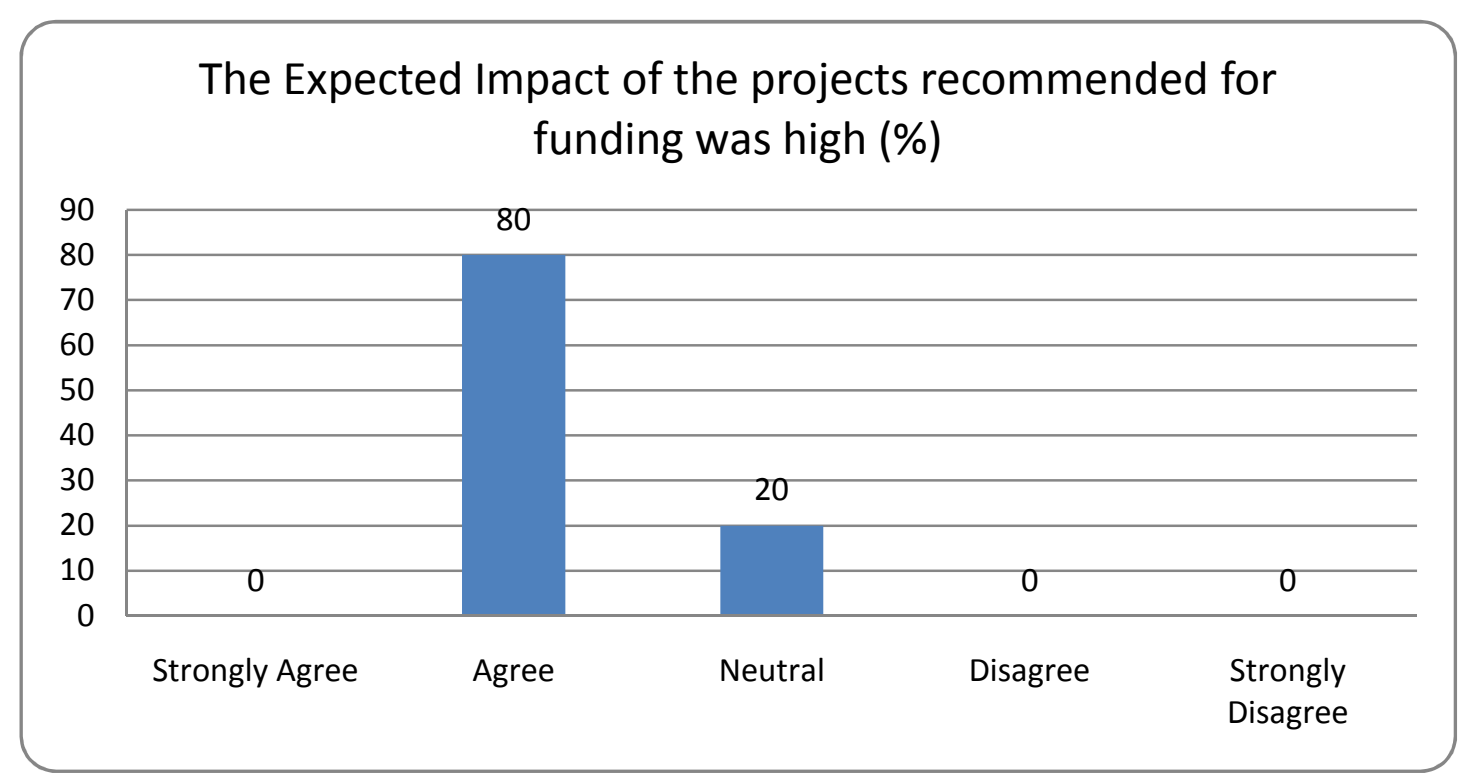


All the responding members of the Scientific Council declared the high quality of the consortium of the projects recommended for funding.

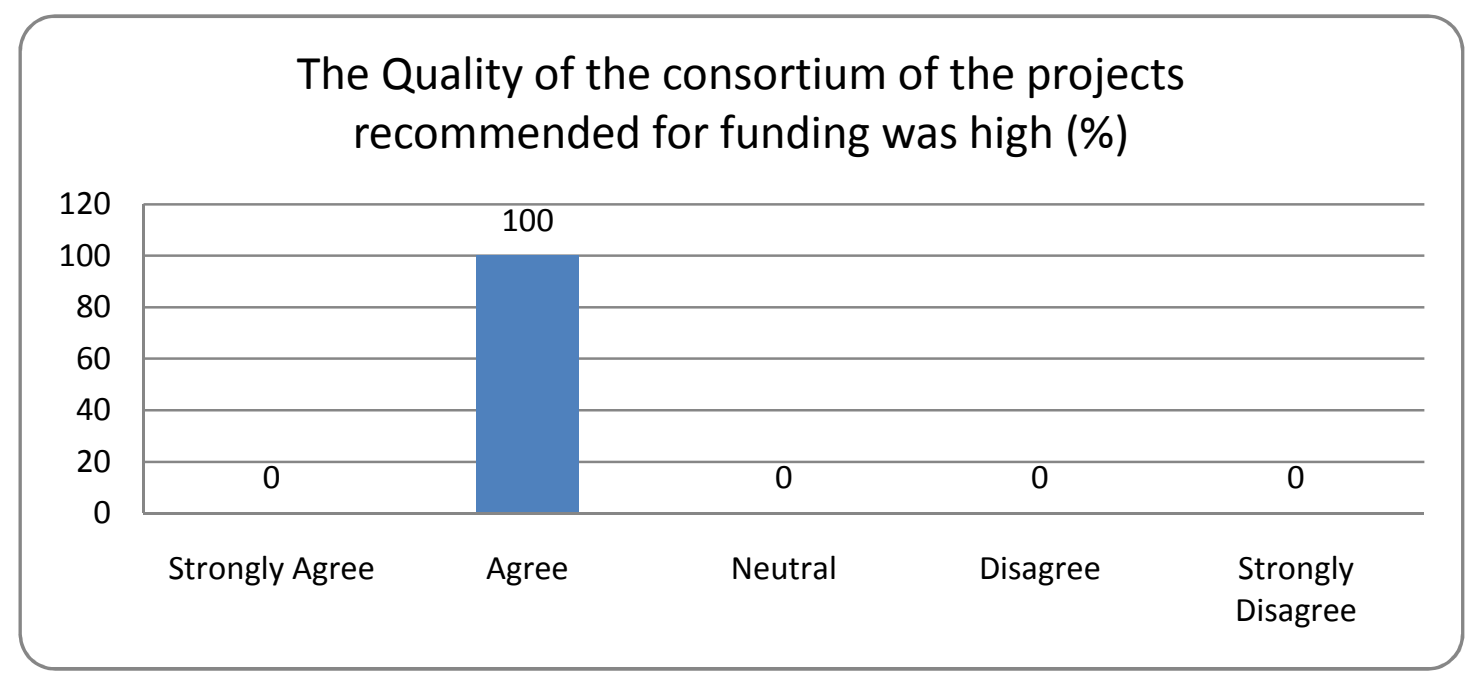

Almost all the responding members of the Scientific Council declared the quality of the management of the projects recommended for funding to be high.

The Quality of the project management of the projects recommended for funding was high (\%)

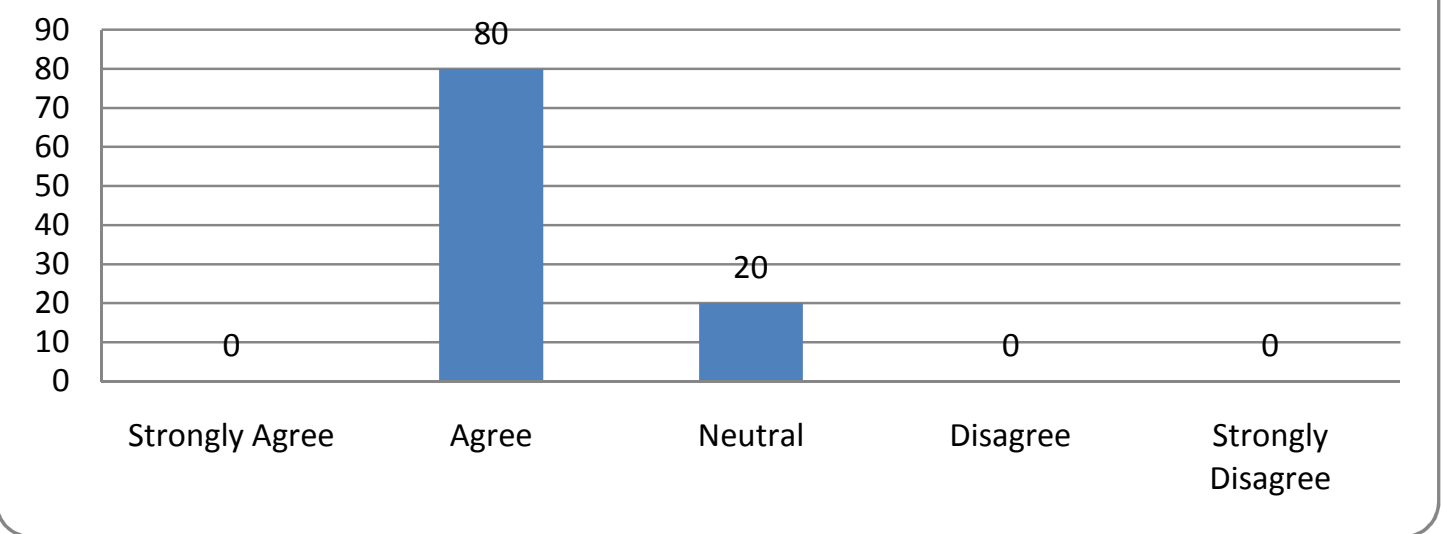


Almost all the responding members of the Scientific Council declared the quality of the presentation of the proposals of the projects recommended for funding to be high.

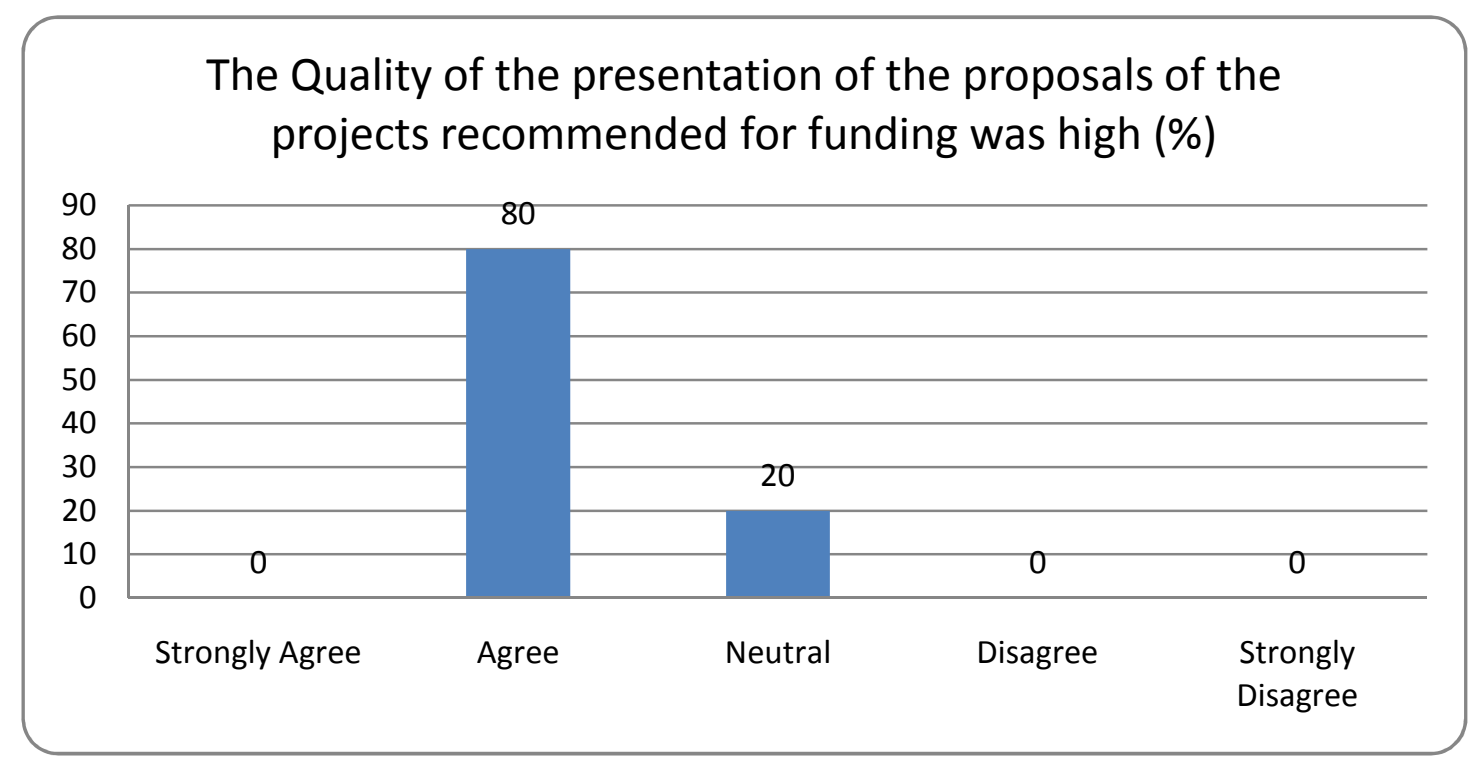

The Scientific Council was not convinced about the tentative budgets of the projects recommended for funding being reasonable and well justified.

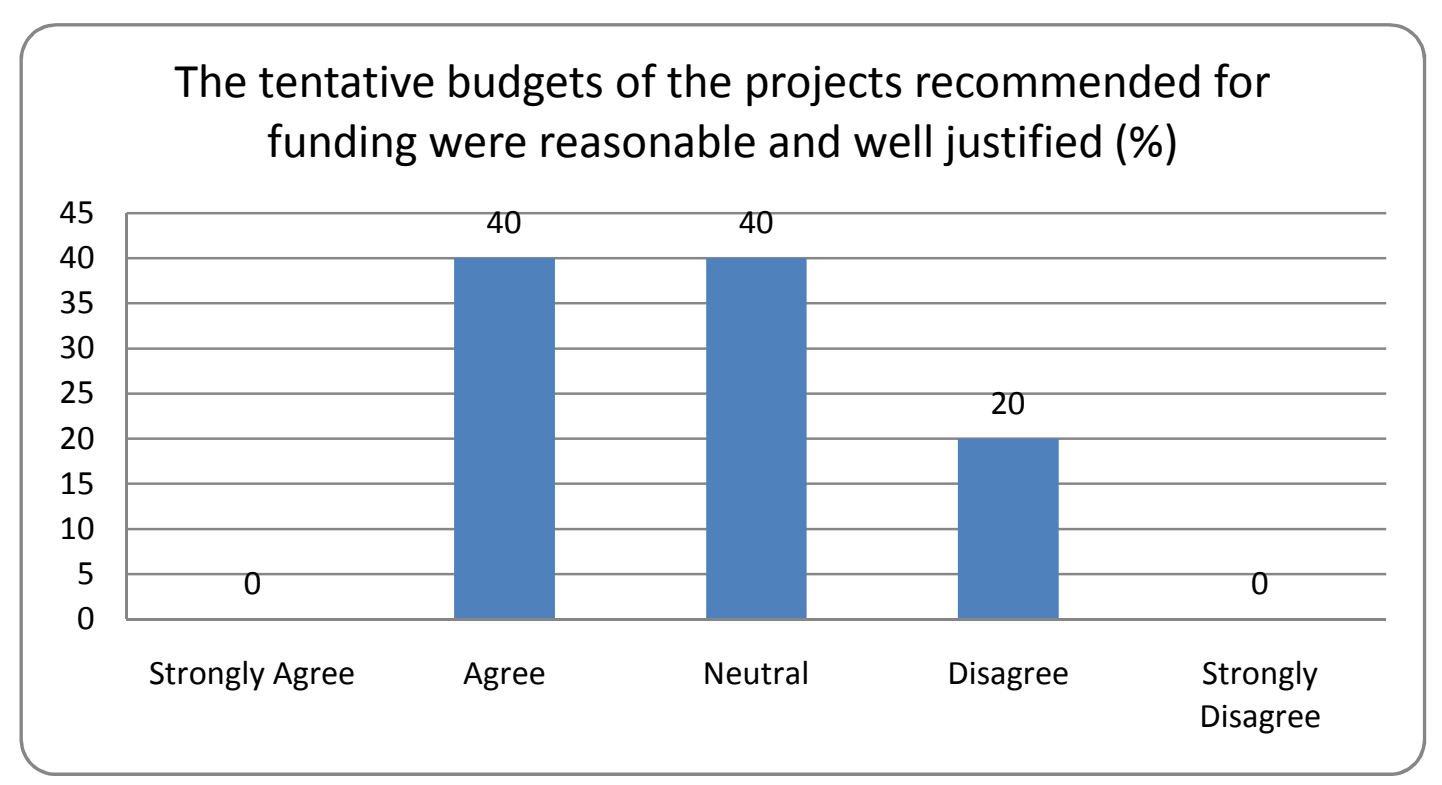


Conclusion 23: The Scientific Council considered the scientific merit and the expected impact of the projects recommended for funding to be high. Moreover, all the responding members of the Scientific Council declared the quality of the consortium of the projects, the quality of the management of the projects, the quality of the presentation of the proposals of the projects recommended for funding to be high.

The Scientific Council was not convinced that the tentative budgets of the projects recommended for funding were reasonable and well justified.

\subsubsection{Project Contracting}

For each project approved for funding, the Joint Call Secretariat executed an Umbrella Project Contract to be signed both by the Joint Call Secretariat on behalf of the Group of Funding Parties and by each Coordinating institution of a consortium.

Umbrella Project Contracts were complemented by National Project Contracts between each participating institution in a consortium and its corresponding Funding Party. Those contracts prepared the legal ground for project funding at national level according to the rules and regulations of the respective Funding Party.

A significant number of successful applicants pointed out that the administrative procedures of the Joint Call Secretariat concerning the Umbrella Project Contract were not efficient and adequate time wise

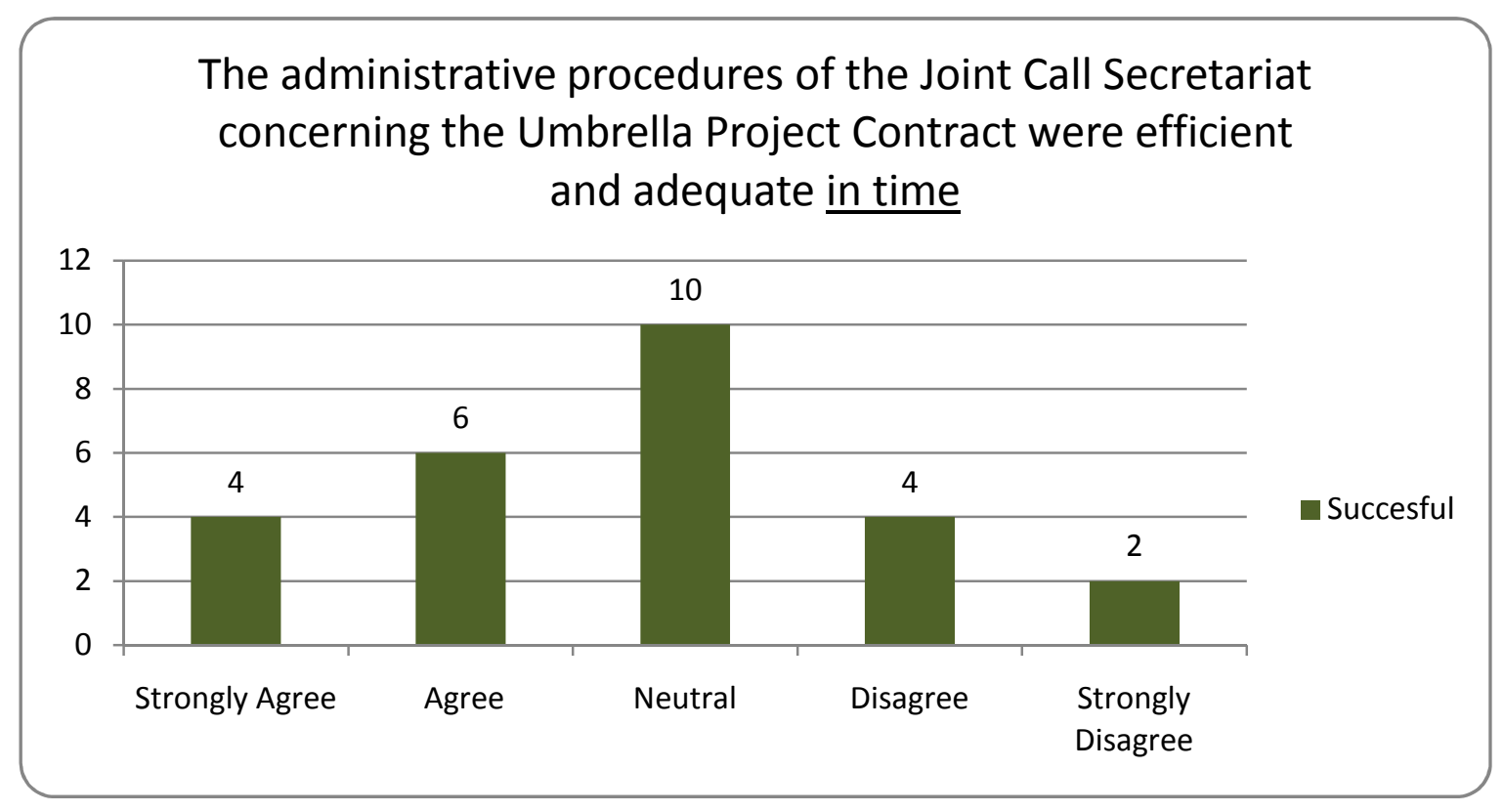


Most of the successful applicants found the administrative procedures of the Joint Call Secretariat concerning the Umbrella Project Contract to be efficient and adequate effort wise

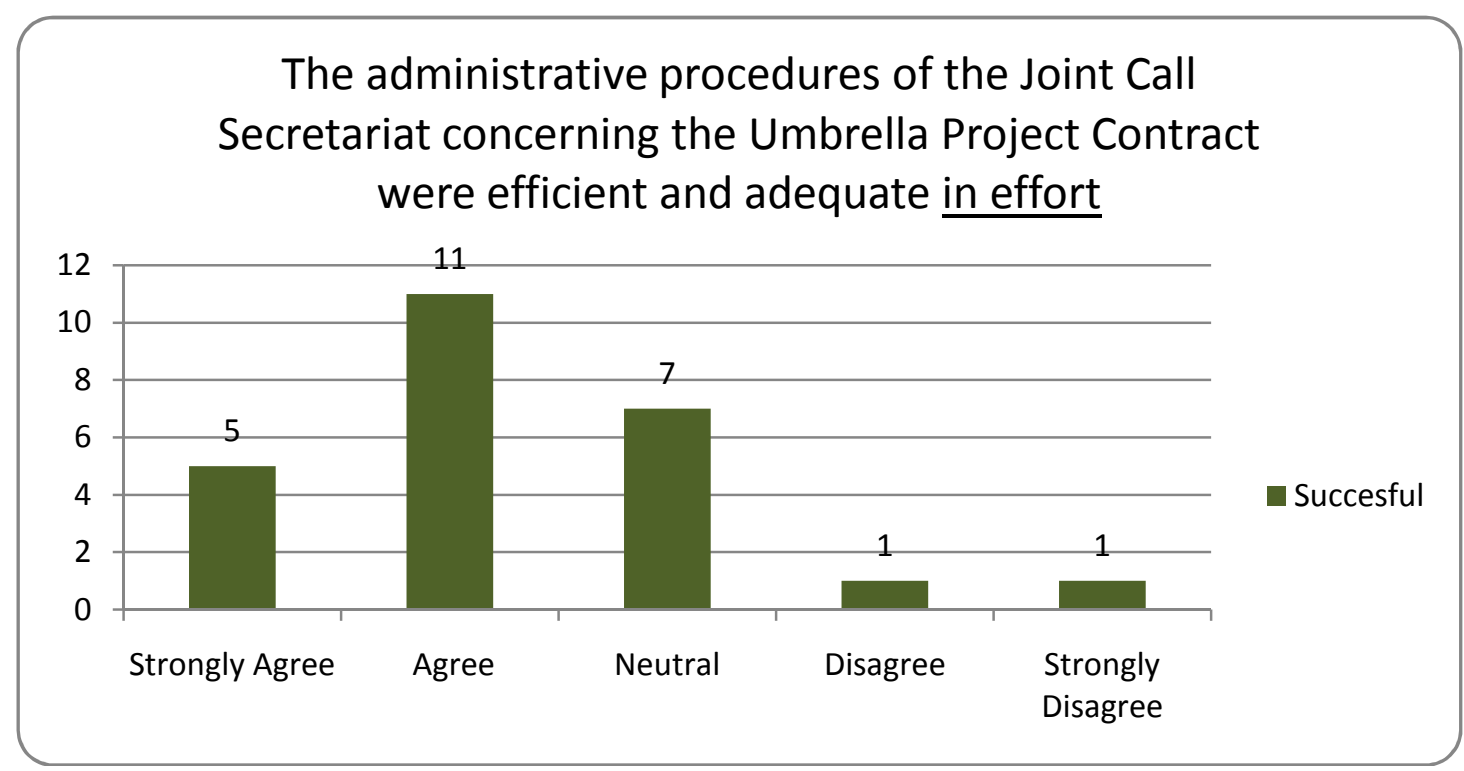

All the funding parties with the exception of the Greek one, agreed that the administrative procedures of the Joint Call Secretariat concerning the Umbrella Project Contract were efficient and adequate both effort and time wise.

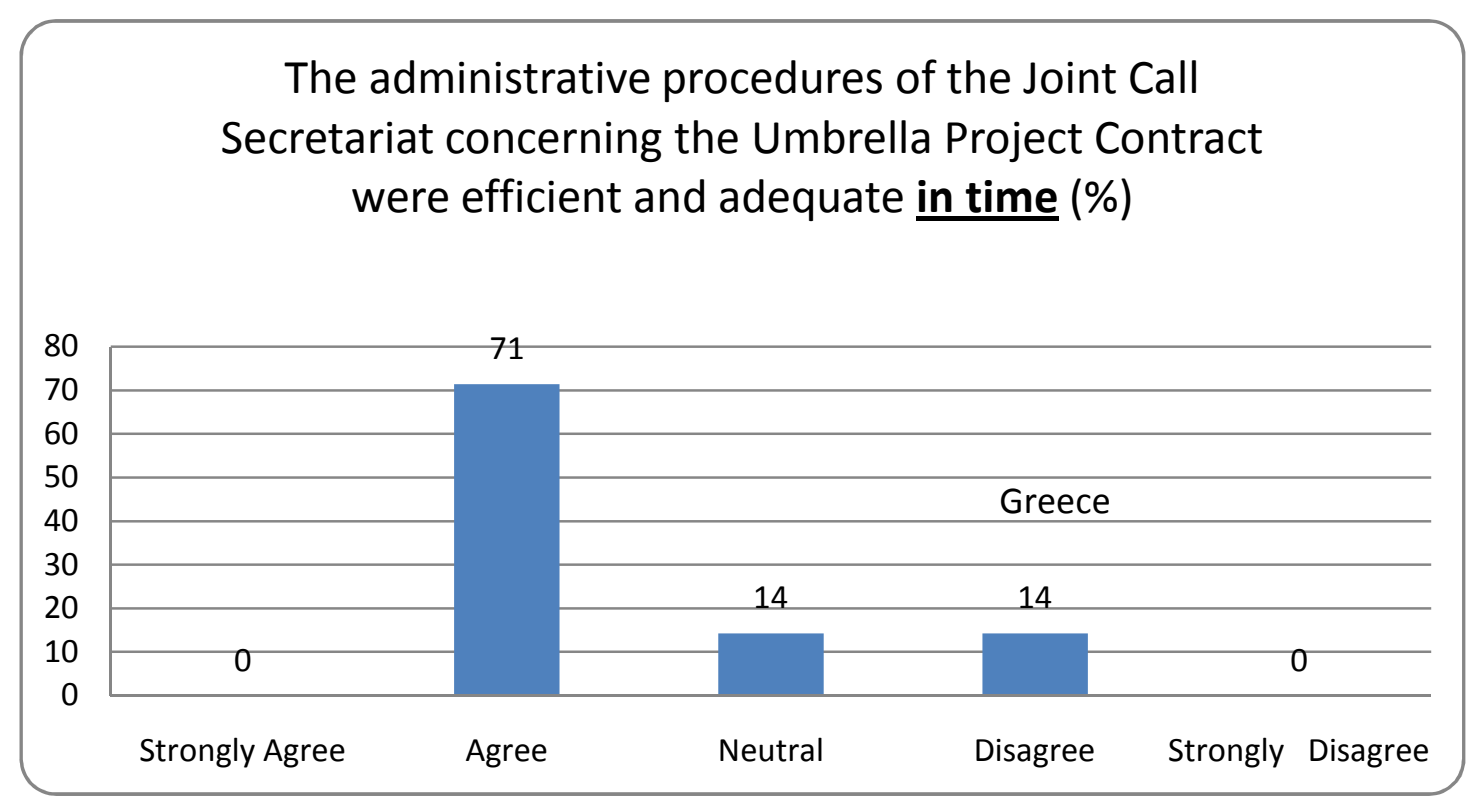




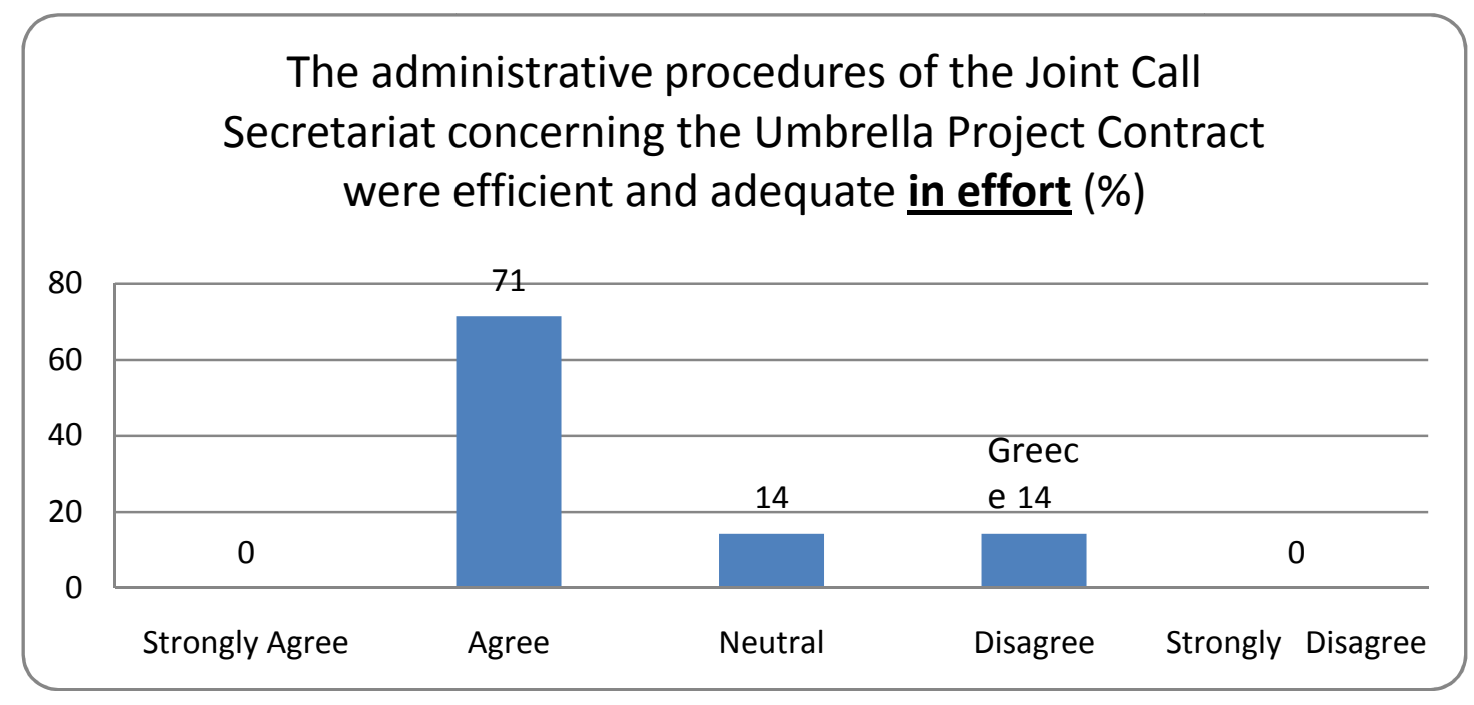

A significant number of successful applicants pointed out that the administrative procedures of their Funding Party concerning the National Project Contract were not efficient and adequate both time and effort wise.

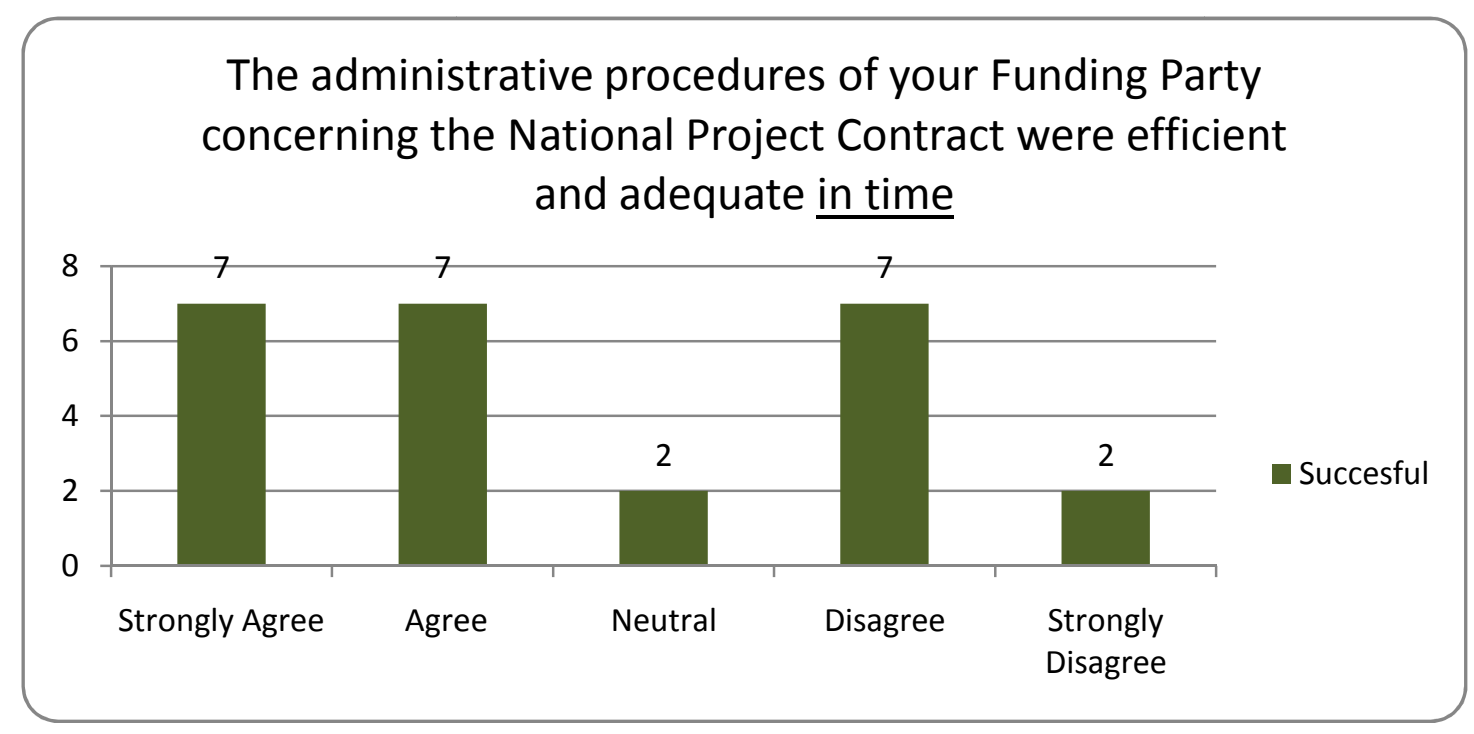




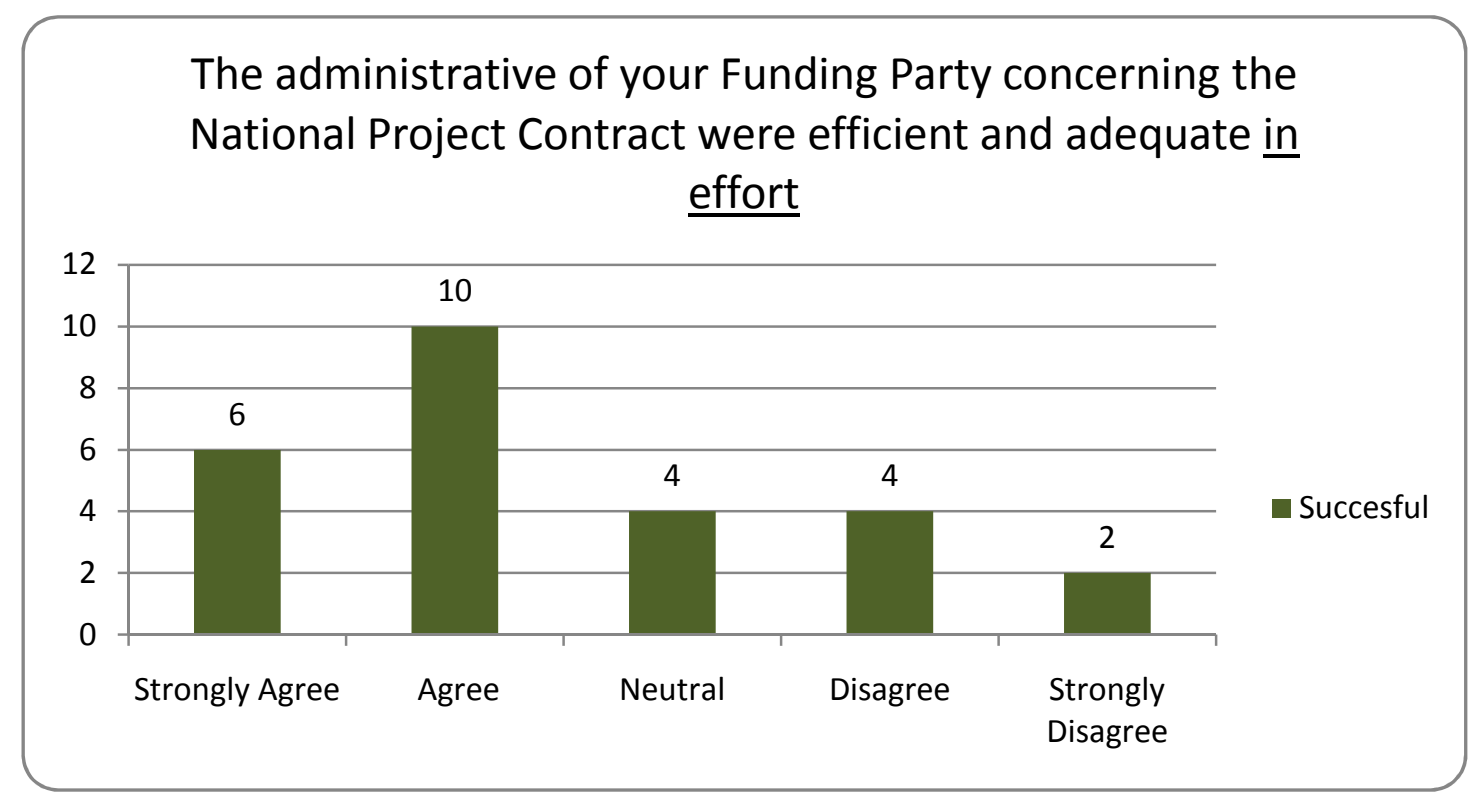

All the funding parties with the exception of the Bulgarian one, agreed that the administrative procedures of their Funding Party concerning the National Project Contract were efficient and adequate both time and effort wise.

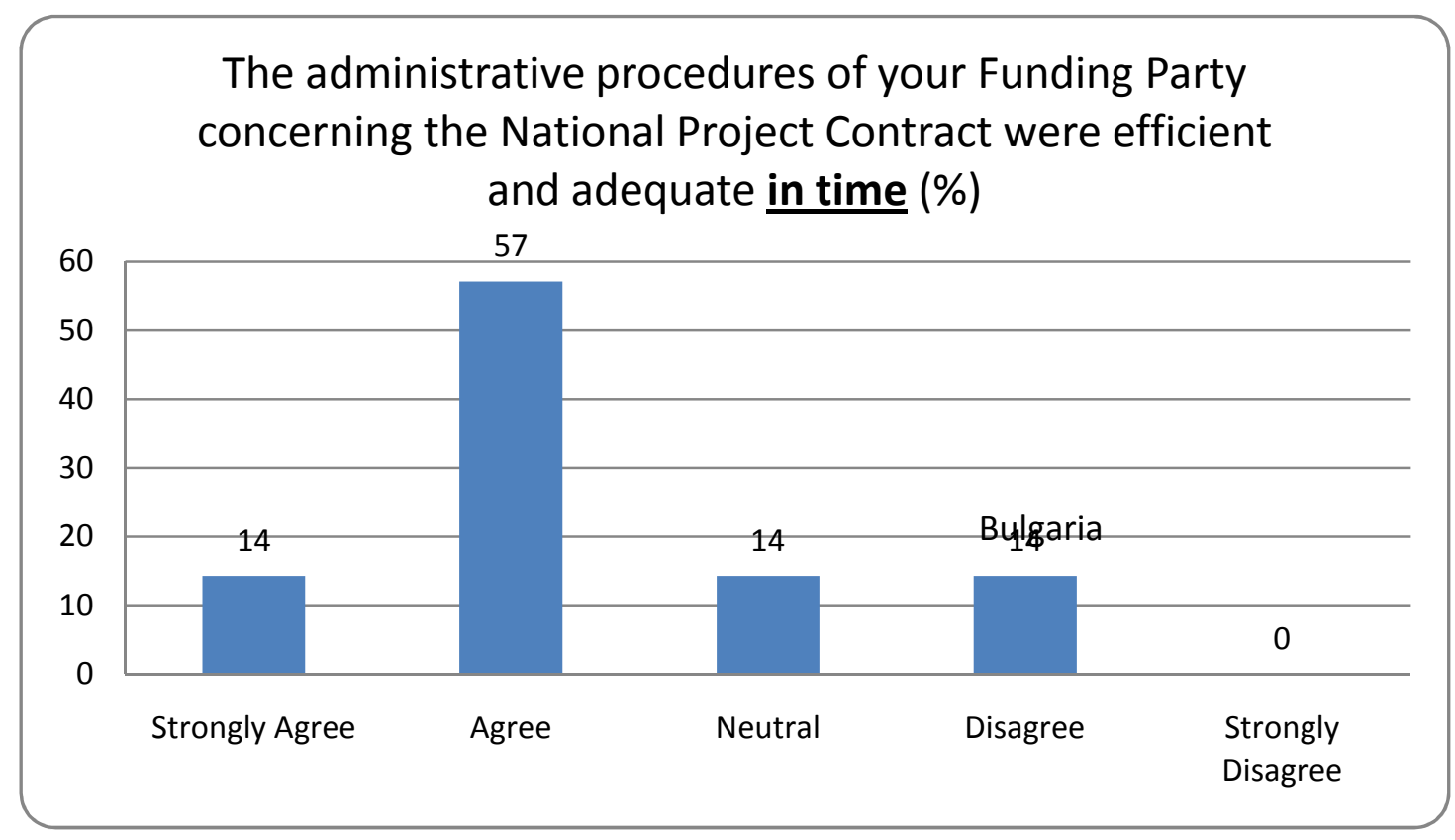




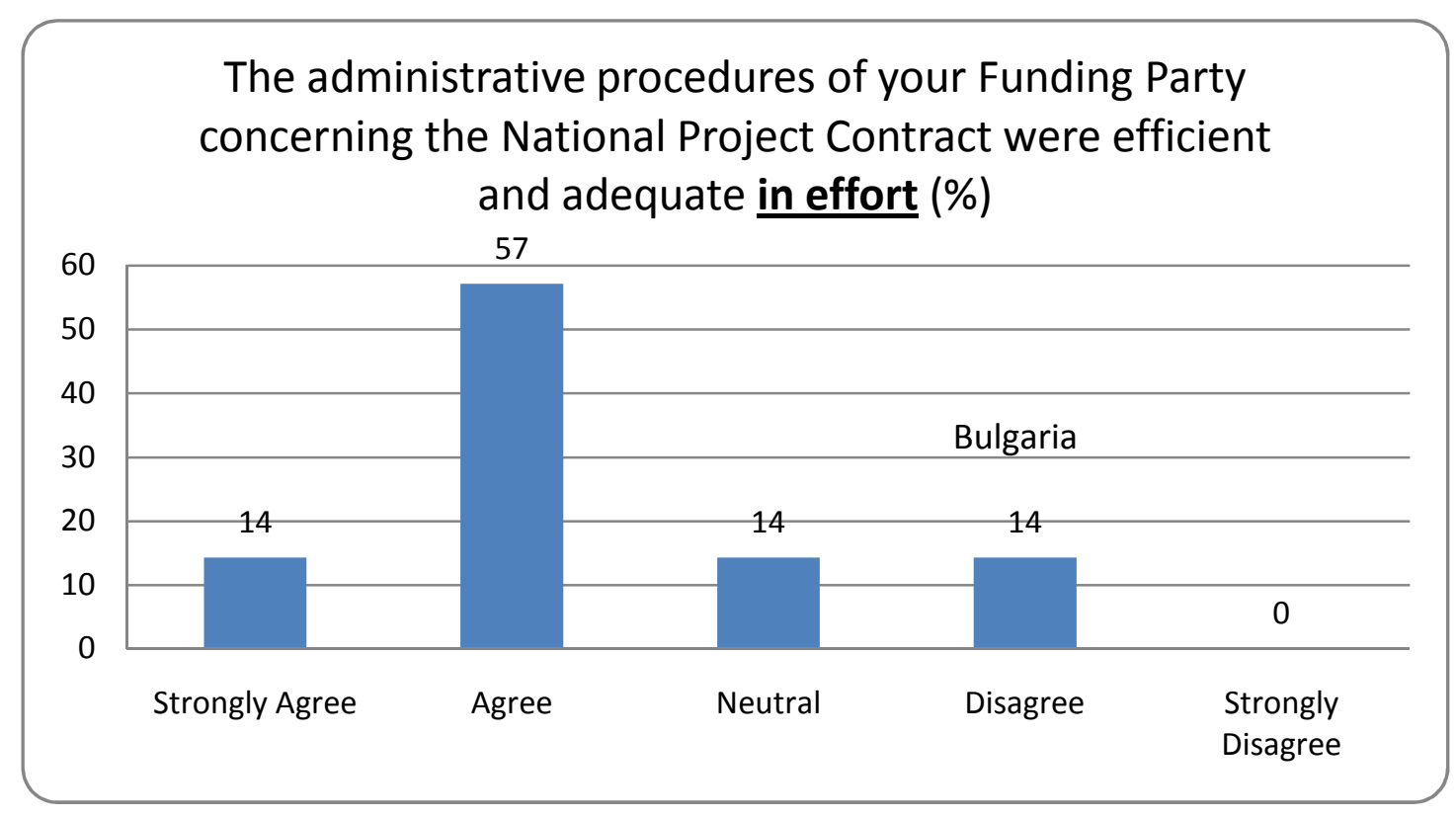

Conclusion 24: As mentioned earlier, in the double eligibility check for every submitted project it is unavoidable not to have a double contracting procedure for every approved for funding project:

a. For each funding approved project the Joint Call Secretariat executed an Umbrella Project Contract to be signed both by the Joint Call Secretariat on behalf of the Group of Funding Parties and by each Coordinating institution of a consortium.

b. Umbrella Project Contracts were complemented by National Project Contracts between each participating institution in a consortium and its corresponding Funding Party. Such contracts prepared the legal ground for project funding at national level according to the rules and regulations of the respective Funding Party.

This double contracting procedure was requested due to the virtual common pot scheme and the national funding of the approved projects which is based on the national rules and regulations.

It is easily understood that this double contracting process can cause serious delays in the contracting of the projects. A significant number of successful applicants pointed out that the administrative procedures of the Joint Call Secretariat concerning the Umbrella Project Contract as well as their Funding Party concerning the National Project Contract were not efficient and adequate time and effort wise.

All funding parties with the exception of the Greek one agreed that the administrative procedures of the Joint Call Secretariat concerning the Umbrella Project Contract were efficient and adequate time and effort wise. All the funding parties with the exception of the Bulgarian one agreed that the administrative procedures of their Funding Party concerning the National Project Contract were efficient and adequate time and effort wise. 


\subsubsection{The NCPs performance in the contracting phase.}

The National Contact Points were contacted by the scientific communities in order to provide support in the contracting phase.

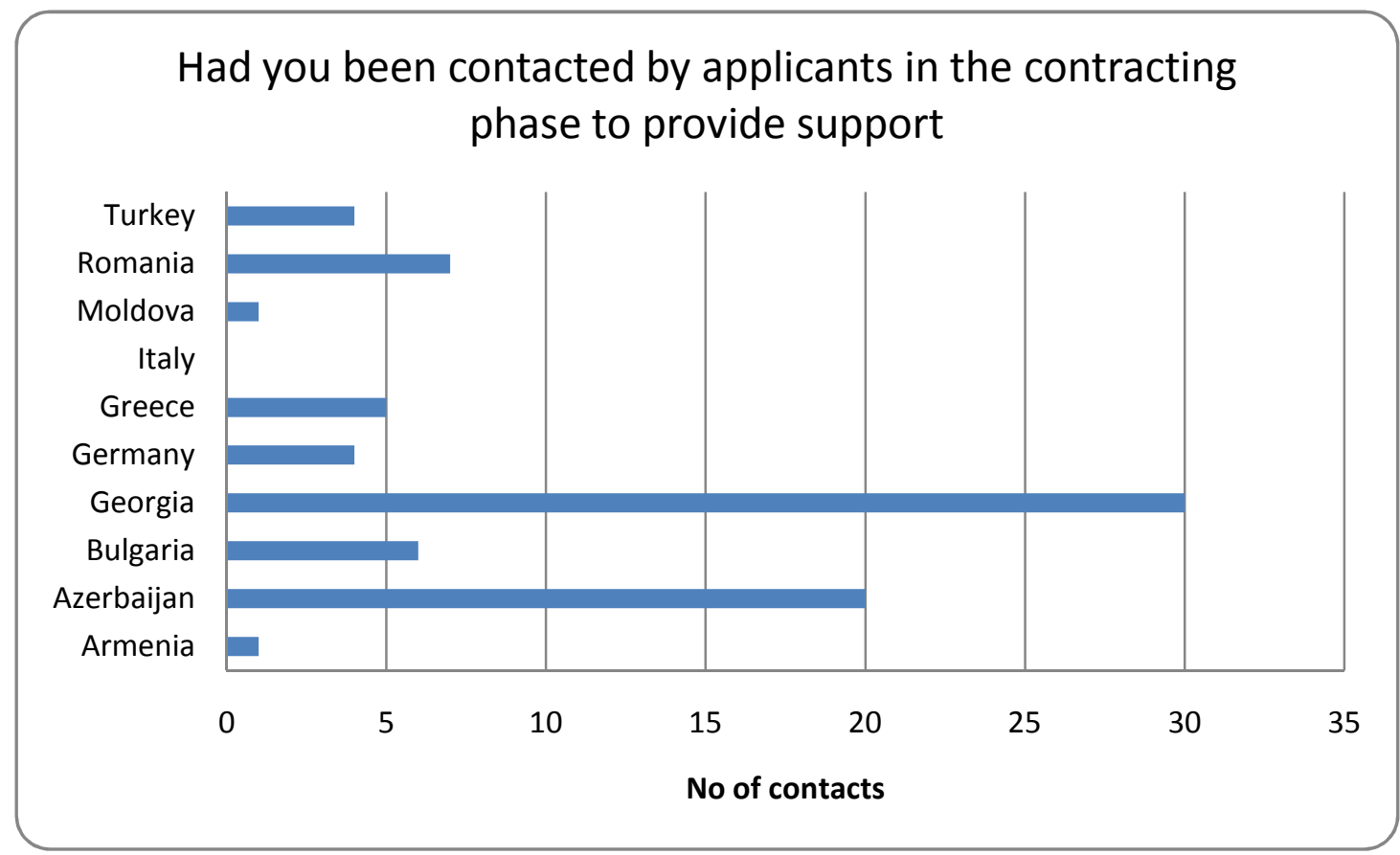

Conclusion 25: All the National Contact Points were contacted by the partners of the approved project in order to provide support in the contracting phase and more specifically for the completion of the contracts.

\subsection{Monitoring phase}

\subsubsection{The funding of the approved projects}

It has been reported that in many cases the first funding rate for the project partners was not synchronized in time by the funding parties. A common case was that for specific approved projects there were partners that had received their funding while others in the same project still waiting for their funding in order to start their work. Especially for projects where their scientific discipline was related with periodic measurements in the field such a delay in funding flow could seriously affect the quality of the scientific work. 
Many of the approved projects' partners reported that the transfer of the first funding rate was not efficient and not adequate time wise.

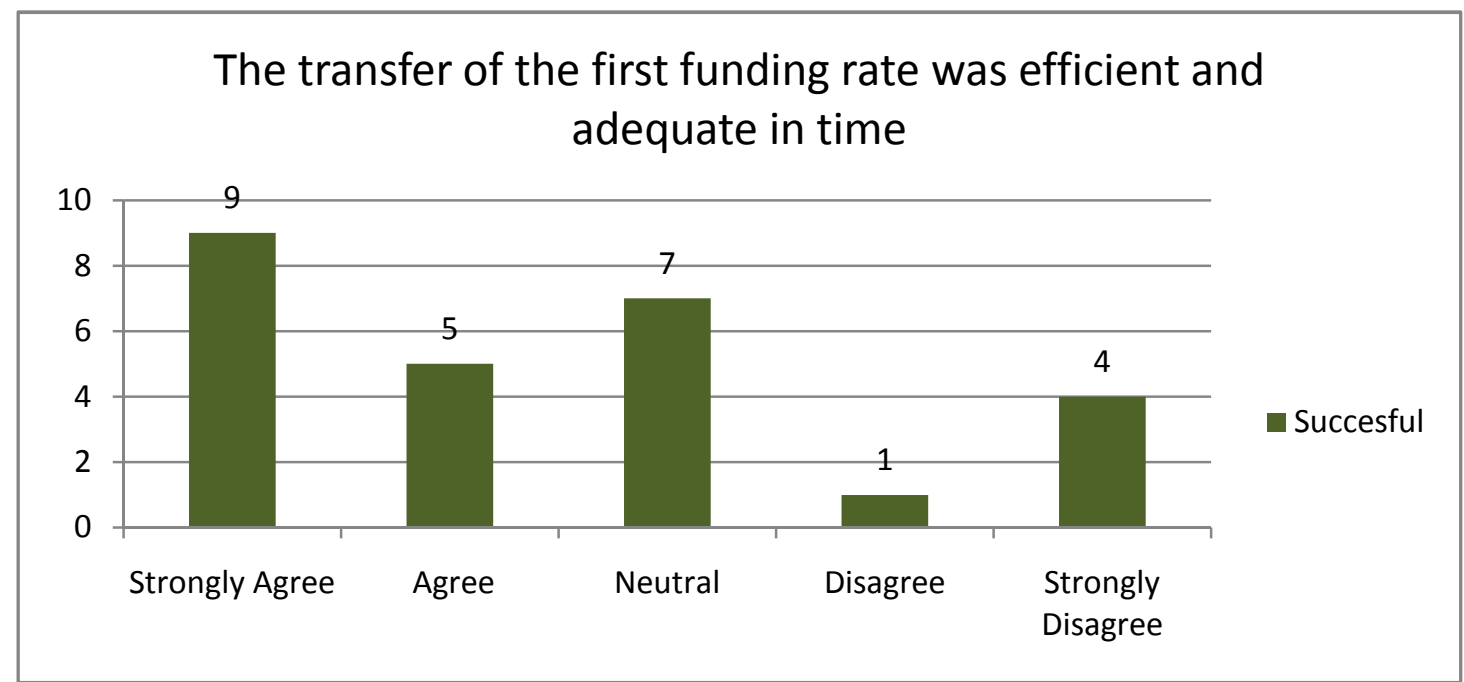

The same view was also expressed in the answers of the members of the funding parties.

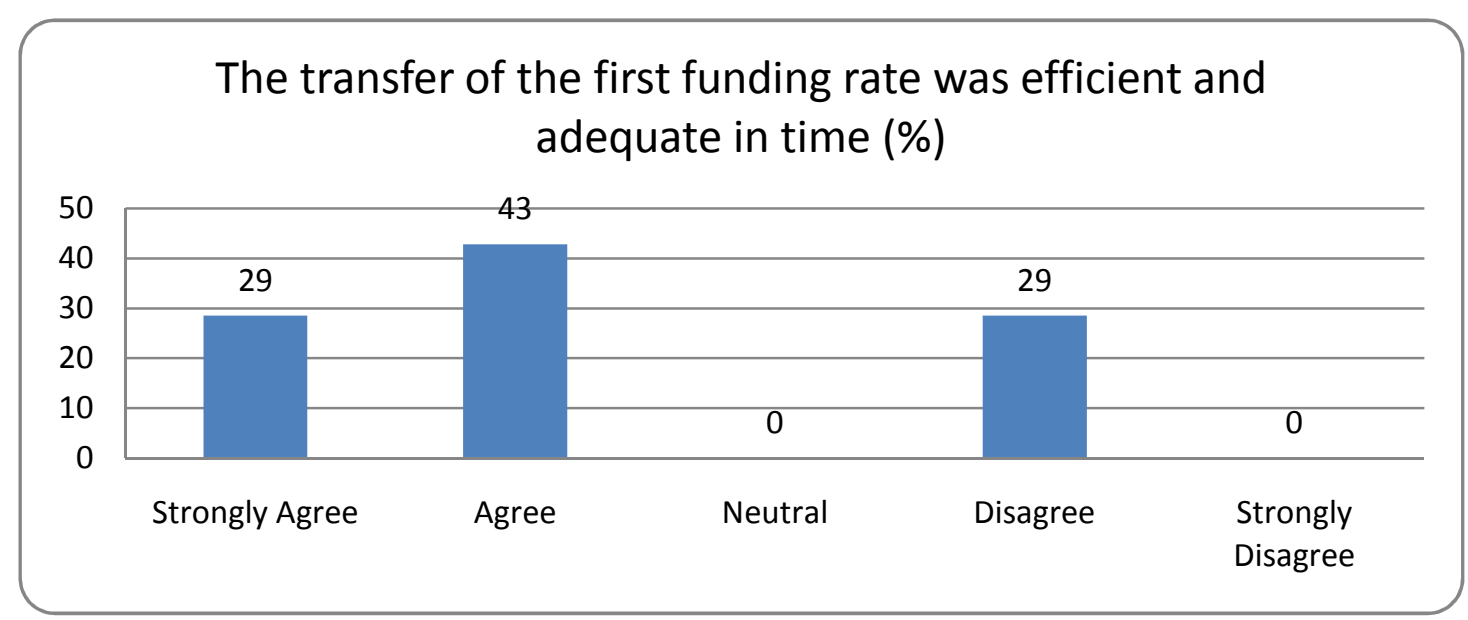

Conclusion 26: A project should have a common starting date for all involved partners, since in a joint research project the scientific work of the different scientific teams is intertwined and interacted. Furthermore, the flow of funds to the different partners of a project should be synchronized for reasons of providing sufficient resources to accomplish the required research work. 
In projects that it was reported that the first funding rate to the project partners was not synchronized, was not efficient and not adequate in time the scientific quality of their implementation could be affected.

It is very interesting that this important issue is also highlighted in the answers of the members of the funding parties.

\subsubsection{The monitoring of the approved projects}

The partners of the approved projects are mostly satisfied with the effective monitoring of their projects by the Joint Call Secretariat.

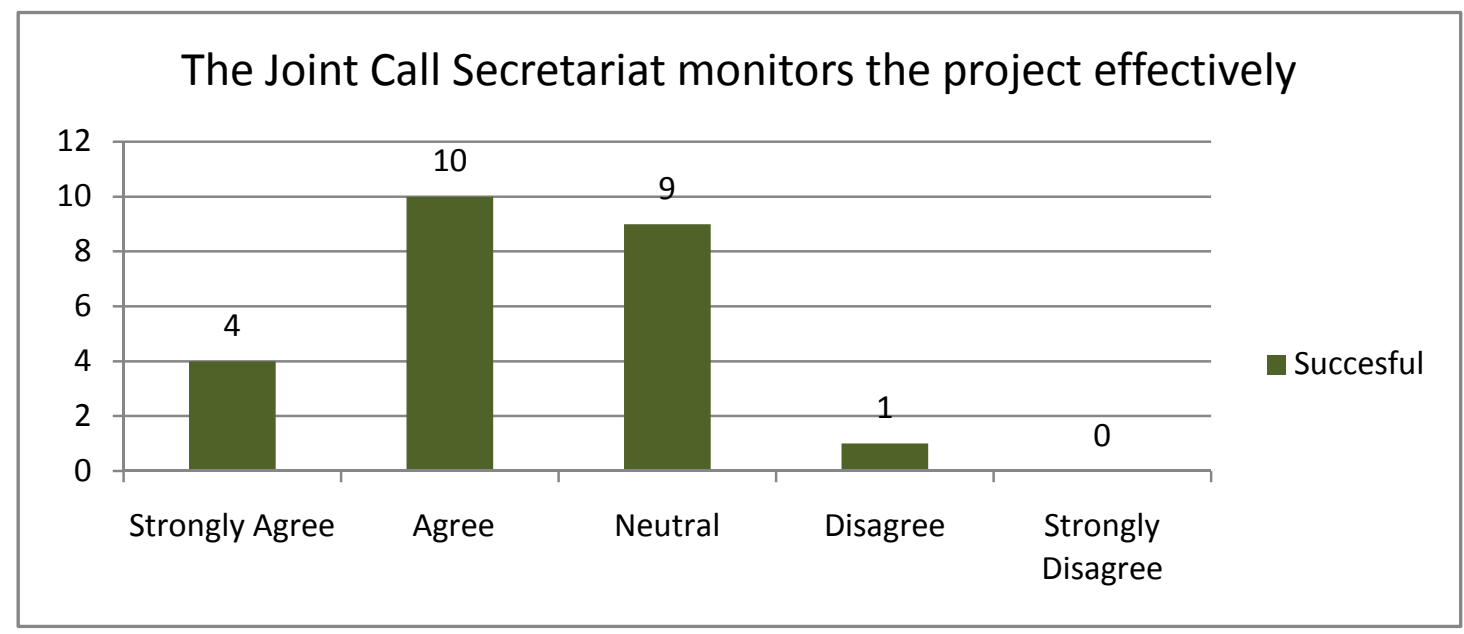

The majority of the group of funding parties presents a neutral approach regarding the effective monitoring of the approved projects by the Joint Call Secretariat.

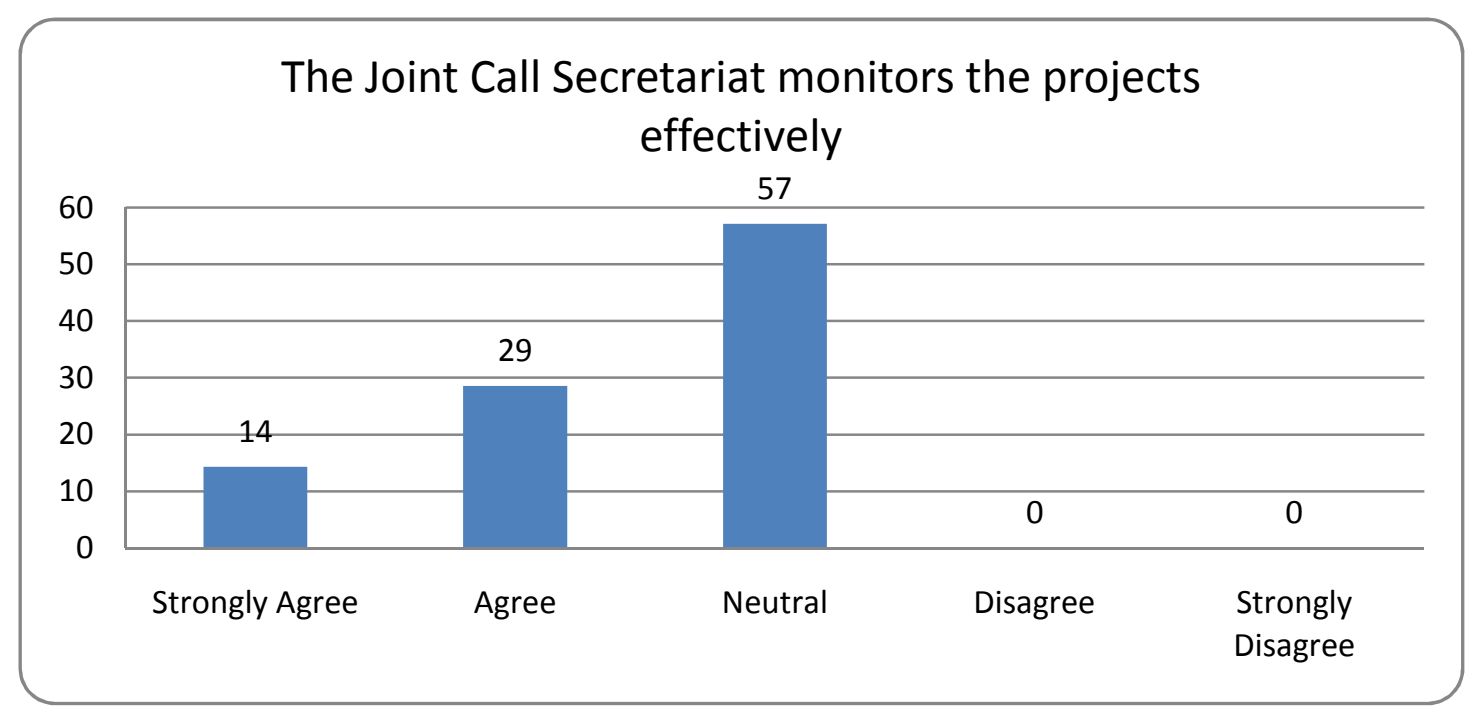


Conclusion 27: The partners of the approved projects are mostly satisfied with the effective monitoring of their projects by the Joint Call Secretariat while the majority of the group of funding parties presents a neutral approach regarding the effective monitoring of the approved projects by the Joint Call Secretariat.

\subsubsection{The NCPs performance in the monitoring phase.}

The National Contact Points had been contacted by the scientific communities in order to provide support in the monitoring phase.

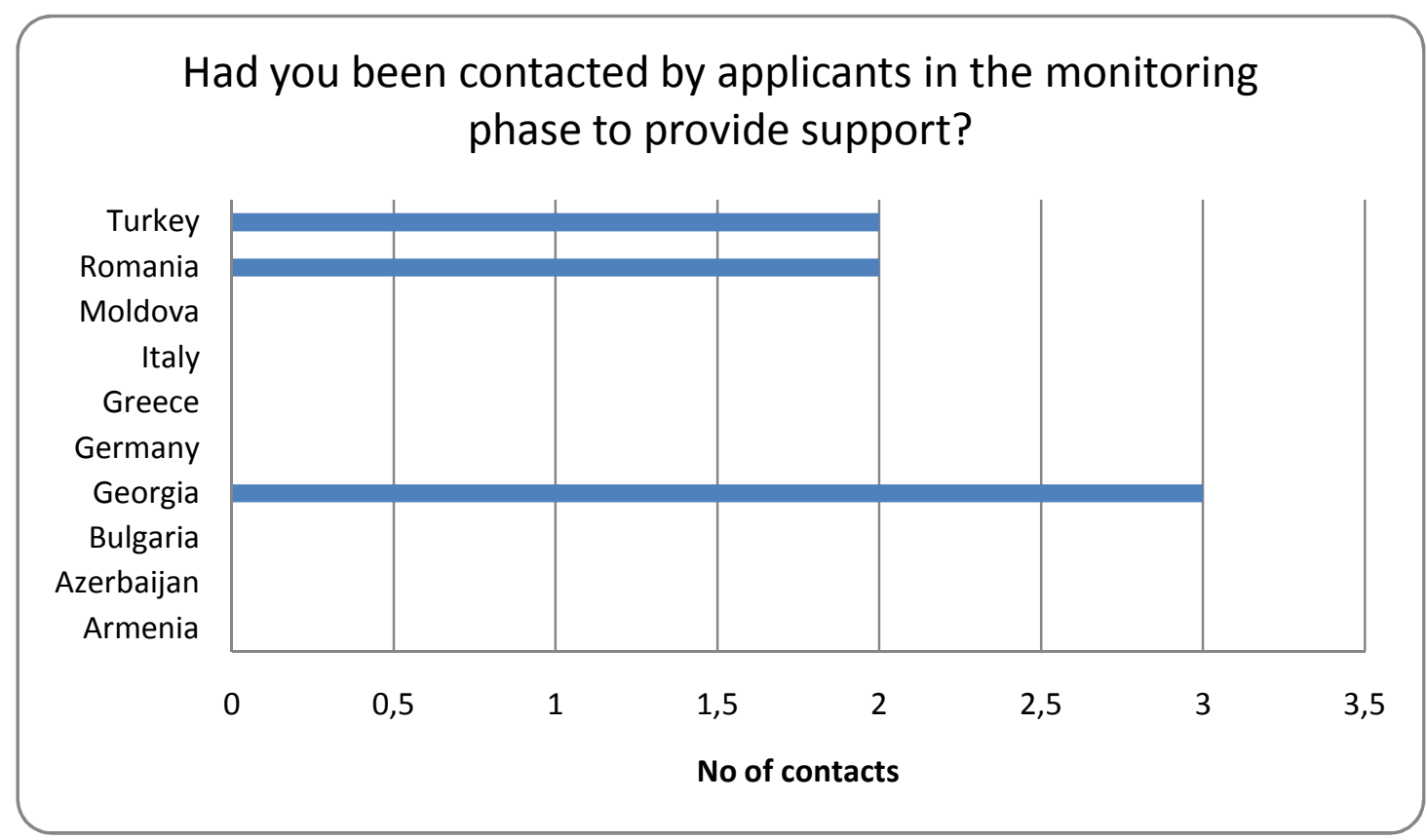

Conclusion 28: Only 3 National Contact Points were contacted by the researchers in order to provide support in the monitoring phase. 


\subsection{Impact of efficiency of the Pilot Joint Call}

The majority of the project partners stated that without funding from the PJC, the specific projects would never have been implemented.

What was the impact of the PJC to the implementation of your project

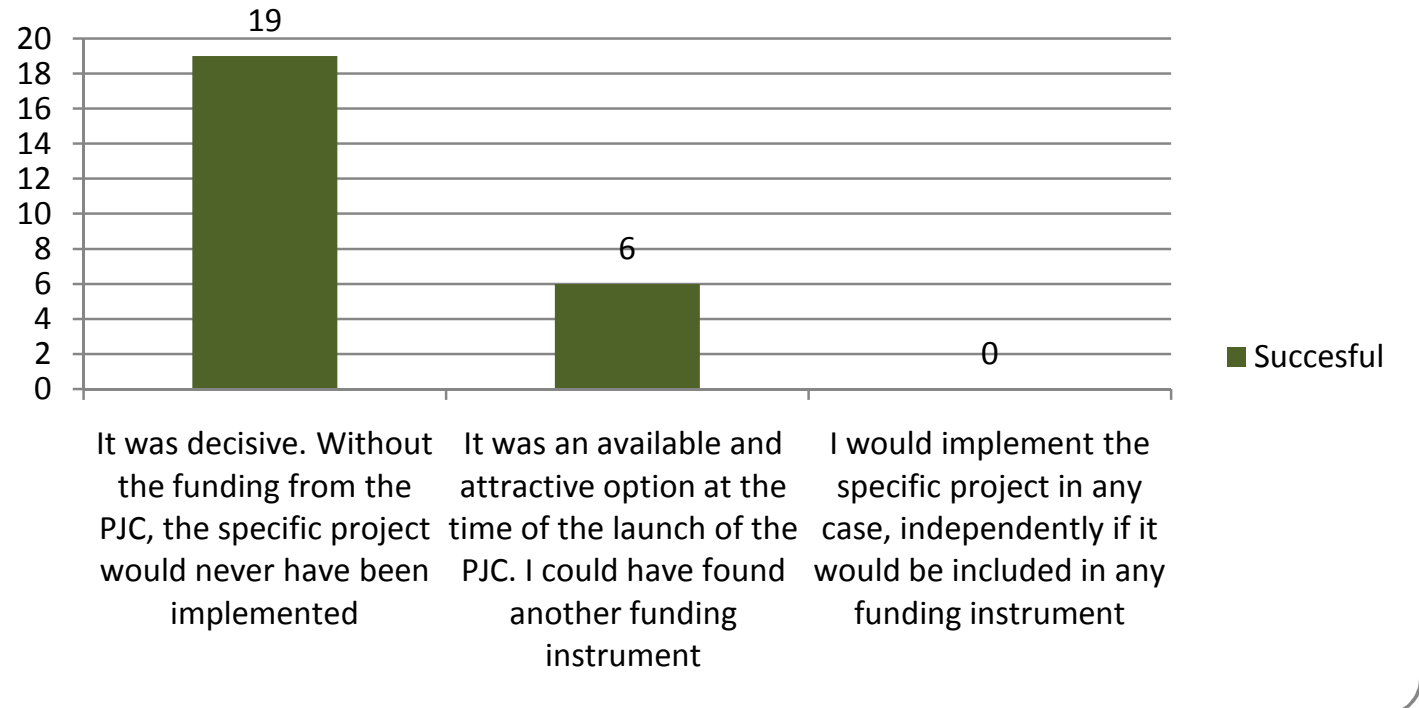

On the other hand, the members of the funding parties consider that beyond the PJC the partners could have found another funding instrument from their organization.

What was the impact of the PJC to the implementation of your funded projects (\%)

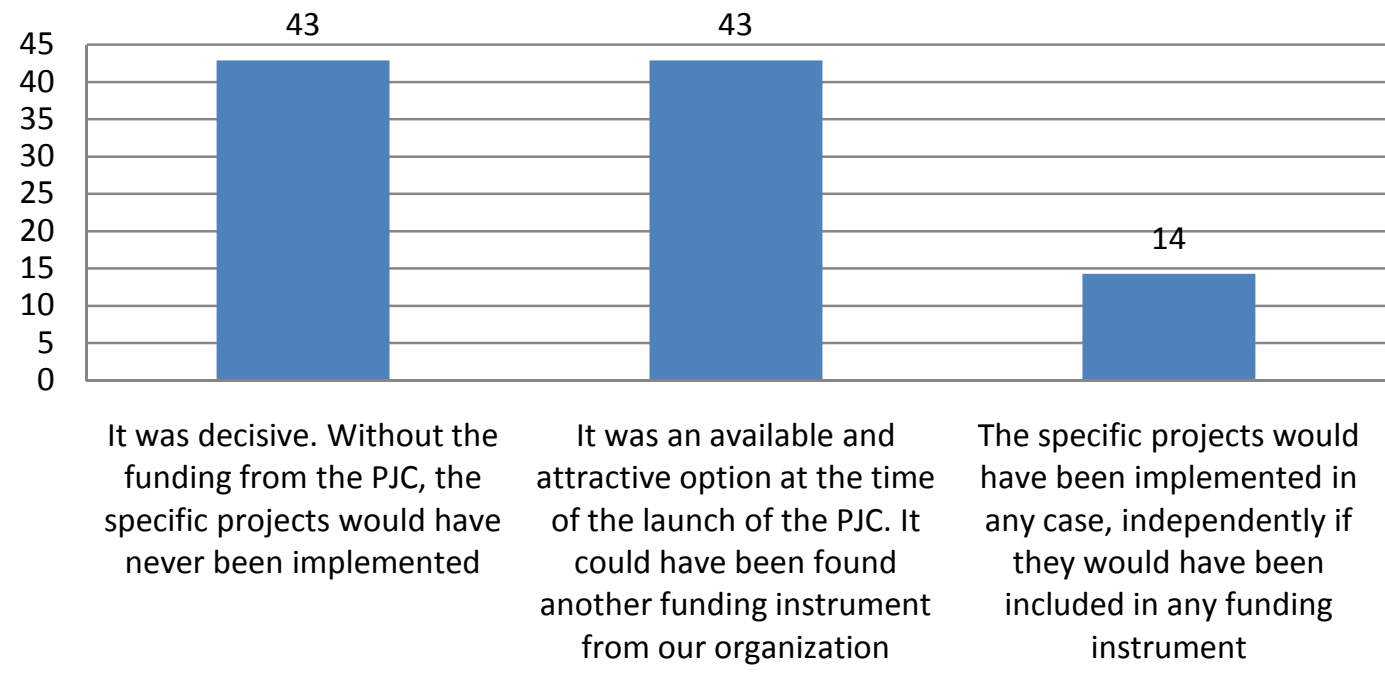


Many of the project partners consider that they needed additional funding for their project, which they have found by other sources. In most of the cases the projects are implemented smoothly.

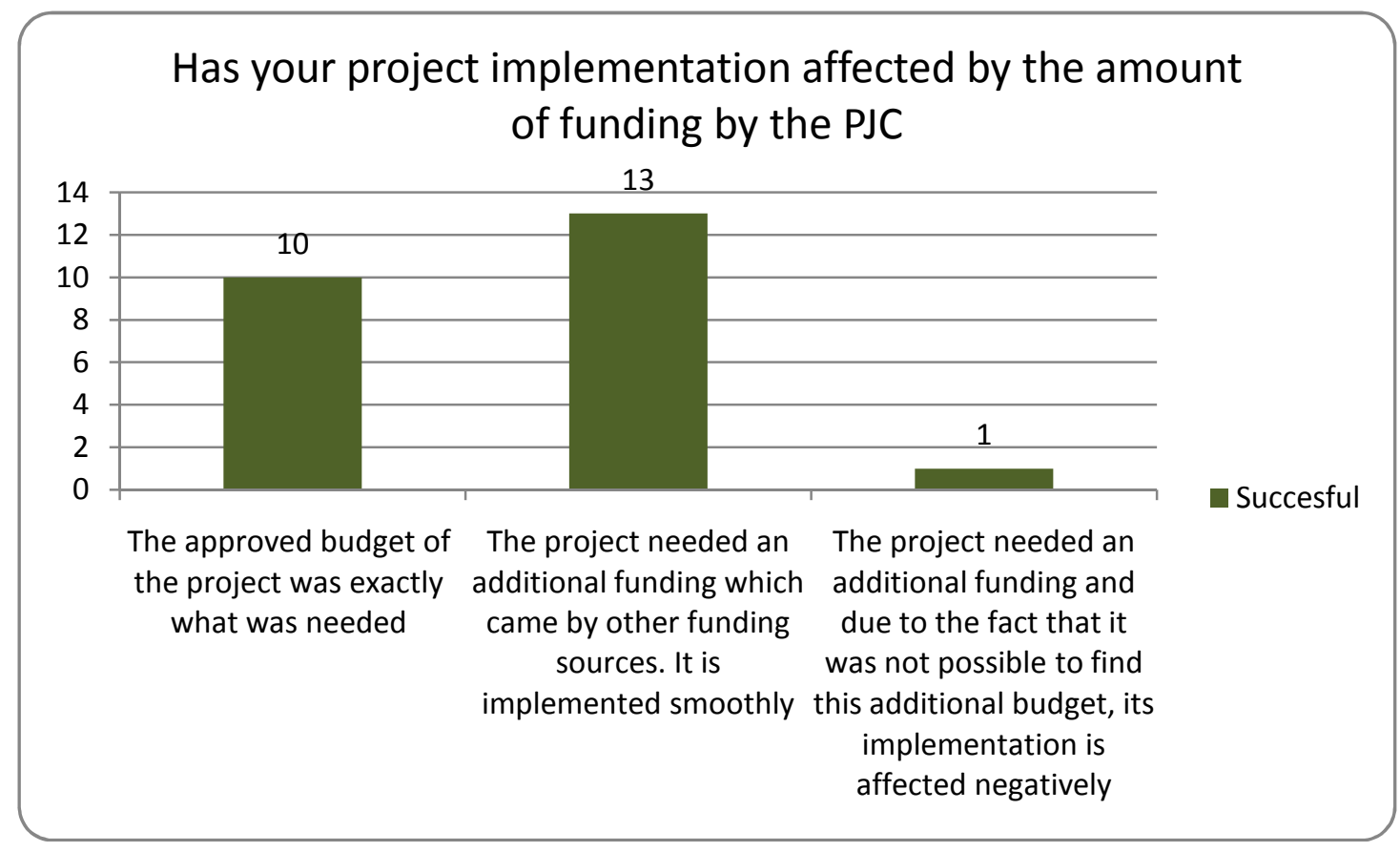

It is very clear that all funding parties found the approved budget of the projects was exactly what was needed.

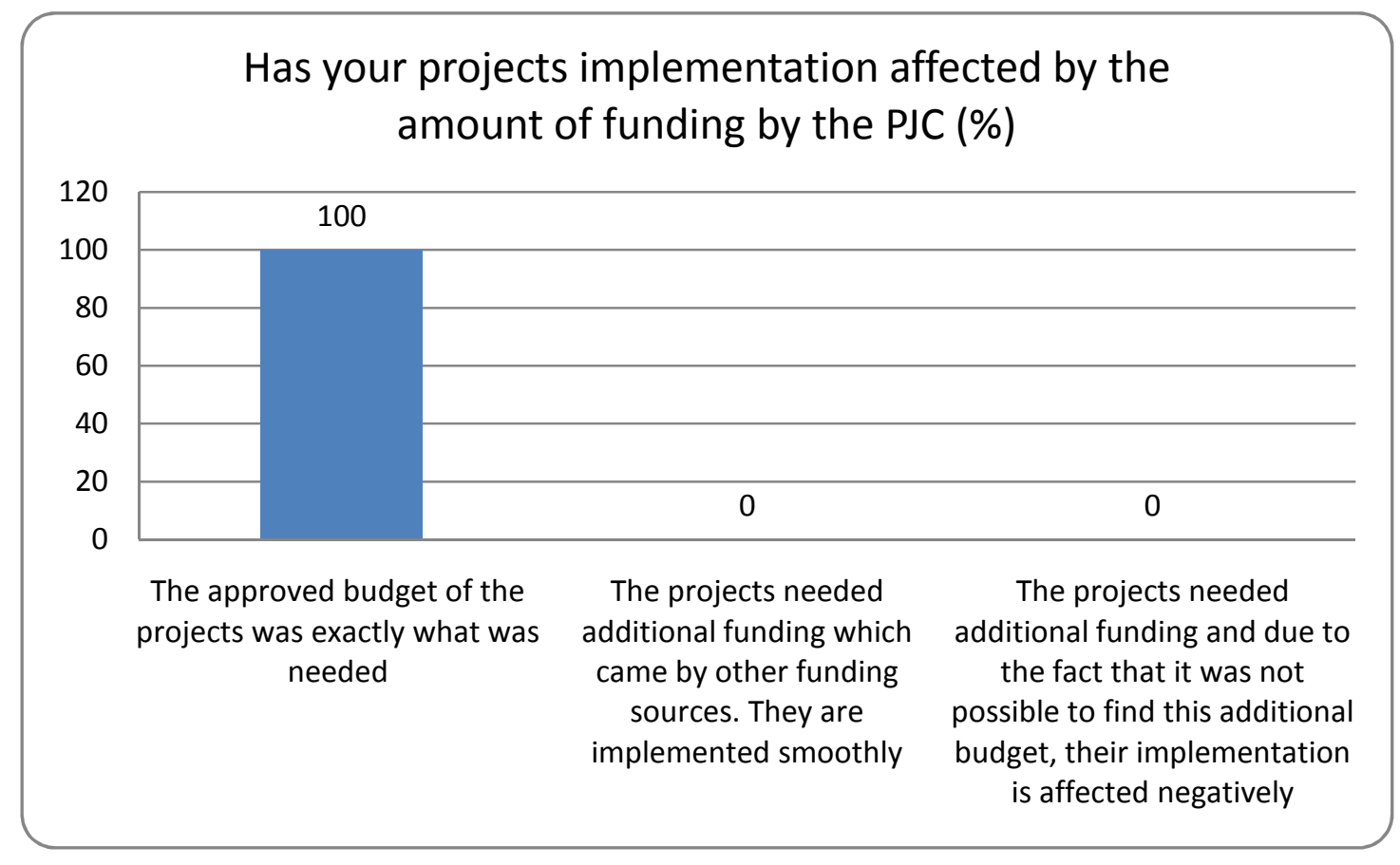


It is clearly stated by the majority of the members of the Scientific Council that the original objective of the Pilot Joint Call to promote collaborative research on Climate and Environment and Energy by taking a proactive and innovative approach to developing solutions for a sustainable development, was fulfilled.

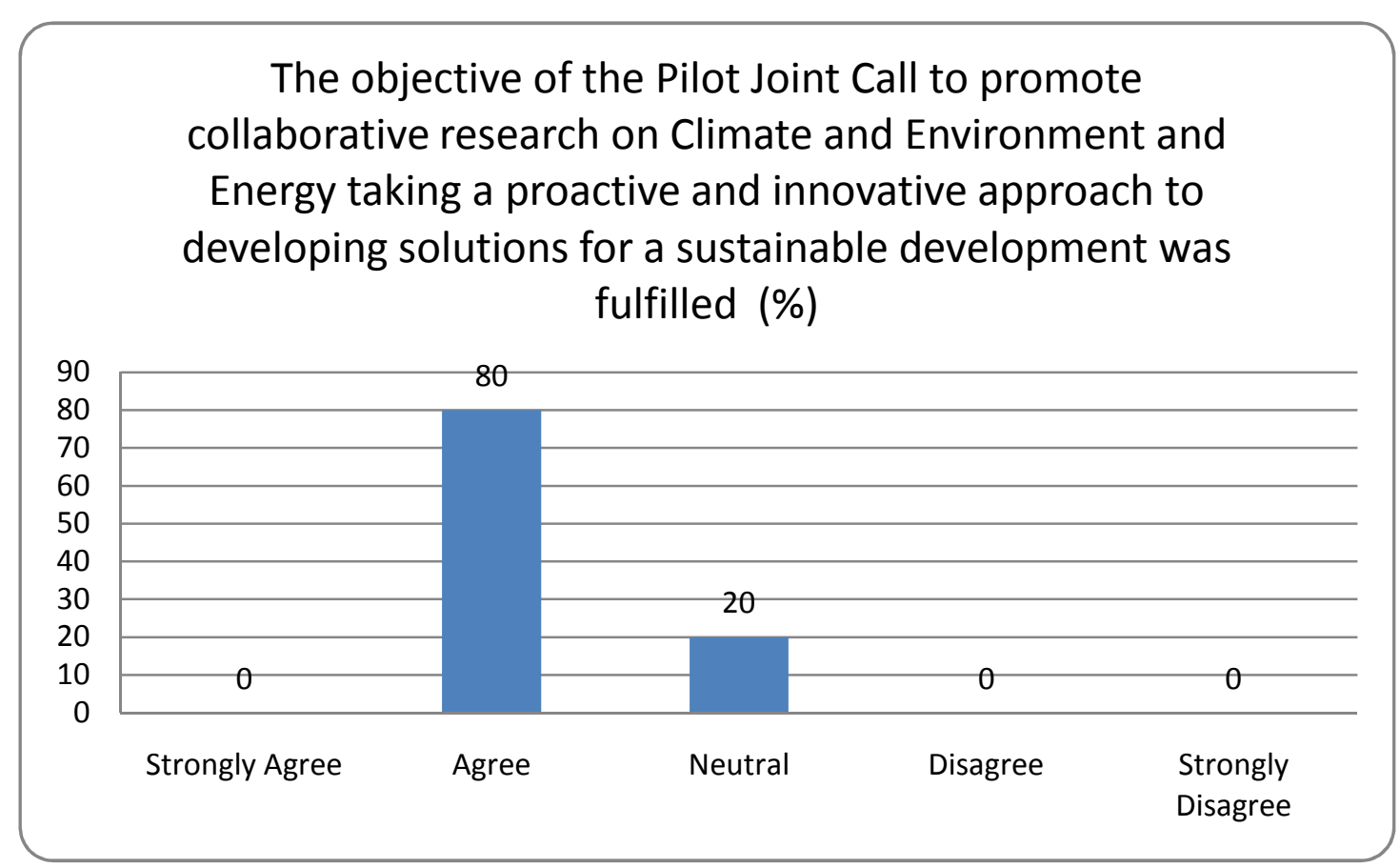

Conclusion 29: For the majority of the project partners the funding from the Pilot Joint Call was very crucial for carrying out their project, without which, specific projects could never have been implemented. On the other hand the members of the funding parties consider that beyond the Pilot Joint Call the partners could have found another funding instrument from their organization.

Many of the project partners expressed need for additional funding for their project, which they have found by other sources. In most of the cases the projects are implemented smoothly. On the contrary, all funding parties found the approved budget of the projects exactly adequate.

It is of great importance what is clearly stated by the majority of the members of the Scientific Council, that the original objective of the Pilot Joint Call to promote collaborative research on Climate and Environment and Energy by taking a proactive and innovative approach to developing solutions for a sustainable development, was fulfilled 


\subsection{The future Call(s) of the Black Sea Research Programme}

\subsubsection{The demand for a future Black Sea Research Programme}

The strong majority of the scientists regardless of being successful or unsuccessful clearly stated that after taking into account the experience from the PJC, they would participate through a collaborative transnational project application in a future call of the Black Sea Research Programme.

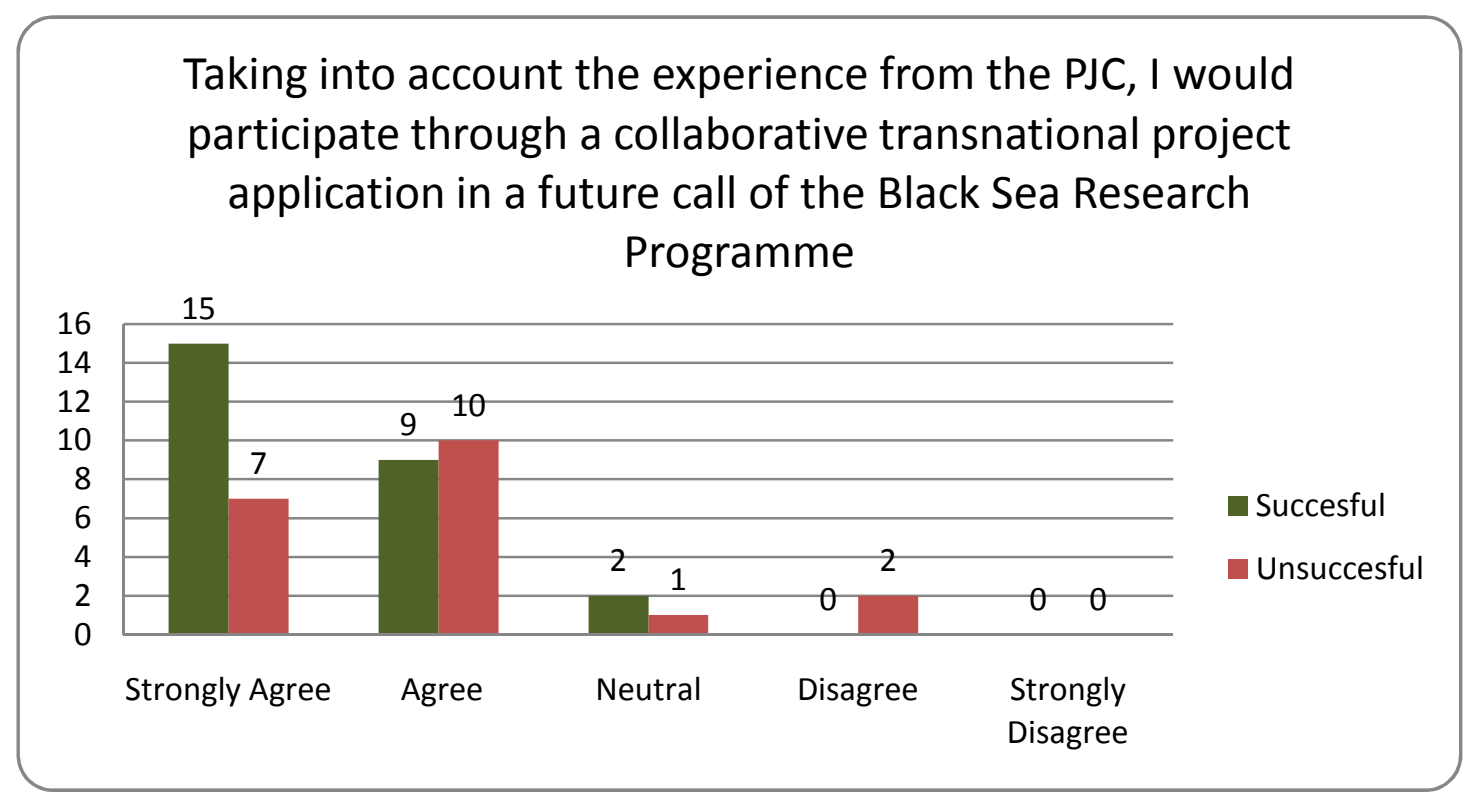

The experience from the Pilot Joint Call provided positive motivation for the funding parties to participate in a future Joint Call of the Black Sea Research Programme, with the exception of Italian partner ENEA that stated specific reservations. More specifically, it was noticed that "the interest of Italy depends on the possibility of finding external to the consortium of BS.ERA-NET funding parties which is also in line with the wish to attract to a future call additional funders. Future calls under Black Sea Research Programme are potentially interesting for the research community in Italy, but on the condition that the funding is provided by a research funding organisation, such as a ministry or funding agency." 


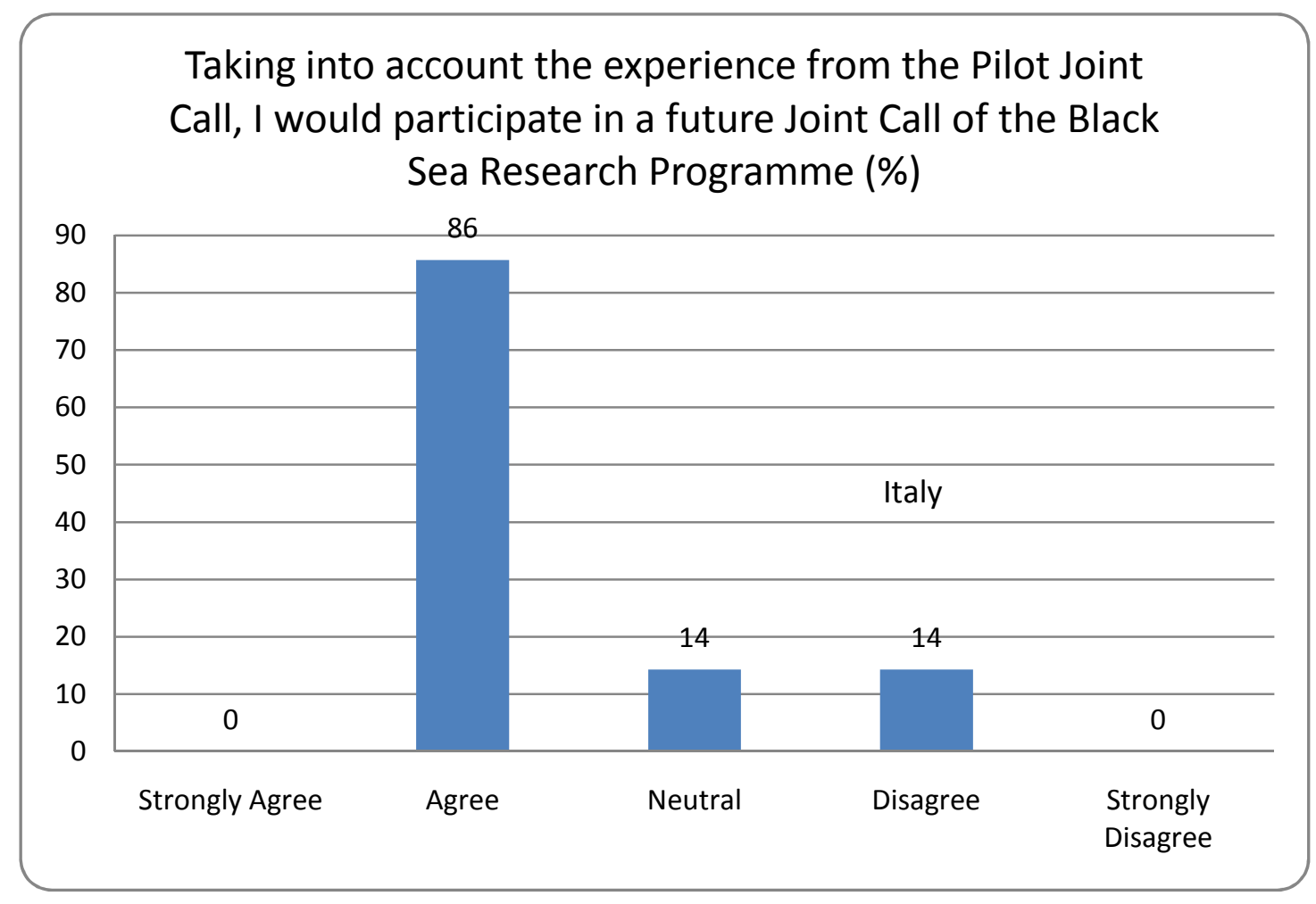

Moreover, many NCPs were contacted by potential applicants who were interested to participate in a future Black Sea Research Program.

Had you been contacted by potential applicants asking information for the Future Black Sea Research

Programme?

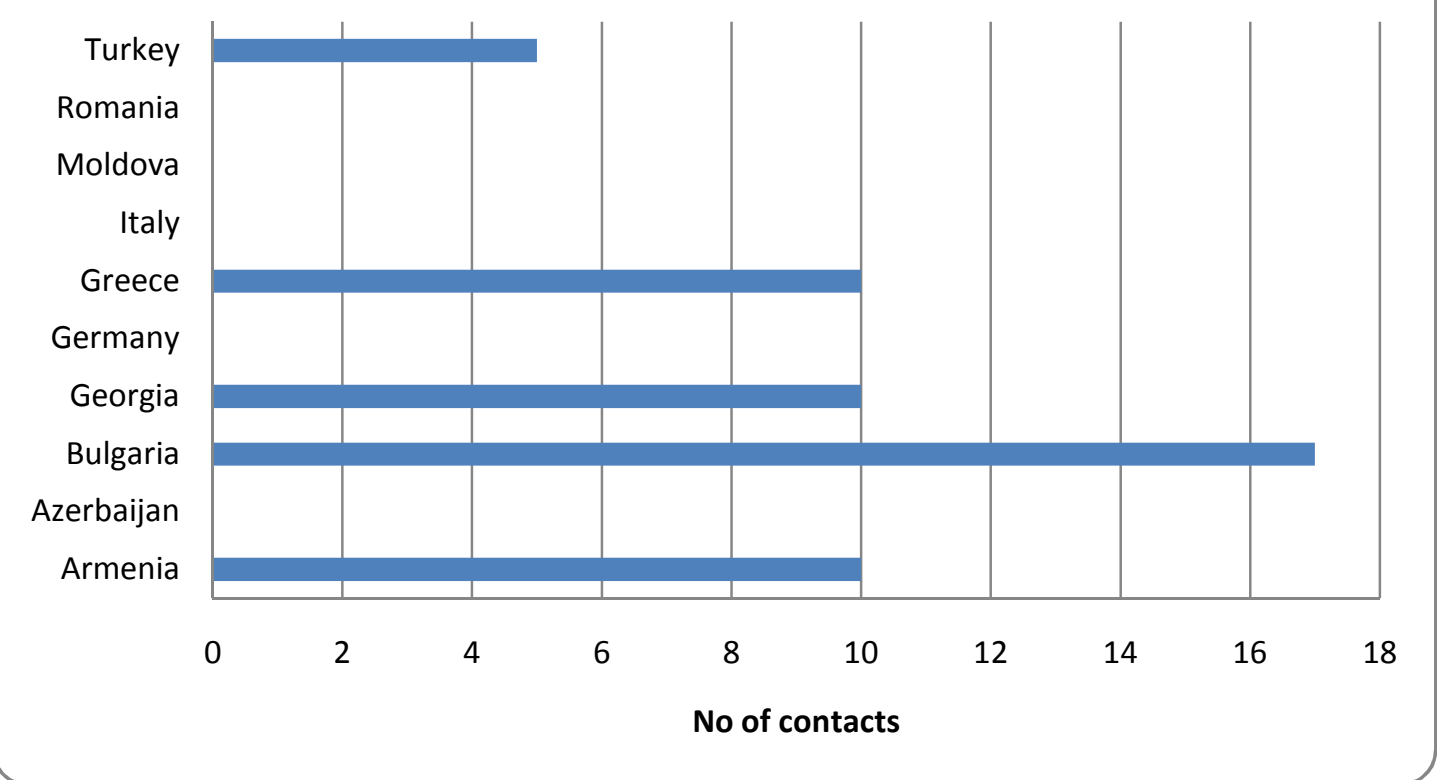


Conclusion 30: It appears that a future call of the Black Sea Research Programme would be both popular and desirable:

The strong majority of the scientists regardless of being successful or unsuccessful clearly declare that taking into account the experience from the Pilot Joint Call, they would participate through a collaborative transnational project application in a future call of the Black Sea Research Programme. The funding parties after the experience from the Pilot Joint Call, have gained a positive attitude towards participating in a future Joint Call of the Black Sea Research Programme with the exception of Italian partner ENEA that expressed specific reservations. More specifically, it was noticed that "the interest of Italy depends on the possibility of finding external to the consortium of BS.ERA-NET funding parties which is also in line with the wish to attract to a future call additional funders. Future calls under Black Sea Research Programme are potentially interesting for the research community in Italy, but on the condition that the funding is provided by a research funding organisation, such as a ministry or funding agency."

Moreover, many NCPs were contacted by potential applicants, who were interested to participate in a future Black Sea Research Programme

\subsubsection{Improvements in the future call(s) of the Black Sea Research Programme}

It has been proposed by the successful applicants among others to have more thematic topics and more participating countries. The unsuccessful applicants focus their interest on more thematic topics and improvement of the evaluation phase as well as the rules of participation and funding. 


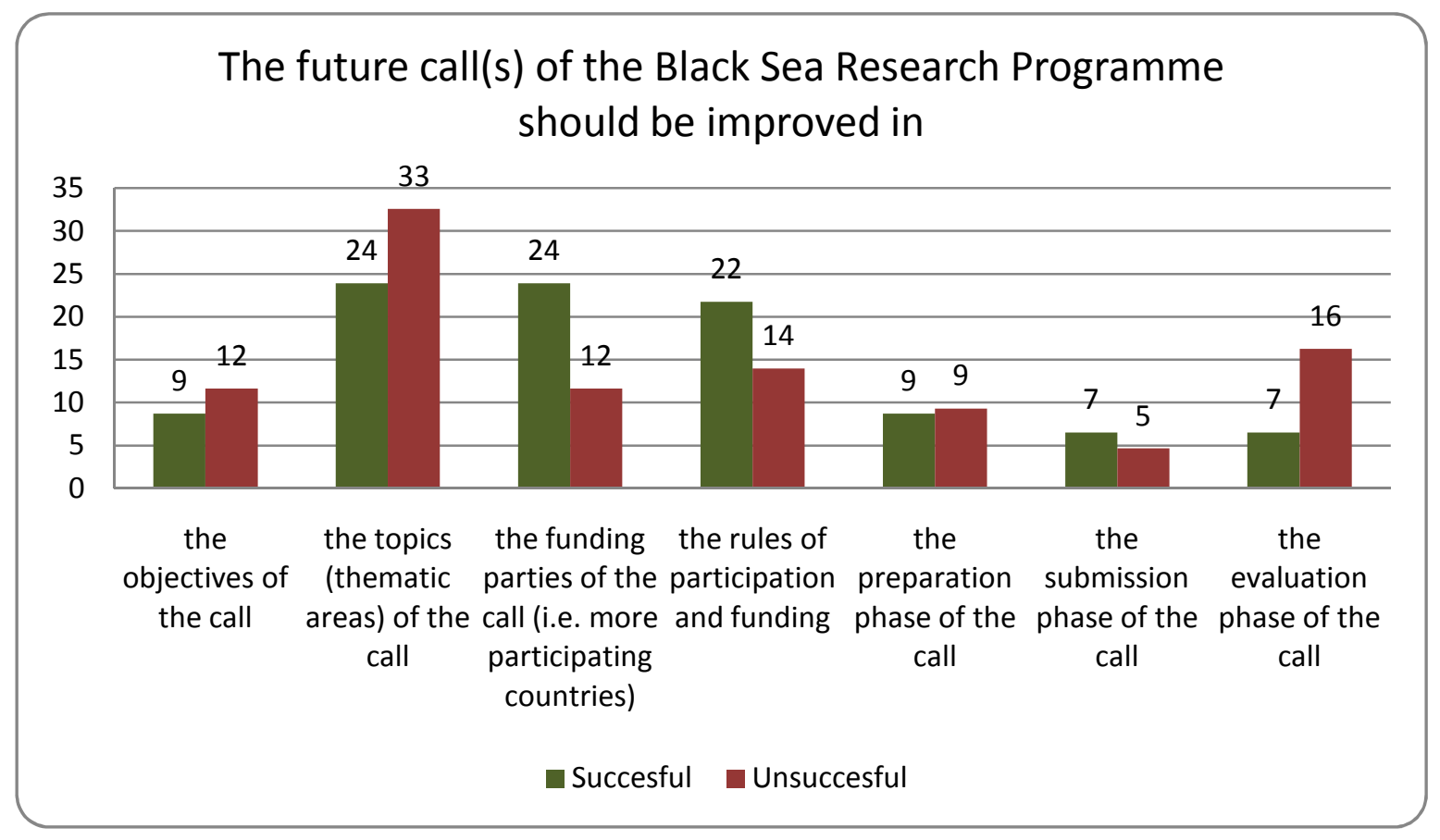

It is extremely interesting that the funding parties as well as the Scientific Council have exactly the same approach with the applicants of the Pilot Joint Call.

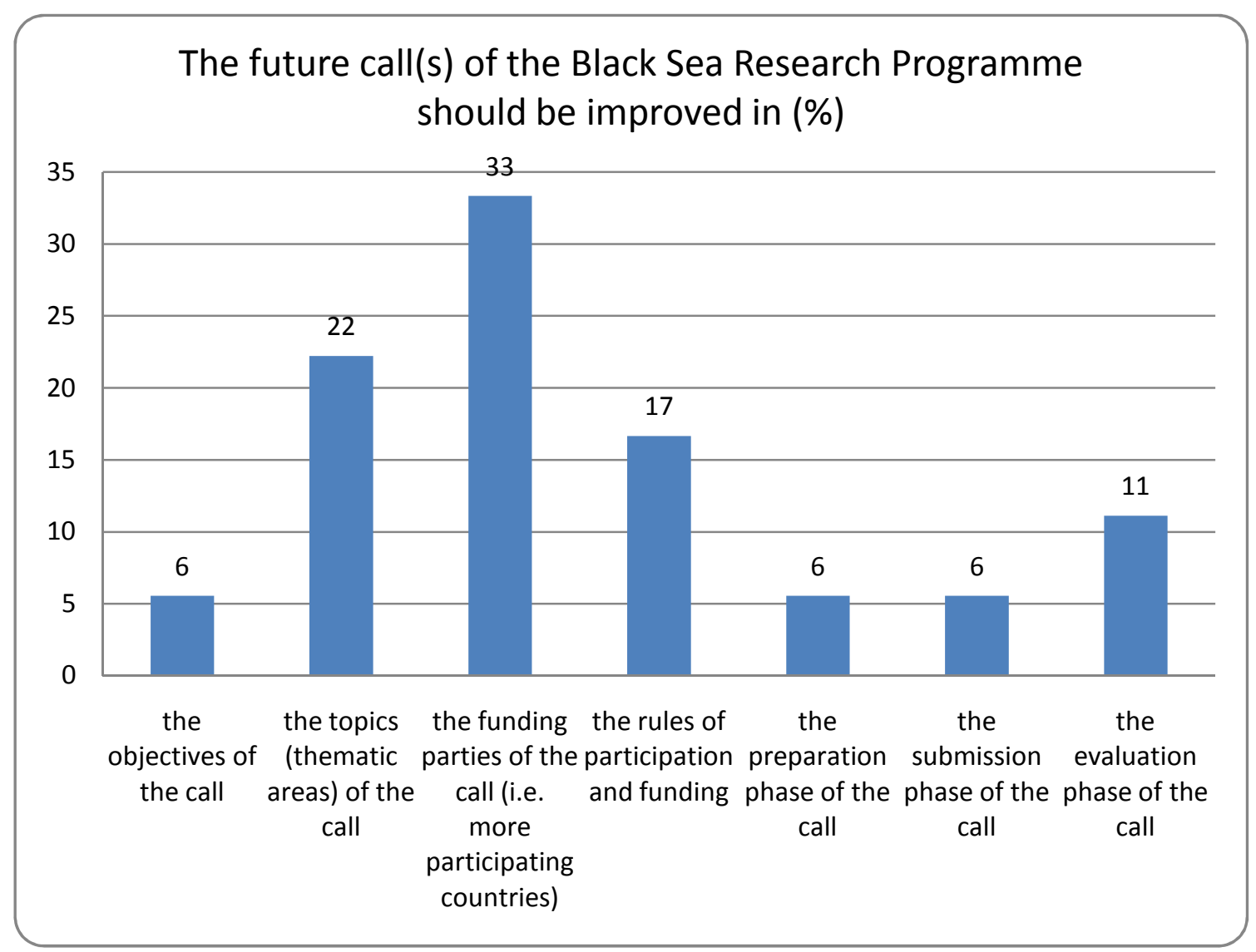




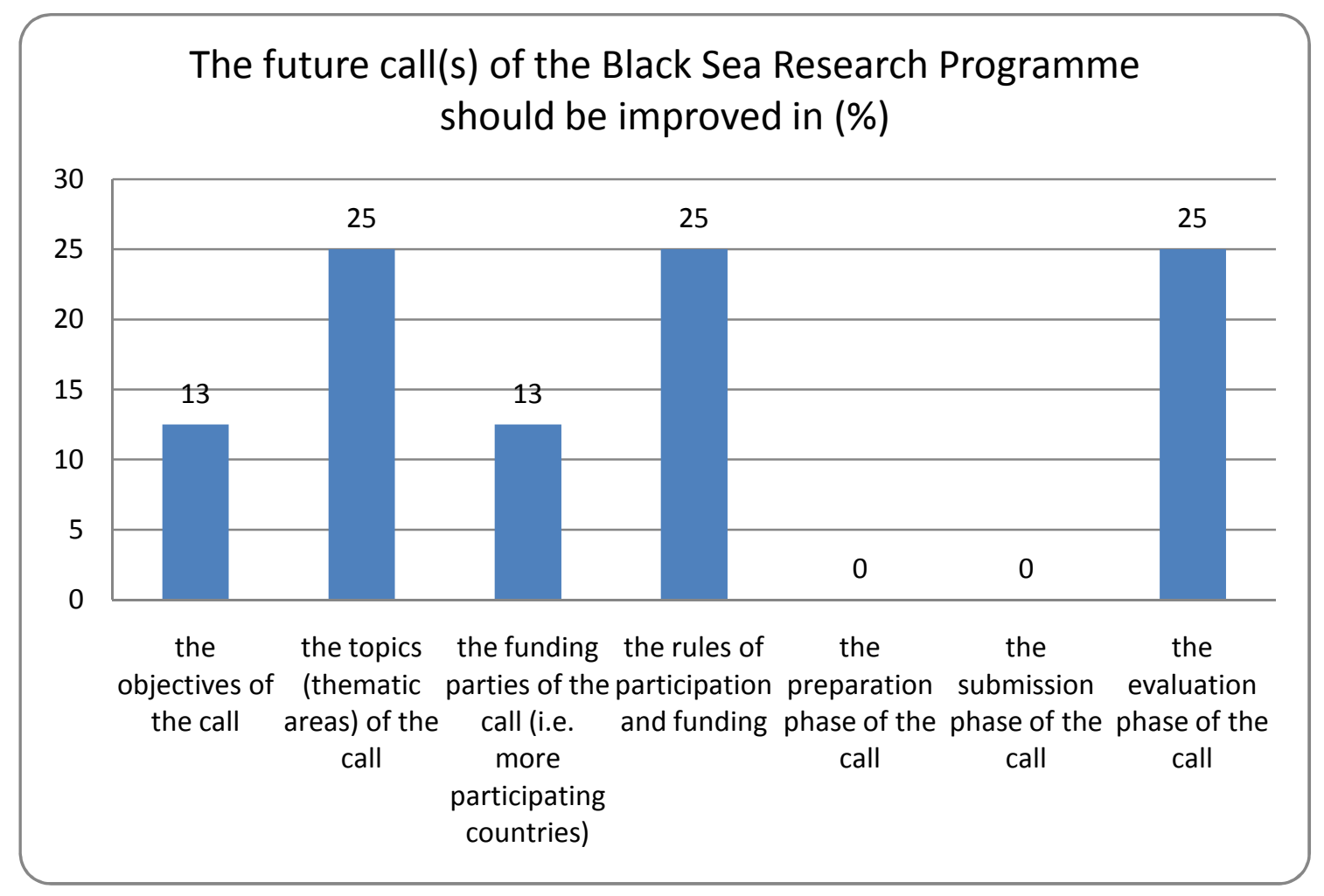

Conclusion 31: It has been mentioned many times, that there is always room for improvement for several aspects of the Pilot joint Call. And it is most interesting that proposals for improvement were suggested for almost all the phases of the Pilot Joint Call.

The successful applicants among others proposed more thematic topics and more participating countries. The unsuccessful applicants focused their interest on more thematic topics and improvement of the evaluation phase as well as the rules of participation and funding.

It is extremely interesting that the funding parties as well as the Scientific Council have exactly the same approach with the applicants of the Pilot Joint Call. 


\section{Recommendations}

This monitoring report includes recommendations on possible modifications and improvements of the call procedures, in order to enhance the performance of future trans-national calls, as well as to increase the impact of the projects to be funded. This provides input for a possible follow-up funding programme between the EU MS/AC and the Black Sea Region. More specifically, the recommendations are as follows:

1. There is a strong demand by the applicants and the group of funding parties for new partner countries in future calls. During the future search for new partner countries to participate in new transnational calls in the Black Sea Region, it is suggested that beyond the scientific merit, the strong economics as well as the political benefits should be displayed and reinforced.

2. The applicants among others propose more thematic topics. The selection of the thematic focus of the future joint call should rely on existing evidence based identification of the research priorities of the Black Sea region, which should be updated to meet the new financial, scientific and technological demands. The updated procedure should be based on detailed analytical work using the relevant adequate methodologies taking into account the national RTDI priorities of the future funding parties.

3. The number of the thematic areas in the new calls should be directly analogous to the available total budget of the call.

4. The set up of the terms of references of the new calls should be elaborated upon by actively involving all the participating countries, in order to avoid any complains and meet the full appreciation of the funding parties.

5. It is suggested that the NCPs of the future calls should act following a given methodology on the basis of a NCPs guide, which will organize their work and assure that certain quality standards have been fulfilled. Moreover, the training of the NCPs through a seminar on the needs of the future calls is suggested, in order to be able to provide a better guidance and support to potential applicants.

6. Special attention in future calls should be given to the time frames from the launching of the call to the deadline of the submission of proposals. Applicants need time to set up their consortium and submit their proposal. Another issue to pay attention is that more time is needed when after the launching of the call public holidays delay the contact and partnership processes.

7. It is of great importance that in future calls an efficient and functional web based call management system should be used. Without doubt the use of the PT-Outline system was a great advantage for the Pilot Joint Call. 
8. The two preliminary eligibility checks (one by the Joint Call Secretariat and the other at national level by the Funding Parties) cause delays in the evaluation phase. It is obvious that the rationale for this double check is that the submitted projects should be checked against the eligibility criteria of the call itself (terms of references) but at the same time should fulfil the national eligibility criteria for funding, since the virtual common pot scheme is applied. In future calls, strict timelines should be applied for the preliminary eligibility check especially by the funding parties.

9. The Eval-Inco database, should be regularly updated and cleaned of reviewers that are not active anymore. Additionally, in these types of expert's databases the expertise of the evaluators is not verified by means of crosscheck and "evaluation" of the enlisted evaluators. A systematic "evaluation system" of the evaluators should be applied. Moreover, the database could be updated constantly with respect to the performance of evaluators during active calls, in order to isolate and remove reviewers of low scientific quality.

10. The role of the Scientific Council is of great importance, namely to be able to consolidate the results of the evaluation and make recommendations to the Group of Funding Parties.

11. In future calls the unsuccessful applicants should be given detailed feedback on the reasons of their failure, such as an informative letter sent by the Joint Call Secretariat with relevant marks by criterion and an adapted summary of the comments of the reviewers attached. This is a principal that assures the transparency of the evaluation procedure and more importantly helps the applicants to improve in future submissions of project proposals.

12. Passing over highly ranked projects because of lack of available funds by the funding parties is quite common in all virtual common pot schemes. Of course this presents an injustice to the successfully evaluated scientists to be above the threshold but not receive funding nonetheless. In future calls, 2 solutions are proposed in order to overcome the specific issue:

a. To substitute the virtual common pot with a real common pot where the funding of a project will be dependent exclusively on the scientific excellence.

b. Due to the fact that solution (a) is difficult to be accepted by almost all national funding parties, in the future a combination of real and virtual common pot could be used. More specifically, it could be agreed that a standard percentage of the national contributions (i.e. $20 \%$ ) be allocated to a pot in order to fund highly ranked projects when national funding is insufficient.

13. As mentioned earlier regarding the double eligibility check for every submitted project, a double contracting procedure for every approved for funding project cannot be avoided:

a. An Umbrella Project Contract to be signed both by the Joint Call Secretariat on behalf of the Group of Funding Parties and by each Coordinating institution of a consortium.

b. National Project Contracts between each participating institution in a consortium and its corresponding Funding Party. 
This double contracting procedure is necessary due to the virtual common pot scheme and the national funding procedures, which are based on national rules and regulations. It is easily understood that this double process complicates the contracting of the projects, and causes delays although normally the 2 contracting procedures are running in parallel. In future calls, strict deadlines should be applied for the contracting procedures especially for the funding parties.

14. In future calls, every approved project should have a common starting date for all involved partners, since in a joint research project, the scientific work of the different scientific teams is intertwined and interacted. Furthermore, the flow of funds to the different project partners should be synchronized in order to allow for the unobstructed flow of required resources. Cases where it was reported that the first funding rate to the project partners was not synchronized, was inefficient and inadequate time wise, should be avoided due to the fact that it could be affected the scientific quality of their implementation.

15. In future calls, the Joint Call Secretariat should monitor the progress of the funded projects through scientific and financial periodical reports and direct contacts with the project coordinators and the project partners. A periodic informative report (i.e. every six months) should be prepared by the Joint Call Secretariat and distributed to the Funding Parties.

16. It is strongly recommended that the Pilot Joint Call be ex-post evaluated at programme and project level, in order to identify their scientific and economic impact. Moreover, in future calls, beyond the on-going evaluation (monitoring and assessment), it should be foreseen their post evaluation which will be conducted a short time after the end of their implementation.

17. It was proven through this survey that the strong majority of scientists both successful and unsuccessful, clearly state that taking into account the experience from the Pilot Joint Call, they would participate through a collaborative transnational project application in a future call of the Black Sea Research Programme. Moreover, the experience from the Pilot Joint Call has given the funding parties a positive attitude towards participating in a future Joint Call of the Black Sea Research Programme. Additionally, many NCPs were contacted by potential applicants interested to participate in a future Black Sea Research Programme. All the above mentioned provide a very strong indication of the sustainability of the Black Sea Programme. It is strongly recommended that this successful so far action in the Black Sea Region should be continued.

18. It is most important to take the most advantage of the momentum of the consortium of the BS-ERA.NET. The existing funding parties have expressed their intention to participate in a future Joint Call of the Black Sea Research Programme by allocating national funds and the Joint Technical Secretariat has proven its capacity to successfully administrate the future call. Waiting for suitable funding schemes from the EU or other international organizations in order to ensure additional funding might cause serious delays and loss of momentum. It is suggested that the 
existing funding parties with the addition of new potential partner countries should proceed as soon as possible to launch a scale up joint call. The cost of management and administration of the new call could be covered by a small (2\%-5\%) percentage of the national financial contributions to the call. 


\section{ANNEX 1}

Interviews that have been conducted with:

$\begin{array}{ll}\text { Name } & \text { Institution/Country } \\ \text { Akkoyun Akin } & \text { DLR, Germany } \\ \text { Arzumanyan Tigran } & \text { NAS-RA, Armenia } \\ \text { Bonas George } & \text { ICBSS, Greece } \\ \text { Bonin Martine } & \text { CNRS, France } \\ \text { Borda lan Gauci } & \text { MCST, Malta } \\ \text { Cotet Domnica } & \text { UEFISCDI, Romania } \\ \text { Haliloglu Ilter } & \text { TUBITAK, Turkey } \\ \text { Hasanov Adalah } & \text { National Academy of Sciences, Azerbaijan } \\ \text { Kalhe Andreas } & \text { DLR, Germany } \\ \text { Melnyk Olena } & \text { NIP, Ukraine } \\ \text { Nastasiuc Lucia } & \text { ASM, Moldova } \\ \text { Panaitescu Serban } & \text { UEFISCDI, Romania } \\ \text { Pletsa Vasiliki } & \text { GSRT, Greece } \\ \text { Rost Erika } & \text { BMBF, Germany } \\ \text { Sliwka Peter } & \text { DLR, Germany } \\ \text { Sonnenburg Joern } & \text { DLR, Germany } \\ & \end{array}$

